\title{
Effects of Periodic Unsteady Wake Flow and Pressure Gradient on Boundary Layer Transition Along the Concave Surface of a Curved Plate, Part III
}

M. T. Schobeiri and R.E. Radke

Texas A\&M University

College Station, Texas

January 1996

Prepared for

Lewis Research Center

Under Grant NAG3-1256

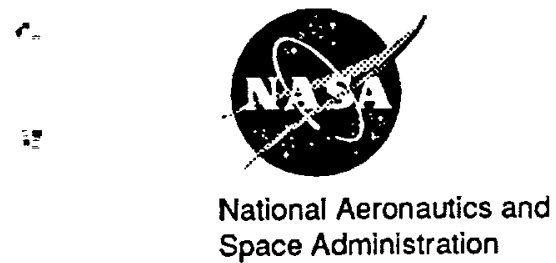

Space Administration 



\section{PREFACE TO FINAL REPORTS, PART III}

The present report constitutes the third part of a three part research report that deal with experimental and theoretical investigations of steady and unsteady wakes and their influence on boundary layer transition and heat transfer. The experimental research was performed in the recently established Turbomachinery Performance and Flow Research Laboratory, a division of the Turbomachinery Laboratory of Texas A\&M University.

In this Part, the effects of periodic unsteady wake flow and pressure gradient on boundary layer transition along the concave surface of a curved plate are reported. The measurements were performed on an unsteady flow research facility using a rotating cascade of rods positioned upstream of the curved plate. Boundary layer measurements using a hot-wire probe were analyzed by the ensemble-averaging technique.

The effects of periodic unsteady wake flow and pressure gradient on heat transfer along the concave surface of a curved plate is currently being investigated. A special heat transfer curved plate with the same geometry as the boundary layer plate has been designed, developed and manufactured in Texas A\&M University. The heat transfer instrumentation is being performed by the NASA Lewis Research Center. The heat transfer investigations on this plate as well as the theoretical evaluation of the boundary layer transition process using the wavelet method as a new approach exhibit the continuation of this ongoing research.

\section{M.T. Schobeiri}

College Station, Texas

January 1994 
III I 


\begin{abstract}
Boundary layer transition and development on a turbomachinery blade is subjected to highly periodic unsteady turbulent flow, pressure gradient in longitudinal as well as lateral direction, and surface curvature. To study the effects of periodic unsteady wakes on the concave surface of a turbine blade, a curved plate was utilized. On the concave surface of this plate, detailed experimental investigations were carried out under zero and negative pressure gradient. The measurements were performed on an unsteady flow research facility using a rotating cascade of rods positioned upstream of the curved plate. Boundary layer measurements using a hot-wire probe were analyzed by the ensemble-averaging technique. The results presented in the temporal-spatial domain display the transition and further development of the boundary layer, specifically the ensemble-averaged velocity and turbulence intensity. As the results show, the turbulent patches generated by the wakes have different leading and trailing edge velocities and merge with the boundary layer resulting in a strong deformation and generation of a high turbulence intensity core. After the turbulent patch has totally penetrated into the boundary layer, pronounced becalmed regions were formed behind the turbulent patch and were extended far beyond the point they would occur in the corresponding undisturbed steady boundary layer.
\end{abstract}




\section{ACKNOWLEDGEMENT}

The principal investigator and his students would like to express their sincere thanks and appreciations to Dr. R. Simoneau, Chief of Heat Transfer Branch and Mrs. B. Lucci and the administration of the NASA Lewis Research Center for the continuous cooperation and support of this project. 


\section{TABLE OF CONTENTS}

Page

ABSTRACT $\ldots \ldots \ldots \ldots \ldots \ldots \ldots \ldots \ldots \ldots \ldots \ldots \ldots \ldots \ldots \ldots \ldots \ldots$

ACKNOWLEDGEMENTS $\ldots \ldots \ldots \ldots \ldots \ldots \ldots \ldots \ldots \ldots \ldots \ldots$ iv

LIST OF FIGURES $\ldots \ldots \ldots \ldots \ldots \ldots \ldots \ldots \ldots \ldots \ldots \ldots \ldots \ldots$

NOMENCLATURE $\ldots \ldots \ldots \ldots \ldots \ldots \ldots \ldots \ldots \ldots \ldots \ldots \ldots \ldots \ldots \ldots$

1. INTRODUCTION $\ldots \ldots \ldots \ldots \ldots \ldots \ldots \ldots \ldots \ldots \ldots \ldots \ldots \ldots \ldots$

2. LITERATURE REVIEW $\ldots \ldots \ldots \ldots \ldots \ldots \ldots \ldots \ldots \ldots \ldots \ldots \ldots \ldots$

2.1 General Transition Research $\ldots \ldots \ldots \ldots \ldots \ldots$

2.2 Concave Surface Transition Research $\ldots \ldots \ldots \ldots \ldots$

2.3 Periodic-Unsteady Transition Research $\ldots \ldots \ldots \ldots \ldots \ldots$

2.4 Pressure Gradient Effects on Transition $\ldots \ldots \ldots \ldots \ldots$

3. OBJECTIVES ........................... 9

4. TEST FACILITY AND MEASUREMENT TECHNIQUE . . . . . . . . . 10

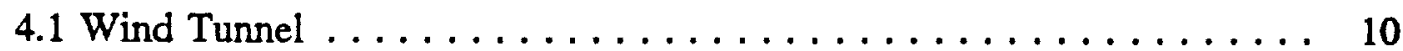

4.2 Curved Plate $\ldots \ldots \ldots \ldots \ldots \ldots \ldots \ldots \ldots \ldots \ldots \ldots \ldots \ldots$

4.3 Measurement Technique $\ldots \ldots \ldots \ldots \ldots \ldots$

5. DATA ACQUISITION AND REDUCTION . . . . . . . . . . . . 17

6. RESULTS AND DISCUSSION $\ldots \ldots \ldots \ldots \ldots \ldots \ldots \ldots \ldots \ldots \ldots$

6.1 Case 1: Steady Flow at Zero Pressure Gradient . . . . . . . . . 22

6.2 Case 2: Steady Flow at Negative Pressure Gradient . . . . . . . . 28

6.3 Case 3: Periodic-Unsteady Flow at Zero Pressure Gradient . . . . . . . 33

6.4 Case 4: Periodic-Unsteady Flow at Negative Pressure Gradient . . . . . 47

7. CASCADE TEST FACILITY DESIGN $\ldots \ldots \ldots \ldots \ldots$

8. CONCLUSION $\ldots \ldots \ldots \ldots \ldots \ldots \ldots \ldots \ldots \ldots \ldots \ldots \ldots \ldots \ldots \ldots \ldots \ldots \ldots$

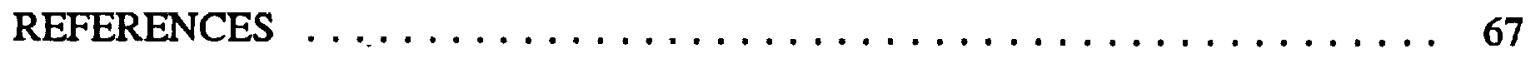




\section{LIST OF FIGURES}

Page

Figure 1. Wind tunnel $\ldots \ldots \ldots \ldots \ldots \ldots \ldots \ldots \ldots \ldots \ldots \ldots$

Figure 2. Wake generator cross section looking upstream $\ldots \ldots \ldots \ldots \ldots 11$

Figure 3. Test section with the curved plate located at the mid-height of the channel ......................... 12

Figure 4. Curved plate detail drawing with side and top views $\ldots \ldots \ldots 14$

Figure 5. Cross-sections A-A (showing the internal static pressure taps without flexible tubing attached) and B-B (showing the internal rib and flexible tubing exit) of Fig. $4 \ldots \ldots \ldots \ldots \ldots \ldots \ldots \ldots \ldots \ldots \ldots \ldots \ldots \ldots$

Figure 6. Data acquisition and reduction flow chart for steady flow cases . . 19

Figure 7. Data acquisition and reduction flow chart for periodic-unsteady flow

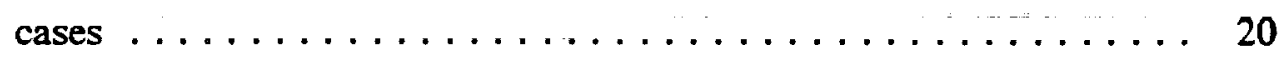

Figure 8. Non-dimensionalized mean free-stream velocity for zero and negative pressure gradient at $y=30 \mathrm{~mm}$ above the plate surface $\ldots \ldots \ldots 21$

Figure 9. Time-averaged reference turbulence intensity contour of the channel at zero pressure gradient and steady flow (Case 1) $\ldots \ldots \ldots \ldots 22$

Figure 10. Instantaneous hot-wire velocity traces at $\mathrm{y}=0.55 \mathrm{~mm}$ at zero pressure gradient and steady flow (Case 1$) \ldots \ldots \ldots \ldots \ldots \ldots \ldots$

Figure 11. Instantaneous hot-wire velocity traces at $\mathrm{y}=2.0 \mathrm{~mm}$ at zero pressure gradient and steady flow (Case 1$) \ldots \ldots \ldots \ldots \ldots \ldots \ldots$

Figure 12. Non-dimensional boundary-layer profiles at different streamwise positions at zero pressure gradient (Case 1$) \ldots \ldots \ldots \ldots \ldots 27$

Figure 13. The Görtler number as a function of streamwise position at zero pressure gradient (Case 1) .................. 27

Figure 14. Time-averaged reference turbulence intensity contour of the channel at negative pressure gradient and steady flow (Case 2$) \ldots \ldots \ldots 28$

Figure 15. Instantaneous hot-wire velocity traces at $y=0.50 \mathrm{~mm}$ at negative pressure gradient and steady flow (Case 2$) \ldots \ldots \ldots \ldots \ldots, 30$ 
Figure 16. Instantaneous hot-wire velocity traces at $\mathrm{y}=2.0 \mathrm{~mm}$ at negative pressure gradient and steady flow (Case 2 . . . . . . . . . 31

Figure 17. Non-dimensional boundary-layer profiles at different streamwise positions at negative pressure gradient (Case 2$) \ldots \ldots 32$

Figure 18. The Görtler number as a function of streamwise position at negative

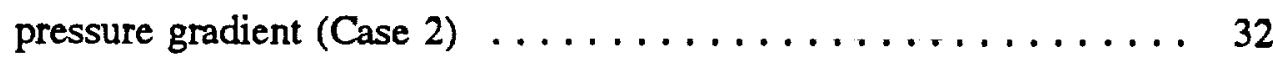

Figure 19. Time-averaged reference turbulence intensity contour for the periodicunsteady case at zero pressure gradient (Case 3 ) . . . . . . . 33

Figure 20. Instantaneous hot-wire velocity traces at $\mathrm{y}=0.5 \mathrm{~mm}$ at zero pressure gradient and periodic-unsteady flow (Case 3 ) . . . . . . . 37

Figure 21. Ensemble-averaged hot-wire velocity traces at $\mathrm{y}=0.5 \mathrm{~mm}$ at zero pressure gradient and periodic-unsteady flow (Case 3 ) . . . . . 38

Figure 22. Instantaneous hot-wire velocity traces at $y=2.0 \mathrm{~mm}$ at zero pressure gradient and periodic-unsteady flow (Case 3 ) . . . . . . . . 39

Figure 23. Ensemble-averaged reference turbulence intensity contours at various instants in the wake passing cycle (Case 3 ) .......... 40

Figure 24. Ensemble-averaged reference turbulence intensity in the temporalspatial domain at $y=0.3 \mathrm{~mm}$ for zero pressure gradient (Case 3) . . 43

Figure 25. Ensemble-averaged reference turbulence intensity in the temporalspatial domain at $y=0.5 \mathrm{~mm}$ for zero pressure gradient (Case 3) . . 43

Figure 26. Ensemble-averaged reference turbulence intensity in the temporalspatial domain at $y=0.7 \mathrm{~mm}$ for zero pressure gradient (Case 3 ) . . 44

Figure 27. Ensemble-averaged reference turbulence intensity in the temporalspatial domain at $\mathbf{y}=1.0 \mathrm{~mm}$ for zero pressure gradient (Case 3 ) ...

Figure 28. Ensemble-averaged reference turbulence intensity in the temporalspatial domain at $y=1.6 \mathrm{~mm}$ for zero pressure gradient (Case 3 ) . . .

Figure 29. Ensemble-averaged reference turbulence intensity in the temporalspatial domain at $y=2.5 \mathrm{~mm}$ for zero pressure gradient (Case 3 ) . . 45 
Figure 30. Ensemble-averaged reference turbulence intensity in the temporalspatial domain at $y=3.5 \mathrm{~mm}$ for zero pressure gradient (Case 3) ... 46

Figure 31. Ensemble-averaged reference turbulence intensity in the temporalspatial domain at $y=5.0 \mathrm{~mm}$ for zero pressure gradient (Case 3) . . 46

Figure 32. Time-averaged reference turbulence intensity contour for periodicunsteady inlet flow at negative pressure gradient (Case 4) $\ldots \ldots 47$

Figure 33. Instantaneous hot-wire velocity traces at $\mathrm{y}=0.5 \mathrm{~mm}$ at negative pressure gradient and periodic-unsteady flow (Case 4 ) ....... 50

Figure 34. Ensemble-averaged hot-wire velocity traces at $y=0.5 \mathrm{~mm}$ at negative pressure gradient and periodic-unsteady flow (Case 4) . . . . . 51

Figure 35. Instantaneous hot-wire velocity traces at $y=2.0 \mathrm{~mm}$ at negative pressure gradient and periodic-unsteady flow (Case 4) . . . . . 52

Figure 36. Ensemble-averaged reference turbulence intensity contours at various instants in the wake passing cycle (Case 4$) \ldots \ldots \ldots . \ldots . \ldots 5$

Figure 37. Ensemble-averaged reference turbulence intensity in the temporalspatial domain at $y=0.3 \mathrm{~mm}$ for negative pressure gradient (Case 4) 56

Figure 38. Ensemble-averaged reference turbulence intensity in the temporalspatial domain at $y=0.5 \mathrm{~mm}$ for negative pressure gradient (Case 4) 56

Figure 39. Ensemble-averaged reference turbulence intensity in the temporalspatial domain at $y=0.8 \mathrm{~mm}$ for negative pressure gradient (Case 4) 57

Figure 40. Ensemble-averaged reference turbulence intensity in the temporalspatial domain at $y=1.0 \mathrm{~mm}$ for negative pressure gradient (Case 4 )

Figure 41. Ensemble-averaged reference turbulence intensity in the temporalspatial domain at $y=1.5 \mathrm{~mm}$ for negative pressure gradient (Case 4) 58

Figure 42. Ensemble-averaged reference turbulence intensity in the temporalspatial domain at $y=2.0 \mathrm{~mm}$ for negative pressure gradient (Case 4)

Figure 43. Ensemble-averaged reference turbulence intensity in the temporalspatial domain at $y=4.0 \mathrm{~mm}$ for negative pressure gradient (Case 4 ) 
Figure 44. Ensemble-averaged reference turbulence intensity in the temporalspatial domain at $y=6.0 \mathrm{~mm}$ for negative pressure gradient (Case 4) 59

Figure 45. Wind tunnel for the investigation of periodic-unsteady wakes on a turbomachinery cascade ................... 60

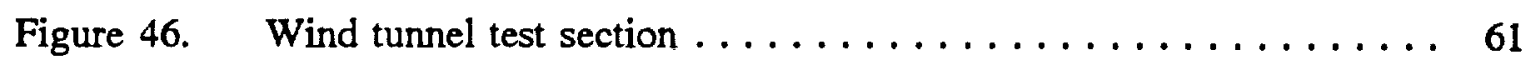

Figure $47 . \quad$ Section A-A of Figure $46 \ldots \ldots \ldots \ldots$

Figure 48 . Section B-B of Figure $46 \ldots \ldots \ldots \ldots \ldots \ldots \ldots \ldots \ldots \ldots \ldots$ 


\section{NOMENCLATURE}

$A_{1}$

$\mathrm{A}_{2}$

d

Gõ

$h$

$N$

$m$

$\boldsymbol{r}$

$\operatorname{Re}$

$\mathbf{S}$

$\mathbf{S}_{\mathbf{o}}$

t

$T u$

$<T u>$

$T u_{\text {loc }}$
- inlet area of the channel above the curved plate

= exit area of the channel above the curved plate

= thickness of the curved plate, $15 \mathrm{~mm}$

$=\quad$ Görtler number, $G \ddot{o}=\frac{U \delta_{2}}{v} \sqrt{\frac{\delta_{2}}{r}}$

$=\quad$ inlet height of test section, $420 \mathrm{~mm}$

$=$ total number of samples of hot-wire data for time-averaging or total number records for ensemble-averaging

$=$ number of hot-wire samples taken per revolution of the wake generator

$=\quad$ radius of curvature of the curved plate, $702.5 \mathrm{~mm}$

$=\quad$ Reynolds number, $\quad R e=\frac{U h}{v}$

$=\quad$ longitudinal distance from the plate leading edge

$=\quad$ arc length of plate, $690 \mathrm{~mm}$

$=$ time

$=\quad$ reference turbulence intensity, $T u=\frac{\sqrt{u^{2}}}{U_{\text {ref }}} \times 100$

$=\quad$ ensemble-averaged reference turbulence intensity

- local turbulence intensity, $T u_{\mathrm{loc}}=\frac{\sqrt{u^{2}}}{\bar{U}} \times 100$ 


$\begin{array}{lll}u & = & \text { turbulent fluctuation velocity } \\ <u> & = & \text { ensemble-averaged fluctuation velocity } \\ U & = & \text { instantaneous velocity } \\ \bar{U} & = & \text { time-averaged mean velocity } \\ U_{\mathrm{ref}} & = & \text { reference velocity for each streamwise position } \\ U_{\mathrm{m}} & = & \text { mass-averaged velocity } \\ U_{\mathrm{E}} & =\quad \text { boundary-layer edge velocity } \\ \mathrm{y} & =\quad \text { lateral distance from plate surface } \\ \delta & =\quad \text { boundary-layer thickness } \\ \delta_{2} & =\quad \text { momentum thickness } \\ \theta & =\quad \text { angular position of the probe location from the inlet } \\ v & =\quad \text { kinematic viscosity of air } \\ \rho & =\quad \text { density of air } \\ \tau & \quad \text { one wake passing period, } 40 \text { ms }\end{array}$

\section{Subscripts}

ref $=$ reference

loc = local

in $\quad=\quad$ inlet to test section 
1 


\section{INTRODUCTION}

The fluid dynamics of a turbomachinery blade channel is affected by several parameters. Blade surface curvature, streamwise pressure gradient, and free-stream turbulence influence the flow field, and specifically the boundary-layer. In addition, the flow in a turbomachinery blade channel goes through a frame-of-reference change as it travels from the stator to the rotor and vice-versa. Due to the wakes created at the trailing edges of the rotor and stator blades, and the frame-of-reference change, the blade channel is subjected to a periodic-unsteady wake passage. These wakes not only introduce an additional disturbance, but they cause the flow of the boundary-layer to change from a laminar to turbulent state with periodicity (i.e., periodic-unsteadiness).

The above parameters control the transition of the boundary-layer from laminar to turbulent flow. Since the flow field is periodically-unsteady, the boundary layer can and does change between laminar, transitional, and turbulent states. The drag and heat transfer coefficients of the blade are directly related to the state of the boundary-layer. Thus, it is important to the turbomachinery designer to be able to predict the behavior of the boundary-layer early in the design process. This would allow better optimization of turbomachinery stage design, which would result in a more efficient turbomachine.

Currently, the complete behavior of the boundary-layer on a turbomachinery blade cannot be predicted theoretically. From a computational point of view, the mathematics are too complex for existing computers to handle in any reasonable amount of time. Furthermore, current empirical models are not sufficient. Thus, experimentation is necessary to isolate the individual and collective effects that contribute to transition for development of better empirical models.

To simplify the complexities found in a turbomachinery blade channel, a constant radius curved plate is used. Boundary-layer measurements are taken and ensembleaveraged with respect to the wake passing period to give insight into the transition process that occurs in a turbomachine. Through test cases that isolate various parameters, such

The format of this document follows the ASME Journal of Turbomachinery. 
as streamwise pressure gradient and periodic-unsteadiness, the flow physics of transition are revealed. From this information, the visual insight necessary to develop further research and create better turbomachinery design procedures can be achieved. 


\section{LITERATURE REVIEW}

\subsection{General Transition Research}

The transition of the boundary layer from laminar to turbulent flow has been studied by many researchers. The modes of transition typically found in turbomachinery have recently received a great deal of attention. Due to the number of mechanisms involved in the transition process of a turbomachinery blade, theoretical modeling has been difficult. Abu-Ghannam and Shaw (1980) and Dhawan and Narasimha (1958) have developed empirical models for the start and end of transition based on flat plat research. These models have been applied to flat surfaces and mildly curved surfaces, such as airfoils, with some success. However, they are not capable of an approximate prediction of transition on a gas turbine blade. Currently, many are working on transition models for gas turbines, including Mayle (1991) and Walker (1993), but a complete general model is still not available for use by turbomachinery designers.

\subsection{Concave Surface Transition Research}

The influence of concave curvature on boundary layer transition has been studied by various scientists over the last half century. Görtler (1940) was the first to give a substantial amount of attention to the boundary-layer on a concave surface. He suggested that counter-rotating longitudinal vortices appeared on concave surfaces and they caused the boundary-layer to be highly three-dimensional. In his theoretical study, he found that a dimensionless parameter, now known as the Görtler number $(G o ̈)$, was necessary to characterize the state of stability of the boundary-layer on a concave surface. The experimental measurements of Liepmann $(1943,1945)$ verified that the parameter Gö was appropriate for quantifying transition on a concave surface. Liepmann took measurements on curved plates with radii of $6.10 \mathrm{~m}$ and $0.76 \mathrm{~m}$ at two different values of free-stream turbulence intensity. His measurements revealed that the Görtler number at transition was approximately $G \ddot{o}=9$, for $T u=0.06 \%$, and $G \ddot{o}=6$ for $T u=0.3 \%$. He affirmed that the mechanism leading to the breakdown of laminar flow on a concave surface was fundamentally different than that of a flat or convex surface. It was also noted that the 
point of instability predicted by linear stability analysis occurred far before the measured point at which the transition actually occurred.

Additional early experimental work was carried out by Tani and Aihara (1969). Their work centered on determining whether Görtler vortices were the primary causes of transition on a concave surface. It was concluded that transition occurred not from the effect of the vortices directly, but from their modifying the Tollmien-Schlichting instability oscillations. Sabzvari and Crane (1985) used laser anemometry and hydrogen bubble visualization to investigate a concave surface of a $0.50 \mathrm{~m}$ radius with $T u=1 \%$. Görtler vortices were observed and found to become unstable at a Görtler number between 6 and 9 , but information on the point of transition was not reported. It was their conclusion that a transition model for concave curvature would not be possible by a simple adjustment to existing flat plate transition models. Riley, Johnson, and Gibbings (1989) took measurements on concave surfaces of radii $0.50 \mathrm{~m}$ and $1.0 \mathrm{~m}$ at $T u$ levels of $0.7 \%, 2.6 \%$, and $7.2 \%$. They concluded that the effects of Görtler vortices were paramount in causing the growth rate of the boundary-layer to increase on the $0.50 \mathrm{~m}$ radius plate, but that freestream turbulence effects dominated that of the Görtler vortices on the $1.0 \mathrm{~m}$ radius plate. The possibility of determining transition using a momentum thickness Reynolds number correlation calculated using only the inner part of the boundary-layer was studied to no avail, and it was suggested that a transition model that incorporated the Görtler number was necessary.

An extensive compilation of transition research was completed by Mayle (1991). From his analysis, he determined that concave curvature could cause an increase or a decrease in the momentum thickness Reynolds number at transition depending upon the radius of curvature and the free-stream turbulence level. By comparing typical values of the curvature parameter $\left(r / \delta_{2}\right)^{1 / 2}$ on turbine blades to the existing concave surface values, he concluded that concave curvature alone was not a major factor in gas turbine transition. Kim, Simon, and Russ (1992) experimentally investigated the effects of turbulence level and concave curvature on heat transfer properties. Their testing was on a concave surface of $0.97 \mathrm{~m}$ radius of curvature and $T u=0.6 \%$ and $8.6 \%$. They found that transition occurred earlier than it would on a flat plate. For the $\mathrm{Tu}=8.6 \%$ case, the free-stream 
turbulence dominated any instability that the Görtler vortices may have introduced.

Concave curvature effects on transition depend on free-stream turbulence level and the radius of curvature. It is generally accepted that concave curvature speeds up the transition process more than that of a flat surface. It can be deduced from the current research that transition onset occurs earlier as the radius of curvature is decreased and the free-stream turbulence intensity is increased. Since higher $T u$ levels over power the effect of concave curvature, the higher amount of turbulence brought about by periodic-unsteady wakes will probably also nullify any effects of concavity. The experimental investigations presented thus far have not included any effect of periodic-unsteady wakes, thus a brief review of pertinent research in this area is in order.

\subsection{Periodic-Unsteady Transition Research}

Experimental research on the effect of periodic-unsteady wakes on the transition process has recently received the attention it needs. Researchers are using long thin cylinders to generate wakes that simulate those from the trailing edge of a turbine or compressor blade. The trailing edge wake characteristics found in a turbomachine are asymmetric with respect to the wake centerline as demonstrated by $\mathrm{Raj}$ and Lakshminarayana (1973). Similar asymmetric characteristics were encountered in the wake of a circular cylinder in a downstream curved channel as measured by Schobeiri, John, and Pappu (1993). Turbomachinery wakes have been modelled with long thin cylinders in various ways by different researchers. The first significant experimental research in this area was performed by Pfeil and Herbst (1979) and Pfeil, Herbst, and Schröder (1983). They took measurements on a flat plate that was located downstream of a rotating squirrel-cage type wake generator. This type of wake generator consists of several long thin cylinders attached between the outer circumference of two parallel rotating disks. Their results allowed them to suggest a qualitative model for the effect of periodic-unsteady wakes on laminar-turbulent transition. To illustrate this model, schematics of the transition process were presented in the temporal-spatial domain. This yielded unique insight into the effect of periodic-unsteady wakes. Furthermore, their measurements showed that periodic-unsteady wakes forced the onset of transition to occur 
at a shorter flow distance than the corresponding flow without wakes present. This research program continued with the work of Orth (1993). He used the same test facility as Pfeil and his co-workers to take detailed hot-wire measurements on a flat plate at different streamwise pressure gradients and also compared results to linear stability predictions. He found that the wakes caused transition to occur much earlier than predicted by linear stability theory. Orth described the pattern of events that occurred during periodic-unsteady transition. He observed that when the wake impinged on the leading edge of the plate, transition did not occur instantaneously. The wake created a disturbance in the boundary-layer while a wake strip appeared in the free-stream. The disturbance convected downstream at a slower speed than that of the free-stream wake strip. The disturbance eventually progressed into a transitional patch, and subsequently into a turbulent patch, that continued to convect downstream. Orth also observed extended laminar becalmed regions between wake disturbances in the boundary-layer far beyond the point at which transition would occur without wakes present, thus confirming the phenomenon first described by Pfeil and Herbst. Furthermore, Orth stated that with increasing turbulence intensity, transition was initiated earlier and pressure gradient effects almost disappeared.

Liu and Rodi (1991) used a test facility similar to that of Pfeil and his co-workers that also employed a rotating squirrel-cage wake generator to take measurements on a flat plate. Transition only occurred on their plate in the presence of periodic-unsteady wakes. A clear correlation between wake passing frequency and transition location was found, and they illustrated that higher wake passing frequencies produced earlier transition onset. Later, Liu and Rodi (1992) used the same test facility to investigate periodic-unsteady flow in a linear turbine cascade. Unlike their previous investigation, the boundary-layer integral parameters did not change substantially with the introduction of periodic-unsteady wakes, but transition onset still occurred earlier by increasing the wake passing frequency. The wakes did cause a visible change in turbulence level that could be followed through the cascade channel. Their heat transfer measurements showed that as wake passing frequency increased, the time-averaged heat transfer coefficient also increased.

Dong and Cumpsty (1990a, b) used two parallel belts carrying long thin cylinders 
to generate wakes in a two-dimensional compressor cascade test facility. This type of wake generation produces very uniform two-dimensional wakes appropriate for twodimensional cascade research. They found that the transition process with unsteady wakes was different when compared to measurements taken without unsteady wakes present. Without wakes, a laminar separation bubble appeared on the blade suction surface. The wakes caused early transition on the blade, but also caused stabilization of the laminar boundary-layer between wakes and the separation bubble to fade in and out periodically. This allowed intermittent laminar flow to extend past the point it would have without wakes present, as also reported earlier by Pfeil, et al. It was also noted that the wakes did not have much significance on boundary-layer at the trailing edge of the blade, and thus the loss coefficient was not changed substantially.

The comprehensive paper of Mayle (1991) is a compilation of much of the work and analysis of laminar-turbulent transition as applied to gas turbines. He emphasized the importance of periodic-unsteady transition as one of the primary mechanisms of transition in gas turbines. Using many sources to support his findings, he described periodicunsteady transition. When a wake impinged on the leading edge, and started to convect downstream, the many wake-induced turbulent spots eventually coalesced to form a turbulent strip. Thus, he stated, the wake was causing a direct effect in the boundarylayer. He admitted that more work was required to determine the production mechanism for wake-induced turbulent strips. Mayle outlined a model for transition prediction and offered many suggestions to researchers to aid in finding a satisfactory model.

Walker (1993) extended the discussion initiated by Mayle by offering a different philosophy on the physics of transition caused by periodic-unsteady wakes. He agreed that turbulent breakdown did coincide with the passing wake disturbance, but suggested that it was an indirect effect that caused the boundary-layer to undergo transition. He argued that whether the breakdown resulted from periodic unsteadiness or wake turbulence ingestion into the boundary layer, the cause was indirect. Furthermore, he supported his argument by noting that Dong and Cumpsty and Orth observed the wake travelling passively over the laminar boundary-layer in the free-stream after initiating a disturbance at the leading edge. Nonetheless, he also noted that future research in this area was 
important to aid in true understanding of periodic-unsteady transition. Many scientists and engineers are studying this phenomenon both theoretically and experimentally, but, it is clear that much more information and insight are needed to be able to accurately quantify the transition process in gas turbines from a general point of view.

\subsection{Pressure Gradient Effects on Transition}

Many of the previous investigations mentioned were carried out over different pressure gradients, but it is hard to single out the individual mechanisms that led to transition. The investigations of Schobeiri $(1976,1980,1990)$ showed that flow, in symmetric and asymmetric channels, had a tendency to separate more readily on convex surfaces with an adverse pressure gradient. According to the presentation of White (1991), in general, a favorable pressure gradient was more stabilizing of the laminar boundarylayer. Thus, it can be deduced that transition occurred earlier for adverse pressure gradients and occurred increasingly later as the pressure gradient was decreased.

The previous studies in the area of boundary-layer transition from laminar to turbulent flow have given much insight into this particular flow phenomenon. Likewise, many questions have been raised, and much more research is needed to aid in the complete understanding of the flow physics of transition. 


\section{OBJECTIVES}

Many have contributed to the determination of the effects of various parameters on the transition process. However, the effect of periodic-unsteady wakes on a concave surface with a constant radius of curvature has not been studied. The intent of this research is to aid in the determination of the individual and collective effects of periodic-unsteady wakes, concave curvature, and pressure gradient on boundary-layer development and transition, with a focus on the periodic-unsteadiness. The results will be analyzed to aid the quest for quantification of the transition process in turbomachines. Furthermore, the design and manufacture of a new experimental test facility for the next generation of research in this area will be accomplished. 


\section{TEST FACILITY AND MEASUREMENT TECHNIQUE}

\subsection{Wind Tunnel}

The test facility in Figure 1 is described in Schobeiri and Pardivala (1992) in detail. The air is supplied with a centrifugal fan driven by a $112 \mathrm{~kW} 3$-phase $\mathrm{AC}$ electric motor. The fan is capable of delivering a maximum mean velocity $36 \mathrm{~m} / \mathrm{s}$ at the test section. This corresponds to a Reynolds number (based on the test section inlet height) of $R e=8.8$ $x 10^{5}$. The present investigation was conducted with a test section inlet velocity of approximately $10 \mathrm{~m} / \mathrm{s}$ to $15 \mathrm{~m} / \mathrm{s}\left(R e=2.4 \times 10^{5}\right.$ to $\left.3.6 \times 10^{5}\right)$. The flow entering the fan passes through a fiberglass filter capable of screening particles down to $5 \mu \mathrm{m}$. Slightly downstream of the fan, a Prandtl pressure probe is permanently located in the straight pipe for close monitor of the velocity at this point. This velocity is taken as a reference point for evaluation of fluctuations in the mean flow.

Directly downstream of the straight pipe, a short diffuser decelerates the flow for preparation before entering the settling chamber. The diffuser has six different internal diffusing sections to aid in breaking up any large scale turbulent vortices as the flow passes through. The settling chamber consists of three sections of $750 \mathrm{~mm}$ in length and

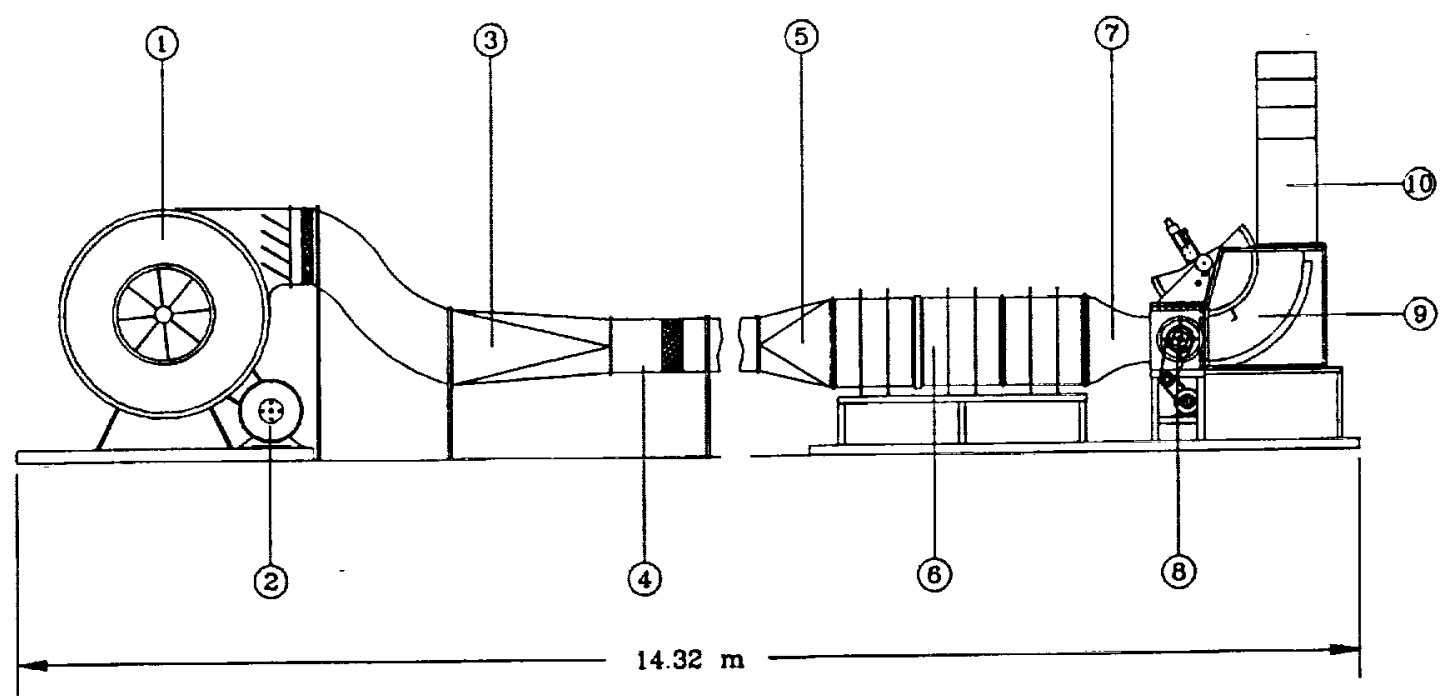

Figure 1. Wind tunnel. 1-centrifugal fan, 2-electric motor, 3-transition duct, 4-straight pipe, 5-diffuser, 6-settling chamber, 7-nozzle, 8-wake generator, 9-curved test section, 10exit duct 
a cross-section of $1200 \mathrm{~mm}$ by $820 \mathrm{~mm}$. The three sections are separated by four screens and one honeycomb flow straightener. The screens allow the adjustment of the free-stream turbulence level at the test section. This is achieved by variation of the number of screens, the mesh size, and the amount of open area of the screen. The current configuration yields a local free-stream turbulence intensity of $1.2 \%$ at the test section inlet. A nozzle is located downstream of the settling chamber. The nozzle has a 4:1 area ratio that accelerates the flow before entering the wake generation area.

The periodic-unsteady wakes are simulated by a wake generator similar to that of Pfeil, et al. (1983). It consists of two parallel rotating disks which are capable of holding up to 30 long thin cylindrical rods around the circumference. The wake generator crosssection is shown in Figure 2, where the disks and two cylinders are positioned at the outer circumference. To avoid the inception of undesirable secondary vortices generated by the rotating disks, two stationary circular disks, connected with the inner shaft, guard the rotating disks from the air flow stream. The wake generator is capable of rotating both

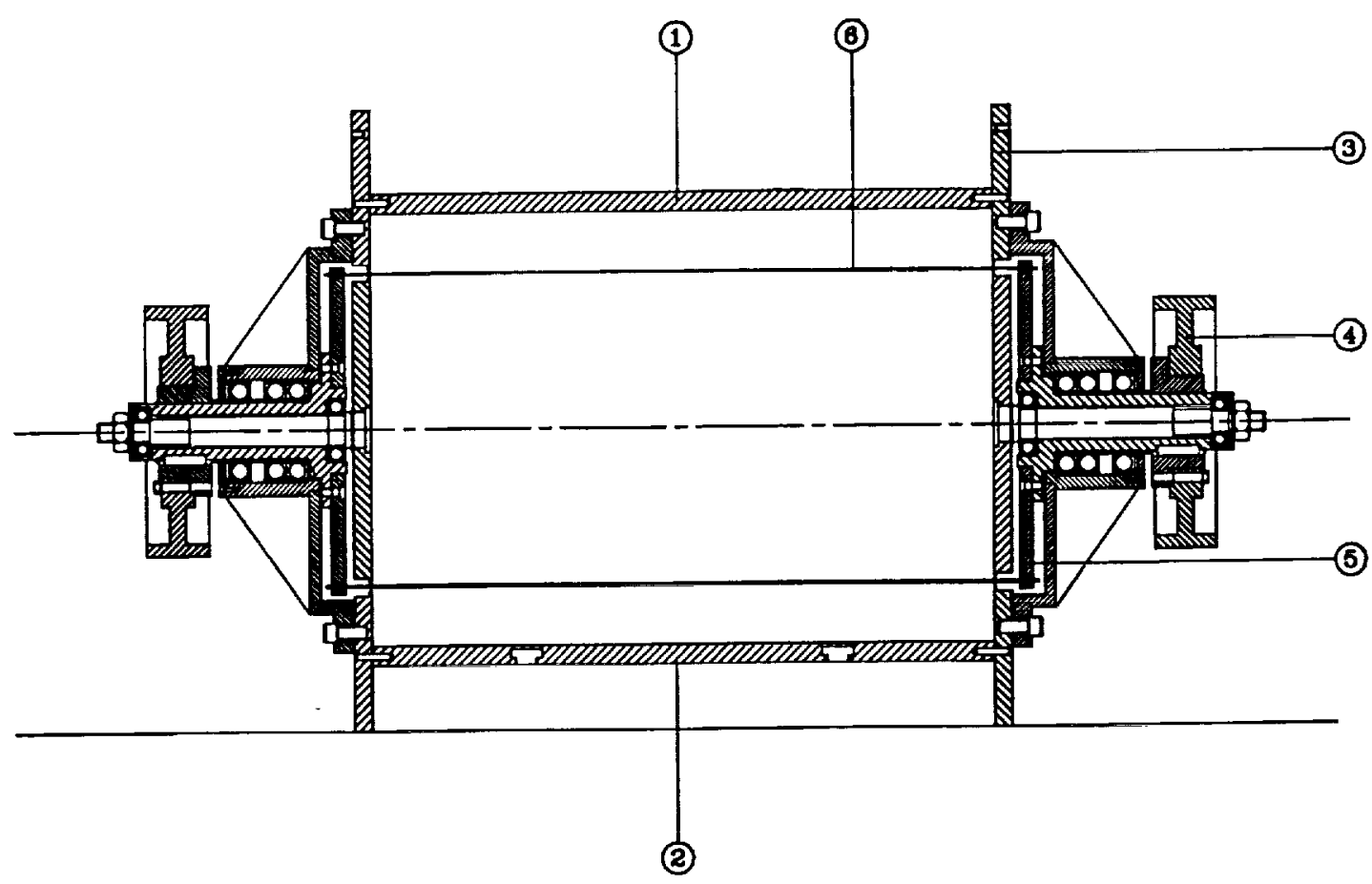

Figure 2. Wake generator cross section looking upstream. 1-upper wall, 2-lower wall, 3side wall, 4-timing belt pulley, 5-rotating disk, 6-long thin cylinder 
clockwise and counter-clockwise. However, in order to simulate the rotor-stator wake interaction within a turbomachinery stage, the disks are rotated in the counter-clockwise direction looking from the point of view shown in Figure 3. The wake size and frequency can be adjusted by changing the diameter and number of rods in the wake generator. For the present study, five rods of $2 \mathrm{~mm}$ diameter were used. A frequency controlled electric motor $(7.45 \mathrm{~kW})$ drives the wake generator. A fiber optic sensor monitors the angular velocity of the wake generator and also serves a triggering mechanism for data collection. The wake generator angular velocity was set at $300 \mathrm{rpm}(5 \mathrm{~Hz})$. There are five primary

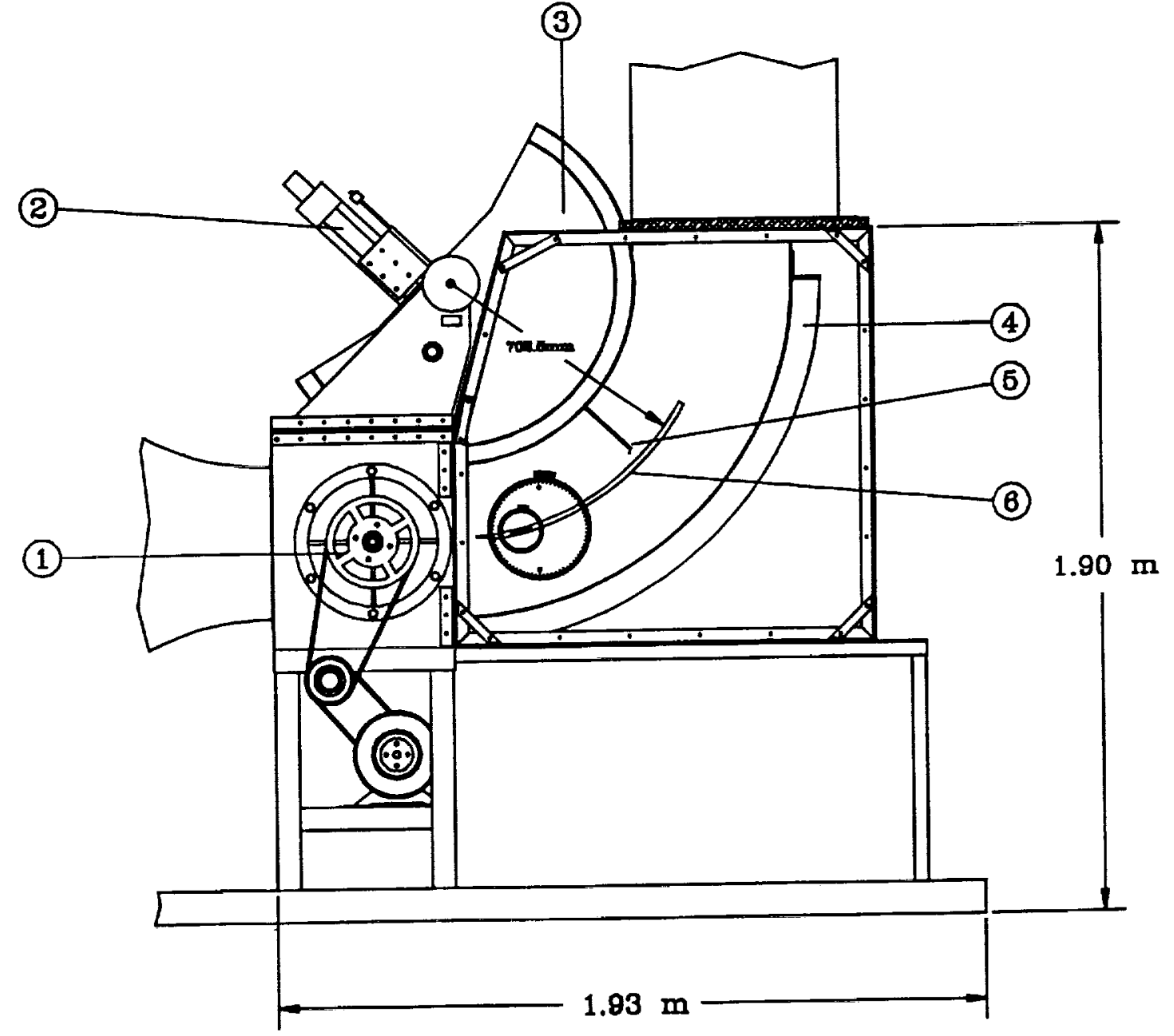

Figure 3. Test section with the curved plate located at the mid-height of the channel. 1wake generator, 2-linear traverse, 3-convex wall, 4-concave wall, 5-hot-wire probe, 6curved plate 
wake passes for each rotation of the wake generator, thus the wake passing frequency is $25 \mathrm{~Hz}$.

The test section (Fig. 3) is located downstream of the wake generator. It consists of a convex upper wall, a concave lower wall, and two transparent acrylic side walls. The convex upper wall rotates about its center of curvature in the streamwise direction to allow detailed movement of the linear positioner used for boundary layer traversing. The concave bottom wall is capable of sliding left and right to allow adjustment of the channel pressure gradient. The upper and lower walls are also equipped with static pressure taps which are connected to a manometer bank for reference purposes.

\subsection{Curved Plate}

The curved plate, also shown in Figure 3, is used to simulate a constant radius of curvature blade. The concave surface of the plate has an arc length of $s_{0}=690 \mathrm{~mm}, a$ width of $593 \mathrm{~mm}$, and a curvature radius of $r=702.5 \mathrm{~mm}$. A detailed view of the plate is shown in Figure 4. The leading edge radius is $1.0 \mathrm{~mm}$. There are 17 static pressure taps mounted flush to the concave surface of the plate (see also Fig. 5), which are at 36.8 $\mathrm{mm}$ arc length spacings. Each pressure tap is connected to individual stainless steel tubes, which in tum are connected to flexible tubing and routed out of the side of the test section to a manometer bank. The streamwise static pressure distribution can be attained from these pressure taps, as well as determination of possible separation near the leading edge. The plate is mounted between the two transparent acrylic side walls of the test section. The position of the plate is adjusted by rotating the transparent acrylic disks that hold the plate between the two side walls. This allows precise adjustment of the streamwise pressure gradient above the plate. Two angular verniers are used to locate the position of the plate relative to the test section.

\subsection{Measurement Technique}

To measure the boundary layer on the concave surface of the plate, a computer controlled traversing system is used. A linear positioner is used to move the hot-wire probe to the correct radial location above the plate. A parallel distance pin is located 


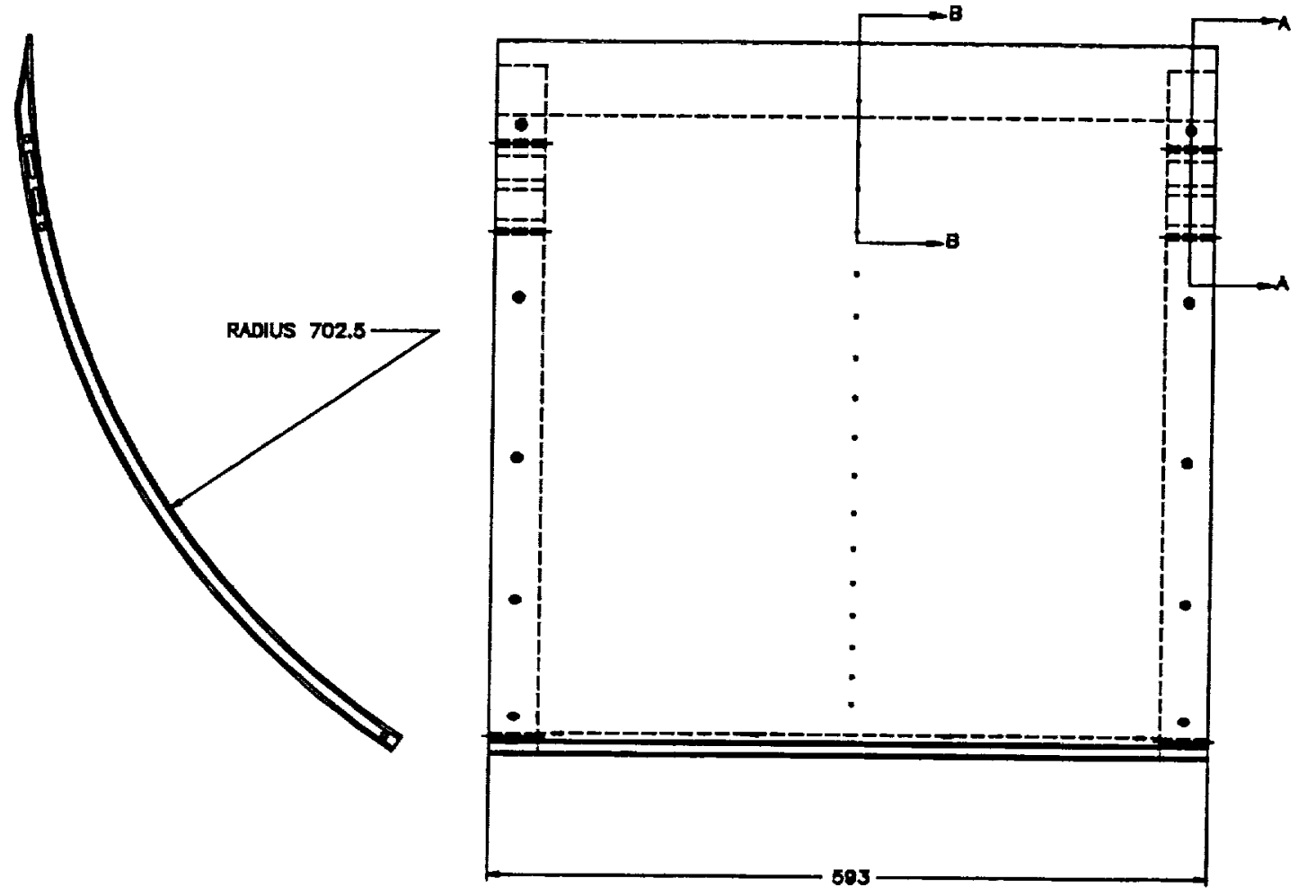

Figure 4. Curved plate detail drawing with side and top views.

approximately $50 \mathrm{~mm}$ in the span-wise direction from the hot-wire probe. Its purpose is to touch the plate slightly before the hot-wire for location of the wall position relative to the hot-wire. When the distance pin comes in contact with the plate, an electric circuit is completed and a red lamp is illuminated. The distance pin will touch the plate when the hot-wire is approximately $0.1 \mathrm{~mm}$ above the surface. The hot-wire traversing schedule is either typed manually into the computer or given in the form of a text file as input to a FORTRAN program. When collecting a boundary layer data set, the probe is manually traversed down until the location of the wall is found with the distance pin, then the positioning schedule is employed to move the probe to the required locations for data collection.

To position the probe in the streamwise direction, the complete convex upper wall of the test section is rotated about its center of curvature. The linear positioner is mounted to the convex wall, and thus moves with the convex wall. The position is indicated with an angular vernier, which is accurate to $0.08^{\circ}$. 
The hot-wire probe is a custom designed model (TSI 1210EJ-T1.5) for the purpose of boundary layer measurement. The wire supports on the probe are angled at approximately $30^{\circ}$ from the horizontal, which positions the wire upstream of the probe support approximately $10 \mathrm{~mm}$. This allows only minimal disturbance of the flow to ensure high accuracy. The hot-wire used is a $4 \mu \mathrm{m}$ diameter tungsten wire. Since the
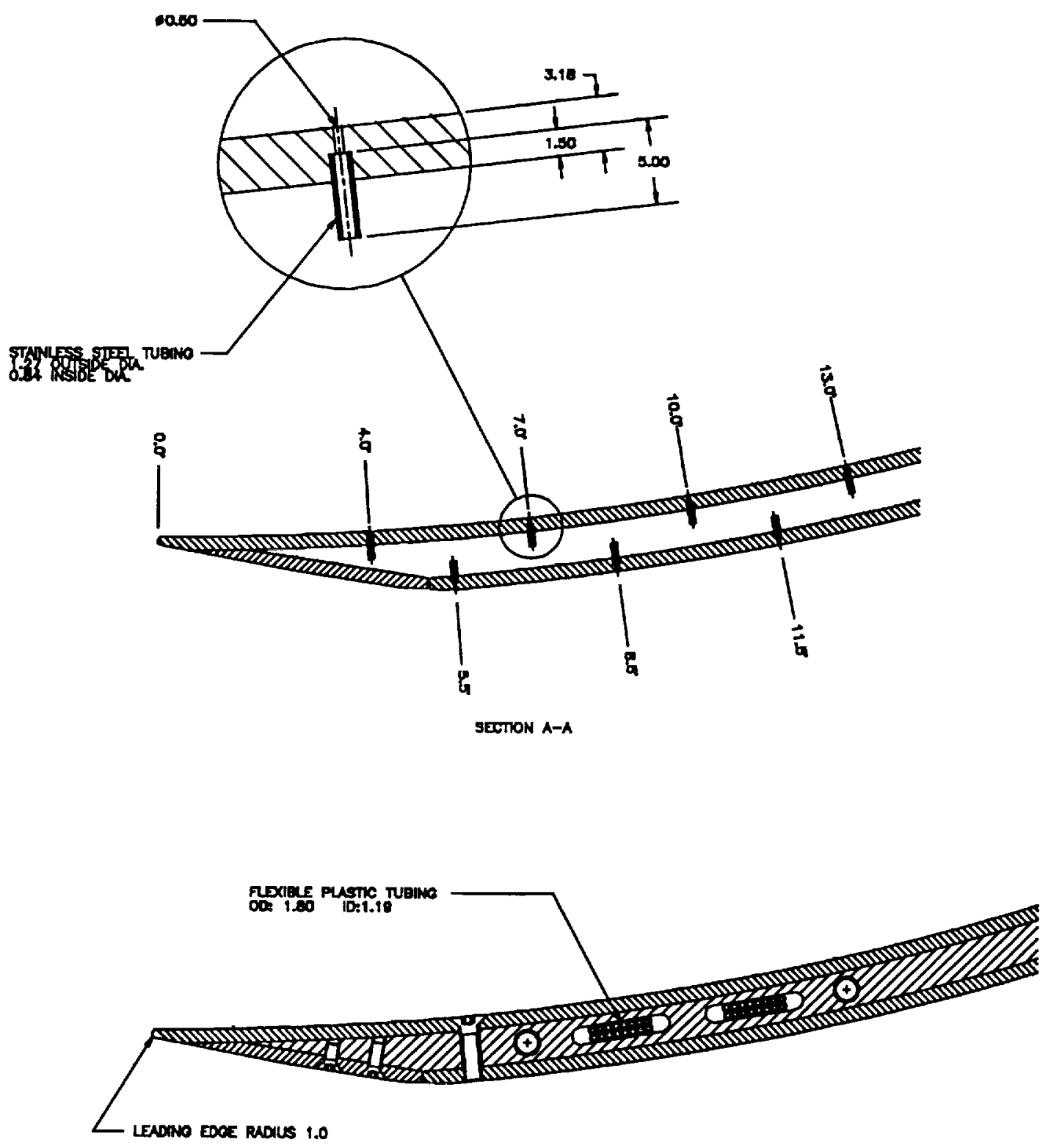

sumion $0-8$

Figure 5. Cross-sections A-A (showing the internal static pressure taps without flexible tubing attached) and B-B (showing the internal rib and flexible tubing exit) of Fig. 4. 
wire is so small, detailed measurements close to the wall can be attained.

To record and analyze the hot-wire data, a computer controlled system is used for all processes. This will be the subject of the next section. 


\section{DATA ACQUISITION AND REDUCTION}

Data acquisition consists of the equipment used to record and collect the measurements needed to analyze the boundary layer. A personal computer, with a 12-bit analog to digital conversion board installed, controls the data acquisition system. The instantaneous velocity signal is obtained from the hot-wire probe via a constant temperature hot-wire anemometer system (TSI IFA 100). Each channel of the system is equipped with a signal conditioner, including variable low and high pass filters, adjustable gain, and DC-offset. Numerous spectral measurements indicate that the turbulence frequencies are less than $20 \mathrm{kHz}$, thus the low pass filter is set to this value to keep high frequency electronic noise out of the signal. The DC-offset and gain are adjusted according to the fluid velocity to be measured and are set at the time of hot-wire probe calibration.

To monitor the wake generator angular velocity and position for periodic-unsteady boundary layer measurement, a high response fiber optic proximity sensor (ATC 7062A) is used. A small piece of reflective tape on the wake generator pulley triggers the sensor, which in turn sends a signal to the personal computer through a signal processor. For periodic-unsteady measurement, this triggering system is necessary to ensure that all data collection is started at the same wake generator position to later facilitate data ensembleaveraging.

Accurate measurement of the data presented in this paper requires calibration of the hot-wire sensor. In order to ensure high accuracy, the calibration facility described in John and Schobeiri (1993) was used for all hot-wire calibration. For the data reduction and analysis, the characteristic response of the hot-wire probe is stored in the form of calibration coefficients. The instantaneous velocity components are calculated from the temperature compensated instantaneous voltages using the calibration coefficients. The instantaneous velocity is represented in the following form,

$$
U=\bar{U}+u
$$

where $\bar{U}$ is the mean velocity and $u$ is the turbulent fluctuation component. The mean 
velocity, also known as the time-average, is given by

$$
\bar{U}=\frac{1}{N} \sum_{j=1}^{N} U_{j}
$$

where $N$ is the total number of samples at one location. A sampling rate of $1 \mathrm{kHz}$ was used for the steady flow investigations. Good convergence was found for $N=16384$ samples. The root-mean-square value of the velocity fluctuation is obtained from the instantaneous and mean velocities by

$$
u=\sqrt{\frac{1}{N} \sum_{j=1}^{N}\left(U_{j}-\bar{U}\right)^{2}}
$$

and the local turbulence intensity is defined as

$$
T u_{l o c}=\frac{u}{\bar{U}} \times 100=\frac{1}{\bar{U}} \sqrt{\frac{1}{N} \sum_{j=1}^{N}\left(U_{j}-\bar{U}^{2}\right.} \times 100
$$

The reference turbulence intensity is

$$
T u=\frac{u}{U_{r e f}} \times 100
$$

where $U_{\text {ref }}$ is the particular reference velocity in the free-stream at each particular streamwise position measured.

The data reduction presented has been incorporated into FORTRAN programs to facilitate quick and accurate calculation of the above quantities. The names and order of the FORTRAN programs used in the data reduction scheme are given in Figure 6. The programs AUTO4 and BPRO have been adapted from those found in John (1993). AUTO4 is a data acquisition program that records measurements and traverses the probe to the proper locations. BPRO is the primary data reduction program which yields an 


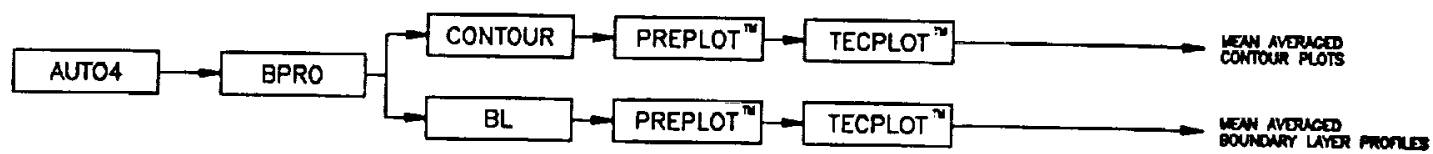

Figure 6. Data acquisition and reduction flow chart for steady flow cases.

output file with the mean velocity, turbulent fluctuation velocity, and local turbulence intensity. The boundary layer integral parameters and other information are calculated by BL. The other programs are primarily used to manipulate the data into the proper format for the plotting program.

As previously mentioned, the data acquisition for periodic-unsteady wake flow is triggered by a once-per-revolution signal from a fiber optic proximity sensor. The unsteady data were reduced by the ensemble-averaging method. Samples were taken $(N=256)$ for each of 400 revolutions of the wake generator at each position. Since the wake generator holds five rods, 400 revolutions of the wake generator produces 2000 near (primary) wakes and 2000 far (secondary) wakes at each position measured. The data are ensemble-averaged with respect to the rotation period $(200 \mathrm{~ms})$ of the wake generator. Thus, the ensemble-averaged results calculated over the 400 revolutions show five wake passes. Variation of the number of samples per revolution and total number of revolutions were performed to determine the optimum settings for convergence of the ensembleaveraged quantities.

The ensemble-averaged velocity, fluctuation velocity, and turbulence intensity is calculated from the instantaneous samples by

$\left\langle U_{i}\left(t_{i}\right)\right\rangle=\frac{1}{N} \sum_{j=1}^{N} U_{i j}\left(t_{i}\right)$

$$
\left\langle u_{i}\left(t_{i}\right)\right\rangle=\sqrt{\frac{1}{N} \sum_{j=1}^{N}\left[U_{i j}\left(t_{i}\right)-\left\langle U_{i}\left(t_{i}\right)\right\rangle\right]^{2}}
$$


$\left\langle T u_{i}\left(t_{i}\right)\right\rangle=\frac{\left\langle u_{i}\left(t_{i}\right)\right\rangle}{U_{\text {ref }}} \times 100$

where $j=1,2, \ldots N$, and $N$ is the total number of periods (i.e. 400 revolutions), and $i=1,2, \ldots, m$, where $m$ is the number of samples taken per period $(m=256)$.

Figure 7 is a flow chart of the data reduction path for periodic-unsteady wake flow. UAUTO4 and UBPRO are the unsteady counterparts to AUTO4 and BPRO mentioned previously. BUSPRO is used to ensemble-average and prepare the data for further processing. BUSPRO has also been adapted from John (1993). UNSBL, UNSCH, UNSCONT and DISTIME are used to manipulate the data into a proper format for contour plotting required by the plotting program.

The items necessary to conduct research have been presented. The experimental results attained will be the subject of the next section.

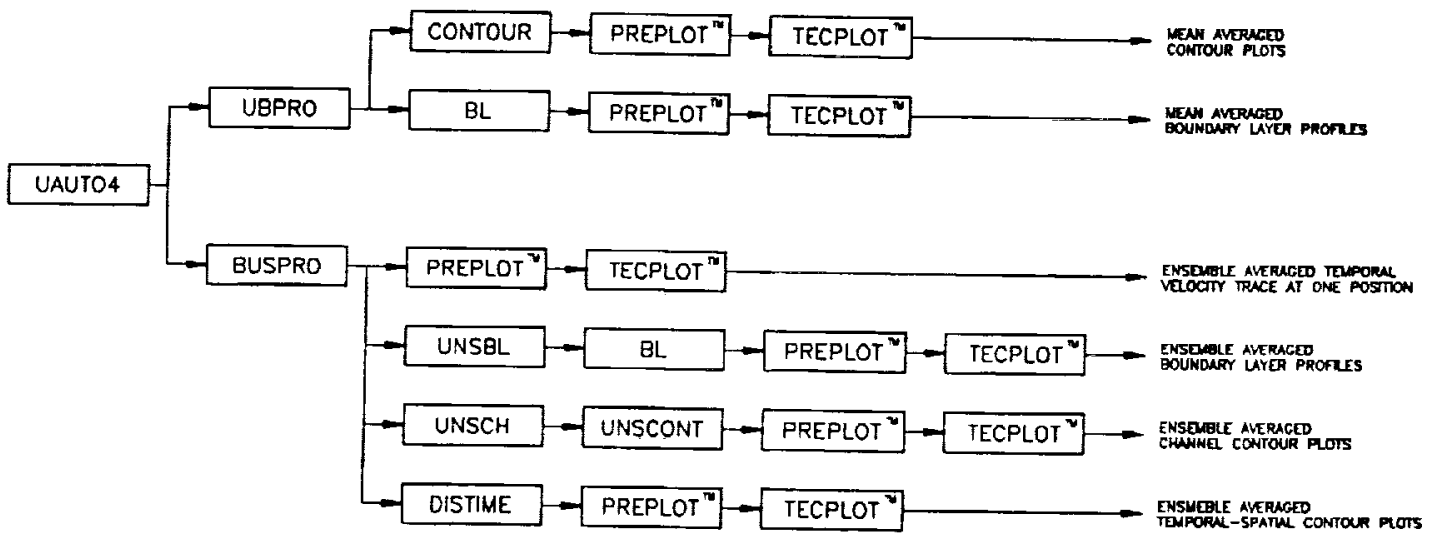

Figure 7. Data acquisition and reduction flow chart for periodic-unsteady flow cases. 


\section{RESULTS AND DISCUSSION}

The experimental program was subdivided into four major investigations and the organization of this chapter will reflect these four cases. The investigations were chosen to isolate the effects of periodic-unsteadiness and presence of a pressure gradient on boundary-layer transition on a concave surface. The cases are divided as follows: Case 1, steady flow at zero streamwise pressure gradient; Case 2, steady flow at negative streamwise pressure gradient; Case 3, periodic-unsteady flow at zero streamwise pressure gradient; Case 4, periodic-unsteady flow at negative streamwise pressure gradient.

The free-stream velocity distribution for the two different pressure gradients is shown in Figure 8. The curved plate was precisely positioned to achieve the desired streamwise pressure gradient. The rise of the free-stream velocity near the trailing edge for zero pressure gradient is probably due to an interaction between the side-wall and plate boundary-layers. The negative pressure gradient velocity increase represents approximately a 1.4 acceleration rate.

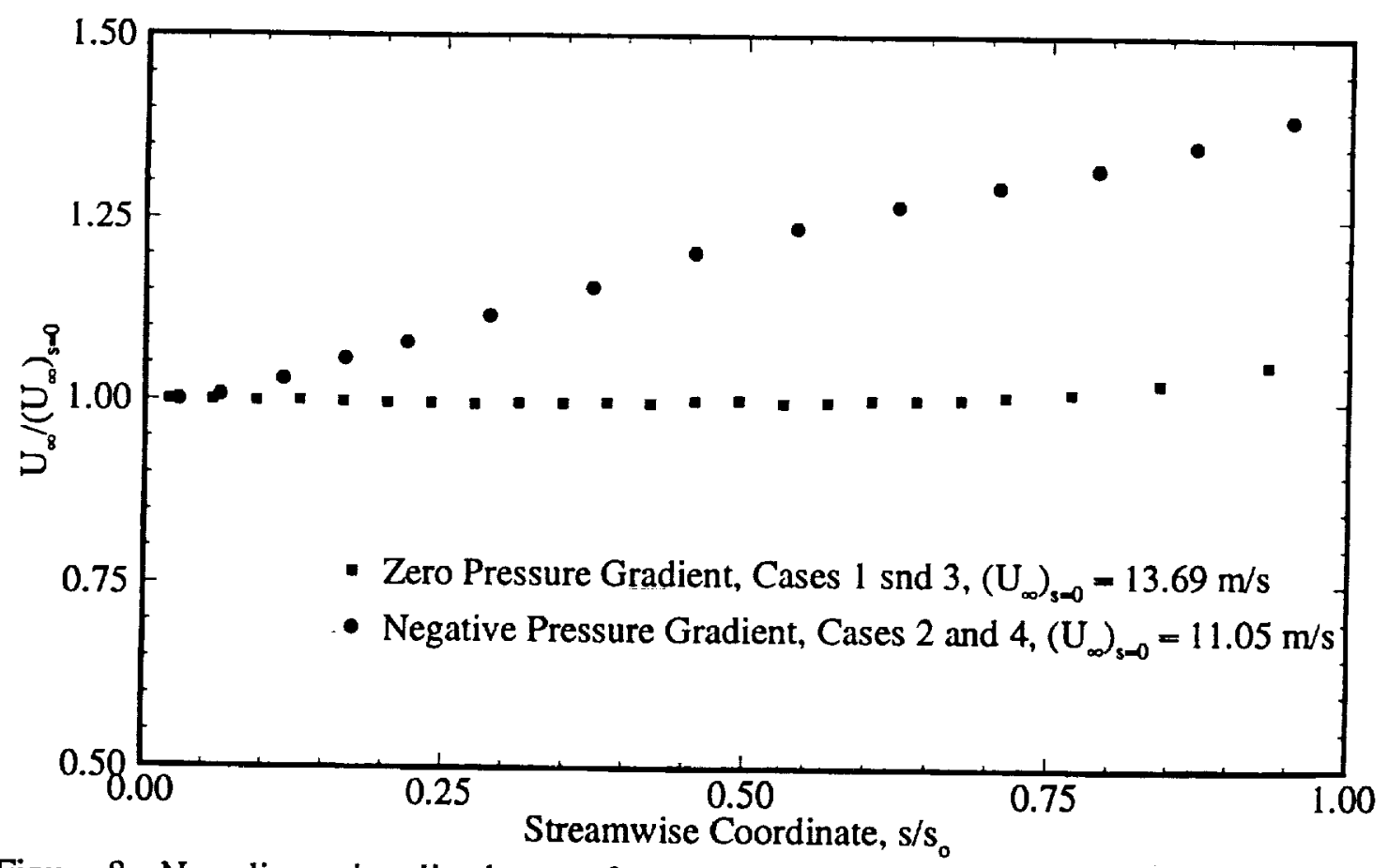

Figure 8. Non-dimensionalized mean free-stream velocity for zero and negative pressure gradient at $\mathrm{y}=30 \mathrm{~mm}$ above the plate surface. 


\subsection{Case 1: Steady Flow at Zero Pressure Gradient}

The channel at zero pressure gradient (Cases 1 and 3) has an inlet height of 219 $\mathrm{mm}$ and an exit height of $221 \mathrm{~mm}$, which yields an area ratio of $A_{1} / A_{2}=0.99$. The state of the boundary layer for this case can be seen at a glance in Figure 9. This figure is a contour plot of the reference turbulence intensity in the channel. The ordinate of this plot is the non-dimensional quantity $y / d$, where $d$ is the thickness of the curved plate $(d=15$ $\mathrm{mm})$. The abscissa is the non-dimensional streamwise distance from the leading edge of the plate. In other words, $s / s_{o}=0.0$ is the position of the leading edge of the plate, and $\mathrm{s} / \mathrm{s}_{\mathrm{o}}=1.0$ is the trailing edge position. The contour lines vary from 3.0 to 13.0 percent, with the unshaded region representing the turbulence intensity between that of the freestream and the boundary-layer. At $\mathrm{s} / \mathrm{s}_{\mathrm{o}}=0.18$, the turbulence intensity starts its sharp gradient in the streamwise direction. The turbulence reaches a maximum point at the center of the $T u=13$ percent contour, which occurs at $\mathrm{s} / \mathrm{s}_{\mathrm{o}}=0.53$. This maximum point will serve as a reference for comparison to the corresponding periodic-unsteady case. The development of the boundary layer from laminar to turbulent flow can be clearly seen,

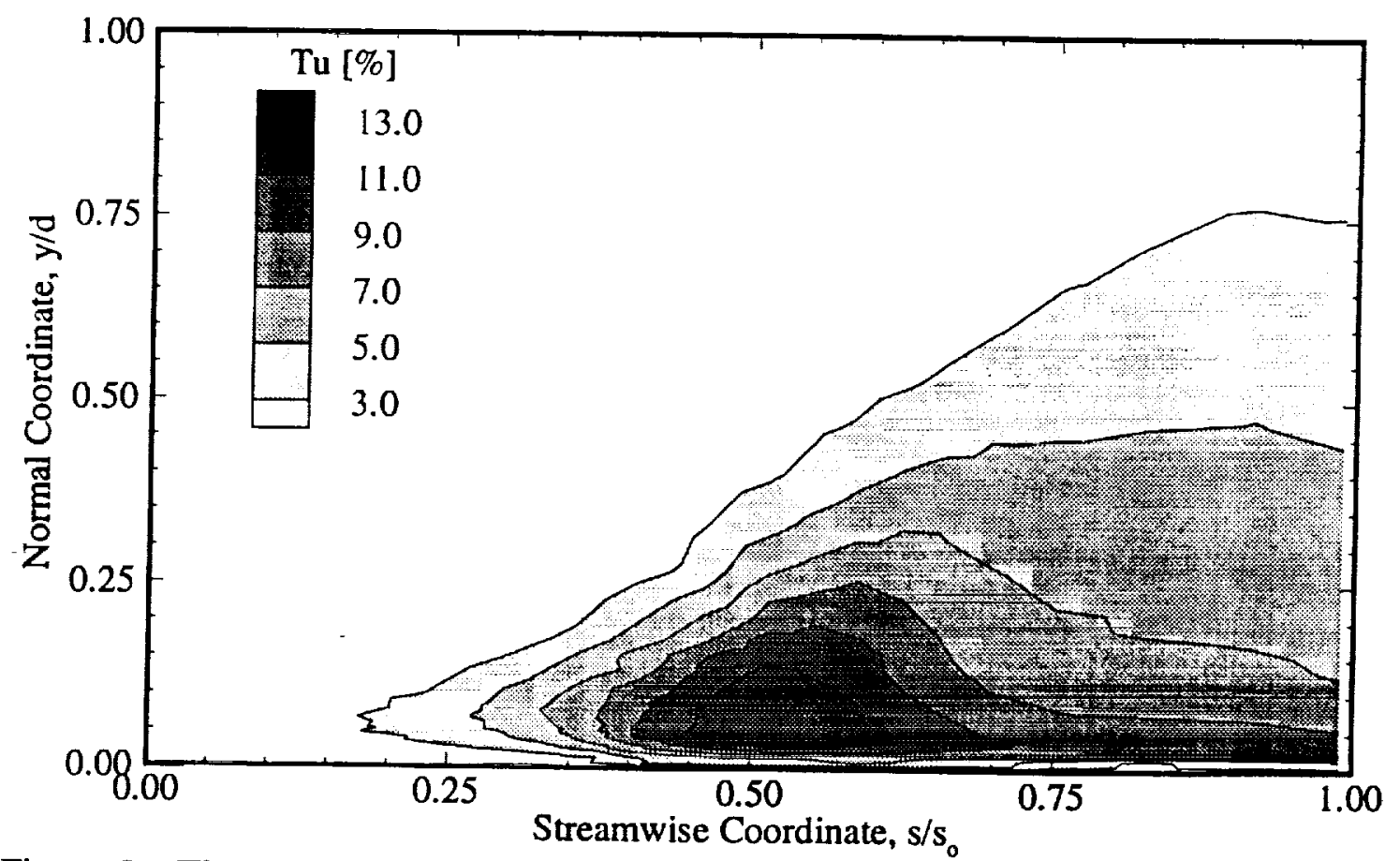

Figure 9. Time-averaged reference turbulence intensity contour of the channel at zero pressure gradient and steady flow (Case 1). 
however, the determination of the exact point of transition onset and transition length is some what arbitrary. The approximate end of the transition region occurs at $s / s_{0}=0.70$.

Figure 10 gives the instantaneous velocity, $U$, as function of time at $\mathrm{y}=0.55 \mathrm{~mm}$ for different streamwise locations. At $s / s_{o}=0.11$, the velocity is fairly smooth and appears to have a turbulence intensity similar to that of the free-stream, since measurement is near the edge of the boundary layer at this streamwise location. As we move downstream to $\mathrm{s} / \mathrm{s}_{\mathrm{o}}=0.30$, clear wave-forms are visible. These disturbances are very likely TollmienSchlichting waves, but are possibly modified by wandering Görtler vortices (see Tani and Aihara, 1969). At $\mathrm{s} / \mathrm{s}_{\mathrm{o}}=0.41$ and 0.51 , the waves continue to amplify and more randomness becomes apparent. The small bursts of randomness between the wave-forms at $s / s_{o}=0.51$ are representative of turbulent spots that have developed and are convecting downstream. These turbulent spots eventually get larger $\left(\mathrm{s} / \mathrm{s}_{\mathrm{o}}=0.59\right)$ and coalesce to form a completely turbulent boundary-layer represented at $\mathrm{s} / \mathrm{s}_{\mathrm{o}}=0.70$ and 0.92 . These velocity profiles, especially at $\mathrm{s} / \mathrm{s}_{\mathrm{o}}=0.92$, characterize a fully developed turbulent boundary layer with no visible periodicity or pattern.

Instantaneous velocity profiles are plotted for $\mathrm{y}=2.0 \mathrm{~mm}$ at various streamwise distances in Figure 11, and are similar to the profiles in Figure 10, with the exception of having slightly lower wave amplitudes. At streamwise positions $\mathrm{s} / \mathrm{s}_{\mathrm{o}}=0.11,0.22$, and 0.30 , the measurements are those of the free-stream, since at $y=2.0 \mathrm{~mm}$ this data is outside the boundary-layer. Distinct wave-forms appear at $s / s_{o}=0.41$. These waves are slightly different than those found in Figure 10 in that they have a primarily negative amplitude. Since the wave-forms are coherent, they probably represent clear turbulent vortices convecting downstream and not a single turbulent spot. Moving to $\mathrm{s} / \mathrm{s}_{\mathrm{o}}=0.51$ and 0.59 , the waves become less distinguished, and more randomness is associated with the velocity distribution. By the time the fluid has reached streamwise position $s / s_{o}=0.70$ and 0.92 , the velocity profiles are, again, completely turbulent.

The non-dimensional boundary-layer profiles are presented in Figure 12 . The variation of profile shape caused by transition from laminar to turbulent flow is clearly evident. Figure 13 shows the value of Görtler number with respect to the streamwise coordinate. The momentum thickness used to determine the Görtler number was 
calculated with the aid of the boundary-layer analysis program developed by Pardivala (1991).

For the purposes of this thesis, the exact point of the onset of transition will be defined as the streamwise location in which a reference turbulence intensity of 3 percent is first observed. The end-point of transition is determined to be the streamwise position at which the reference turbulence intensities have stabilized and appear to have reached steady values. There is arbitrariness associated with determination of these points, just as there is arbitrariness in the scientific community on the rigorous definition of the start and end of the transition. For this case, transition onset occurs at $s / s_{o}=0.18$ and transition end occurs approximately at $\mathrm{s} / \mathrm{s}_{\mathrm{o}}=\mathbf{0 . 7 0}$. This corresponds to a transition length of 52 percent of the surface arc length of the plate (i.e., $358.8 \mathrm{~mm}$ ).

At $\mathrm{s} / \mathrm{s}_{\mathrm{o}}=0.18$ (the earliest location of transition), the value of $G \ddot{o}=3$. The approximate free-stream turbulence intensity for all tests is $T u=1.5 \%$. This value of Görtler number follows the trend of those measured by Liepmann $(1943,1945)(G \ddot{o}=9$ at $T u=0.06 \%$ and $G \ddot{o}=6$ at $T u=0.3 \%$ ). 


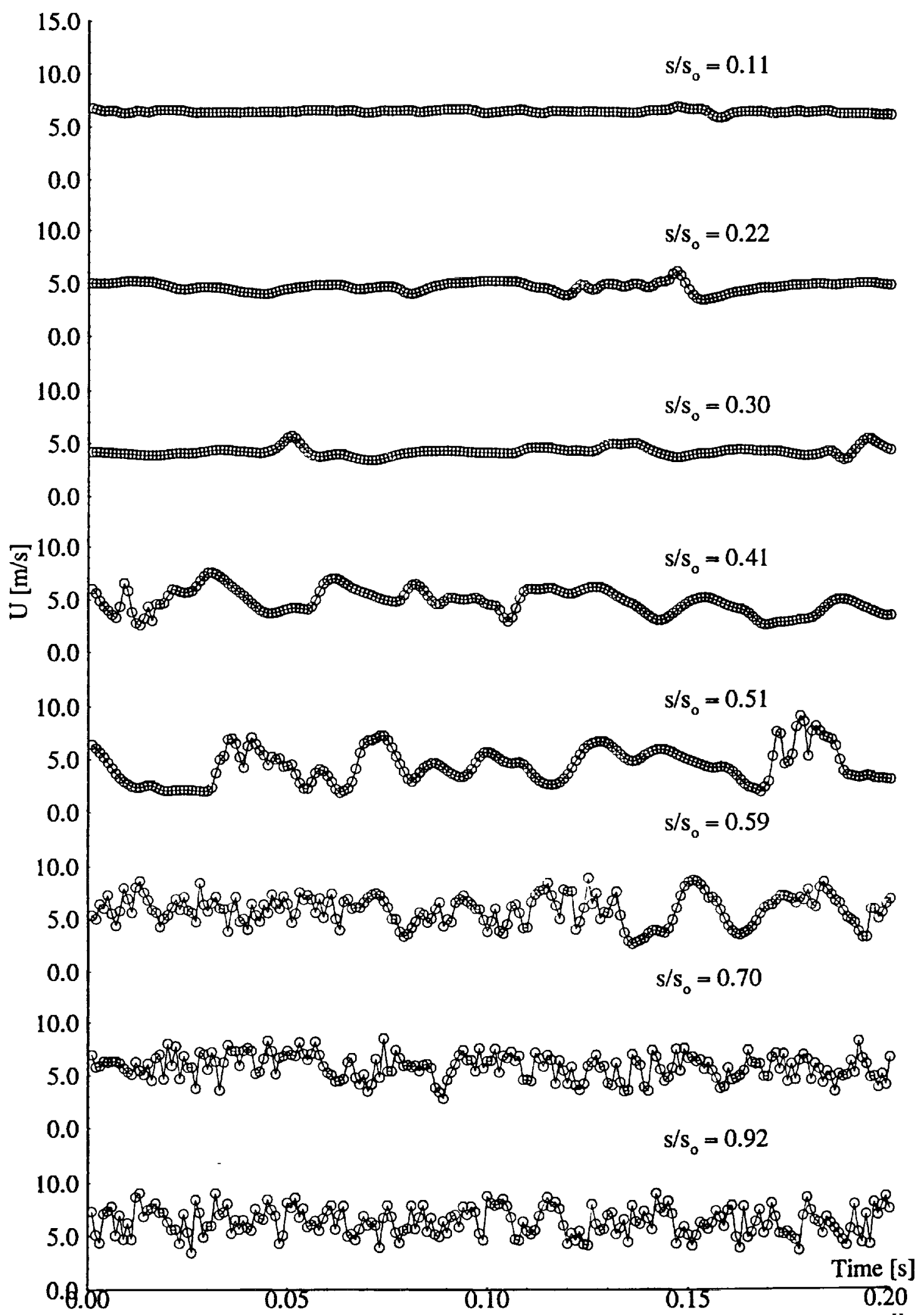

Figure 10. Instantaneous hot-wire velocity traces at $y=0.55 \mathrm{~mm}$ at zero pressure gradient and steady flow (Case 1). 


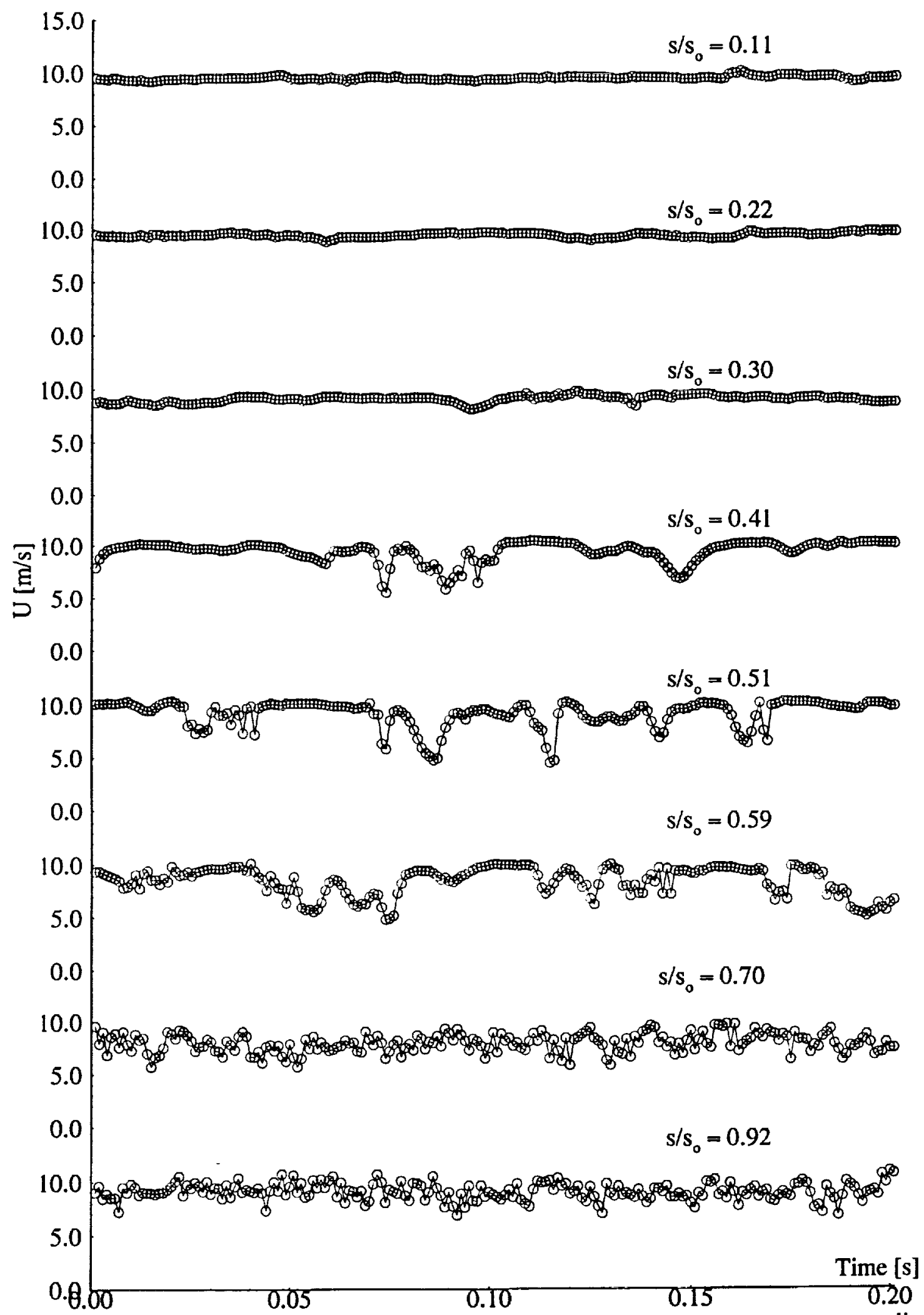

Figure 11. Instantaneous hot-wire velocity traces at $y=2.0 \mathrm{~mm}$ at zero pressure gradient and steady flow (Case 1). 


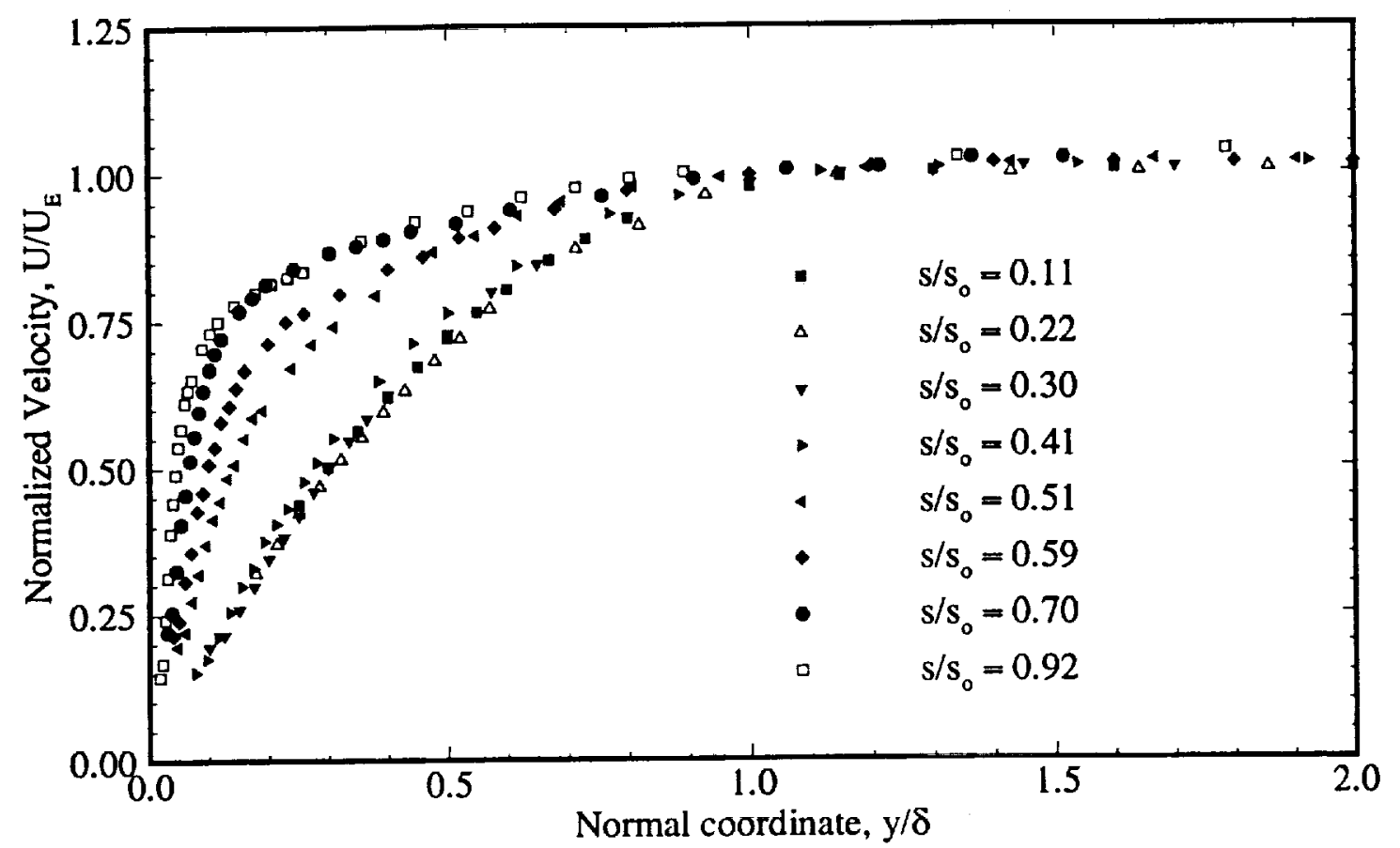

Figure 12. Non-dimensional boundary-layer profiles at different streamwise positions at zero pressure gradient (Case I).

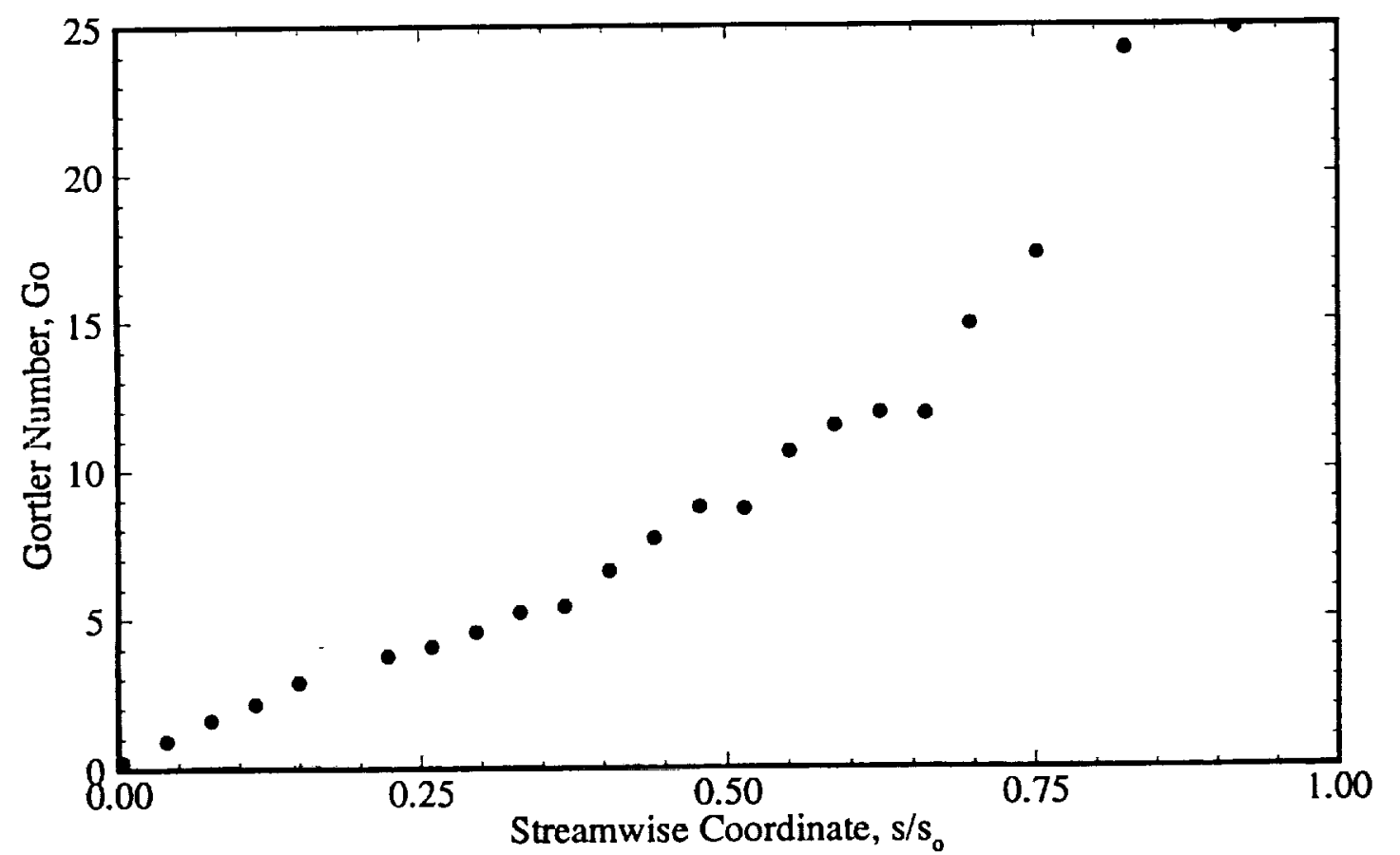

Figure 13. The Görtler number as a function of streamwise position at zero pressure gradient (Case 1). 


\subsection{Case 2: Steady Flow at Negative Pressure Gradient}

After adjusting the plate to a position that caused a converging area above the plate surface, a negative streamwise pressure gradient was achieved. The inlet height of the channel is $192 \mathrm{~mm}$ and the exit height is $138 \mathrm{~mm}$, creating an area ratio of $A_{1} / A_{2}=1.39$ (Cases 2 and 4). The approximate pressure gradient measured using a manometer bank was $-101.8 \mathrm{~Pa} / \mathrm{m}$.

As with Case 1, the transition procedure can be viewed in a plot of the channel turbulence intensity (Fig. 14). The contour shapes are different than Case 1 in a few ways. The overall contour height is smaller which implies a smaller boundary layer thickness, and the 13 percent turbulence contour is flatter. This is probably due to a combination of a thinner boundary layer and the attenuation of disturbances normally associated with a negative pressure gradient. The first streamwise occurrence of the $T u=3 \%$ contour is at $s / s_{o}=0.22$. The peak reference turbulence intensity occurs at $s / s_{o}=0.66$, and the approximate end of transition is at streamwise distance $s / s_{0}=0.81$. This corresponds to a transition length of 59 percent of the plates surface $(407.1 \mathrm{~mm})$. The differences

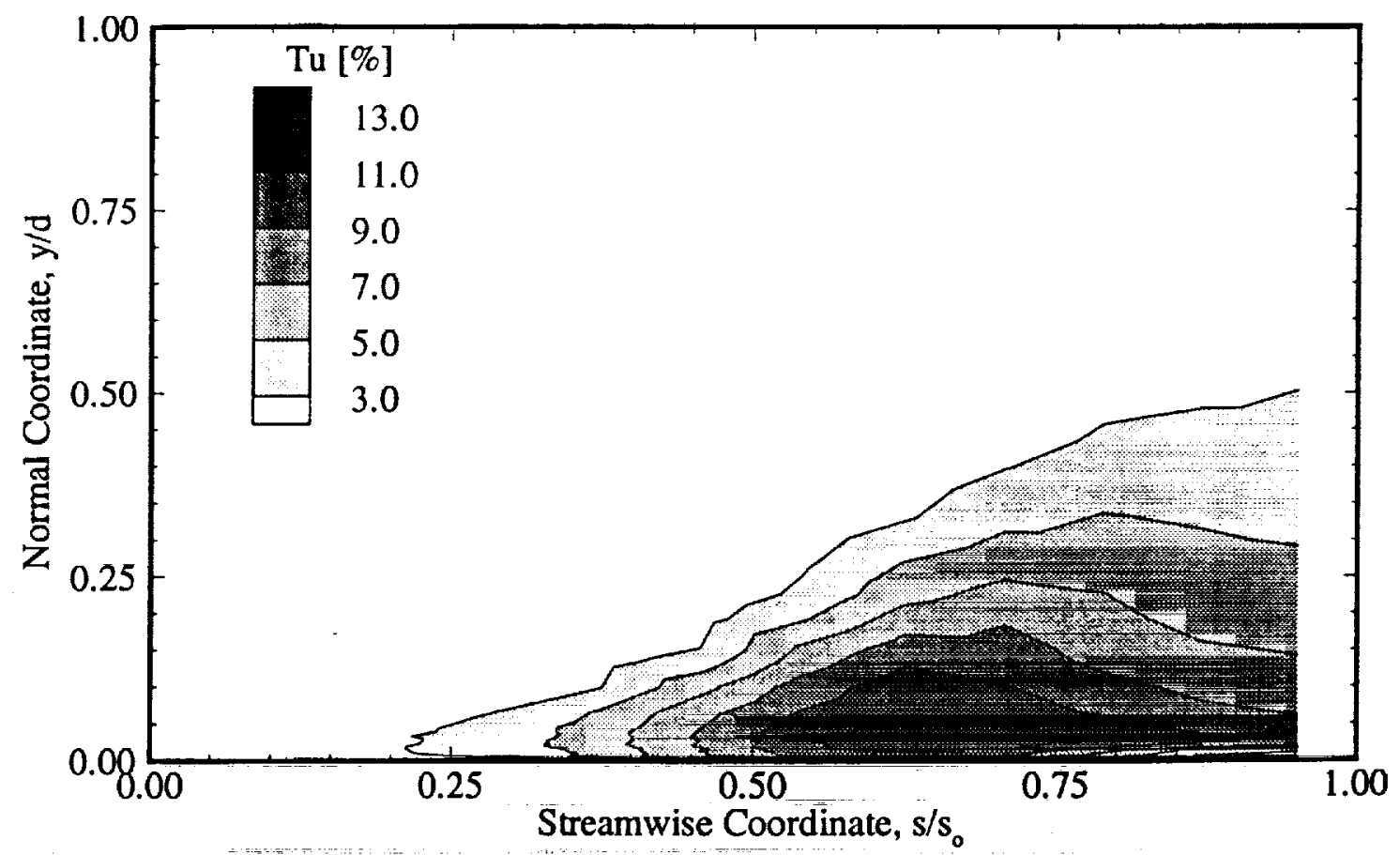

Figure 14. Time-averaged reference turbulence intensity contour of the channel at negative pressure gradient and steady flow (Case 2). 
between Cases 1 and 2 can be primarily attributed to the acceleration of the fluid above the plate surface in Case 2. This acceleration causes a slight attenuation of the TollmienSchlichting wave mechanisms that are primarily responsible for transition.

Figure 15 shows the instantaneous hot-wire velocity traces at $y=0.5 \mathrm{~mm}$ for various streamwise locations. The traces are quite similar to Case 1, except that the fully turbulent boundary-layer does not occur as early. The transition process is clearly visible from streamwise locations $\mathrm{s} / \mathrm{s}_{\mathrm{o}}=0.22$ through $\mathrm{s} / \mathrm{s}_{\mathrm{o}}=0.71$. The waves start at a small amplitude and are sporadic in appearance. As they convect downstream, amplification occurs and the waves become more dense in the velocity trace. At $\mathrm{s} / \mathrm{s}_{\mathrm{o}}=0.79$, random turbulence occupies most of the velocity trace, but partially coherent structures are still visible. With the exception of one small area, the velocity trace at $\mathrm{s} / \mathrm{s}_{\mathrm{o}}=0.87$ is primarily composed of stochastic turbulent fluctuations.

At $y=2.0 \mathrm{~mm}$ above the concave surface, the velocity traces at different streamwise positions are shown in Figure 16. Since the boundary layer thickness is smaller for Case 2, the first few streamwise positions are representative of the free-stream velocity outside the boundary layer. At $s / s_{0}=0.46$, a wave is observed indicating presence inside the transitional boundary layer. It is also apparent that the waves at $s / s_{o}=0.62$ only have a negative amplitude (as also observed in Fig. 11). The more turbulent profiles at $\mathrm{s} / \mathrm{s}_{\mathrm{o}}=0.71$ through 0.87 indicate the end of transition and the beginning of full turbulence, but they appear to still have some coherency. This could quite possibly be due to the nature of a negative pressure gradient turbulent boundary layer.

The non-dimensional boundary-layer profiles for this case appear in Figure 17. The variation in shape between laminar and turbulent profiles is clearly apparent, but not to the extent of those in Case 1 (Figure 12) at a zero pressure gradient. Figure 18 shows the Görtler number distribution with respect to streamwise coordinate. The Gö values have shifted downstream slightly compared to those of Case 1 (see Fig. 13).

All things considered, it can be stated that the presence of a negative pressure gradient delays the onset of transition and increases the transition length over that of a zero pressure gradient. 


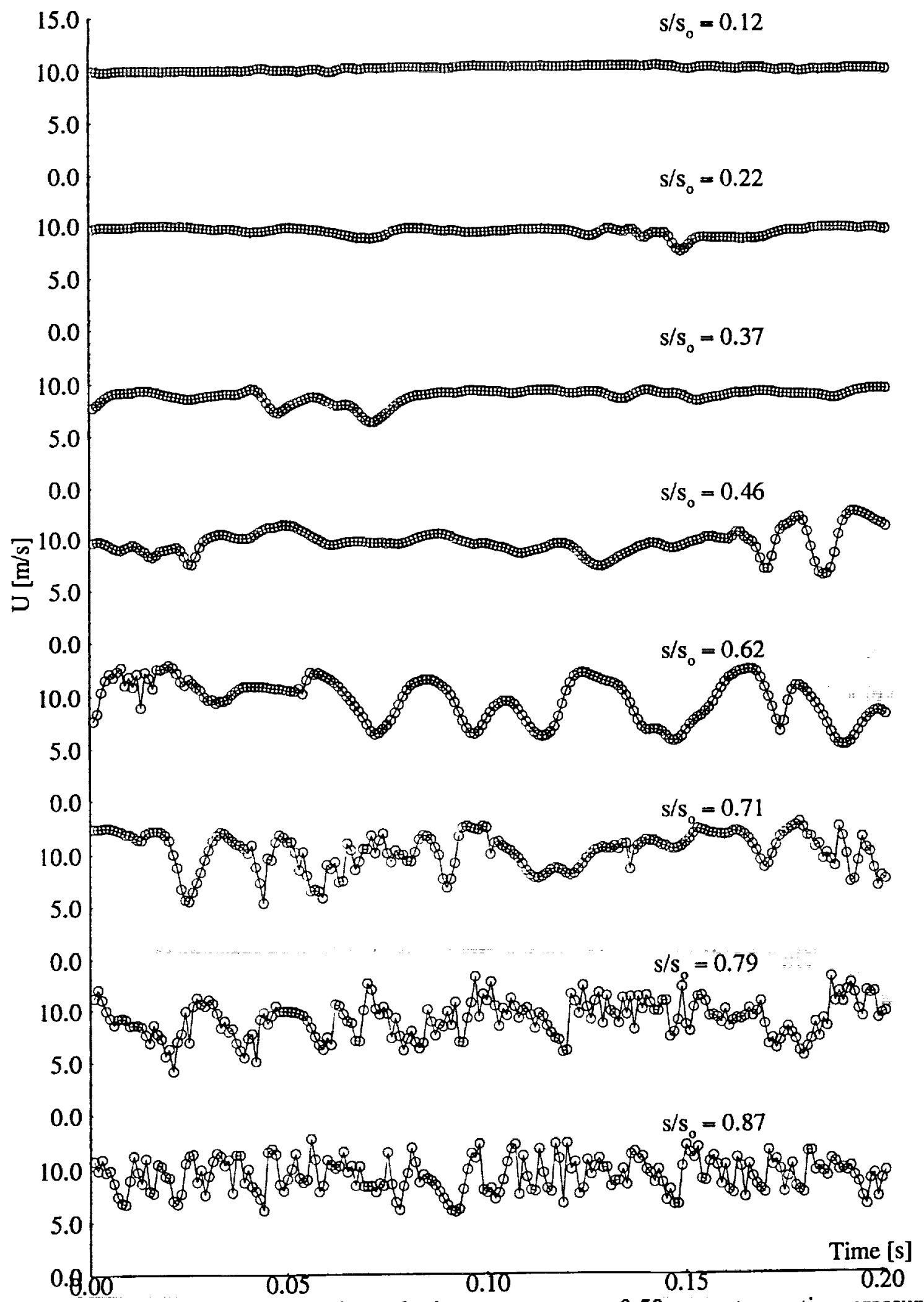

Figure 15. Instantaneous hot-wire velocity traces at $y=0.50 \mathrm{~mm}$ at negative pressure gradient and steady flow (Case 2). 


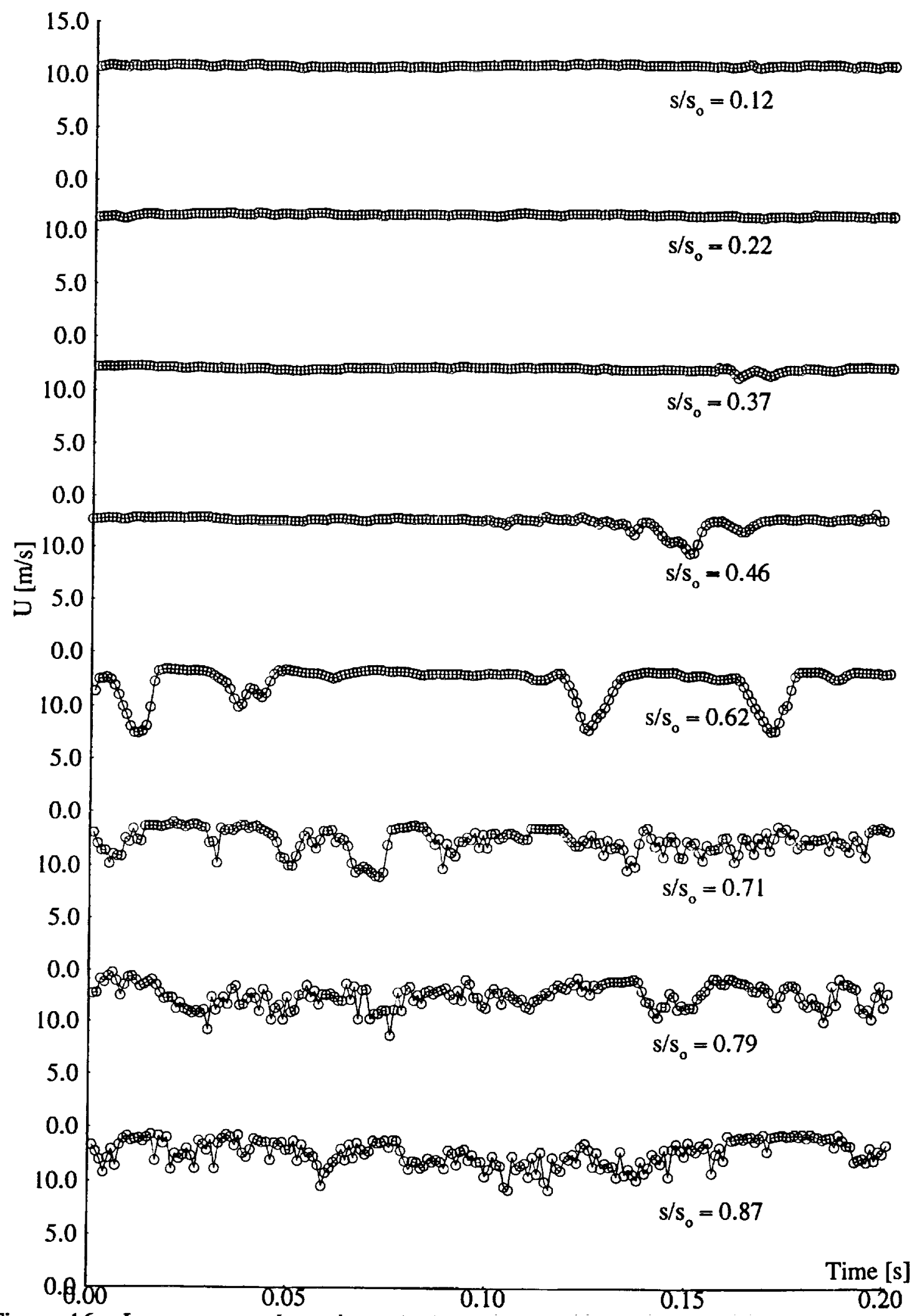

Figure 16. Instantaneous hot-wire velocity traces at $\mathrm{y}=2.0 \mathrm{~mm}$ at negative pressure gradient and steady flow (Case 2 ). 


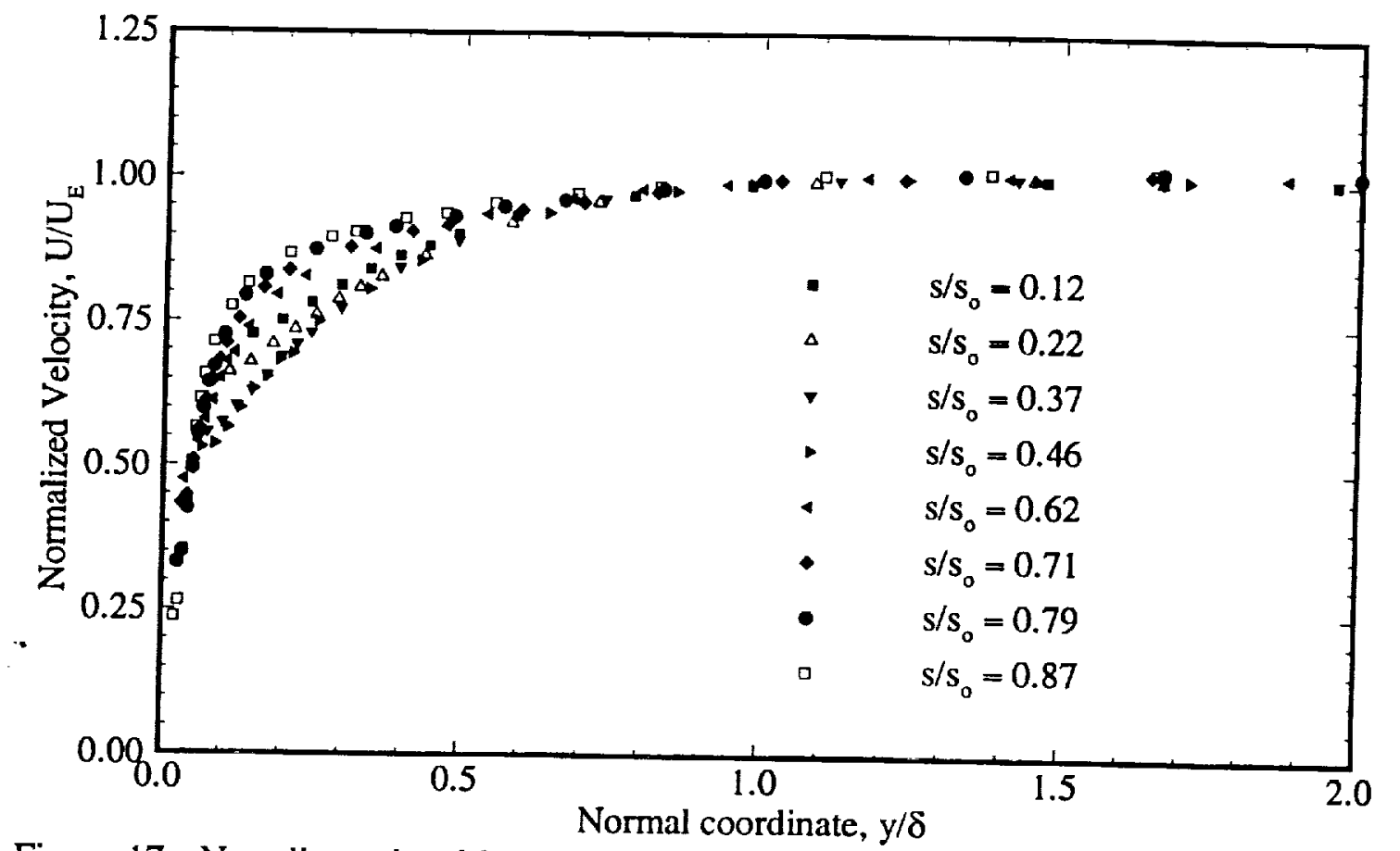

Figure 17. Non-dimensional boundary-layer profiles at different streamwise positions at negative pressure gradient (Case 2).

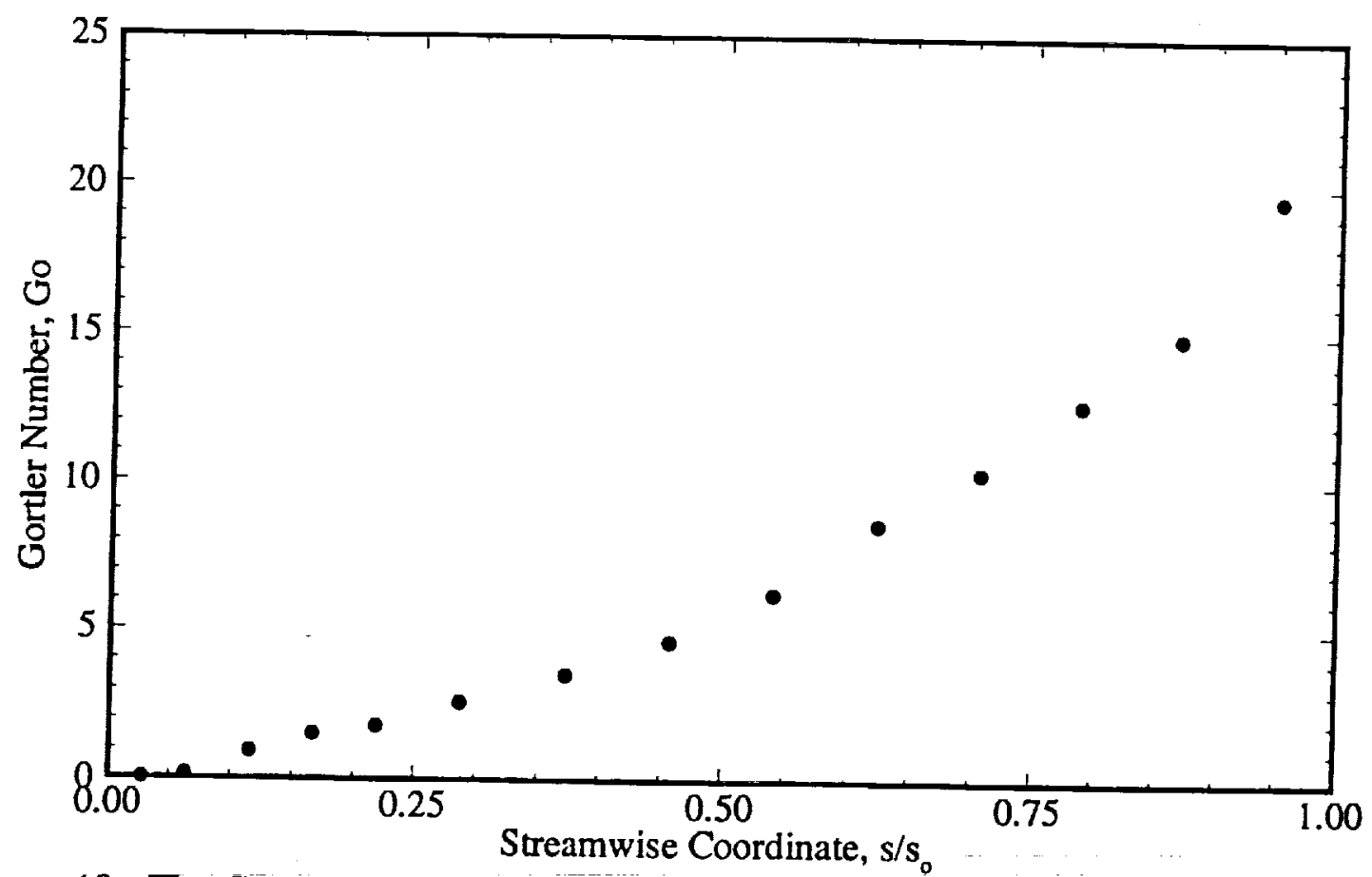

Figure 18. The Görtler number as a function of streamwise position at negative pressure gradient (Case 2). 


\subsection{Case 3: Periodic-Unsteady Flow at Zero Pressure Gradient}

The time-averaged channel turbulence intensity for Case 3 is presented in Figure 19. The time-averaged quantities indicate a fully transitional or turbulent boundary-layer over the entire surface of the plate. The peak reference turbulence intensity is centered at $\mathrm{s} / \mathrm{s}_{\mathrm{o}}=\mathbf{0 . 4 5}$. The steady case at zero pressure gradient (Case 1) shown in Figure 9 has a peak turbulence intensity at $s / s_{o}=0.53$. Thus, it would appear that transition onset has decreased by 8 percent of the plate arc length, but analysis of the ensemble-averaged quantities (below) will reveal a different conclusion.

Periodic-unsteadiness clearly appears in the hot-wire velocity signal. Figure 20 shows the wakes primarily in the earlier streamwise distances of $\mathrm{s} / \mathrm{s}_{\mathrm{o}}=0.11,0.22$, and 0.33. After this region, the velocity signals exhibit a combination of periodic-unsteady wakes and coherent Tollmien-Schlichting waves. At streamwise distances of $s / s_{0}=0.33$ through 0.61 , the coherent regions are separated by areas of full turbulence that are periodic. The velocity trace represents a periodic switching between laminar and turbulent flow. The velocity signals at $s / s_{o}=0.73$ and 0.83 represent a fully turbulent boundary

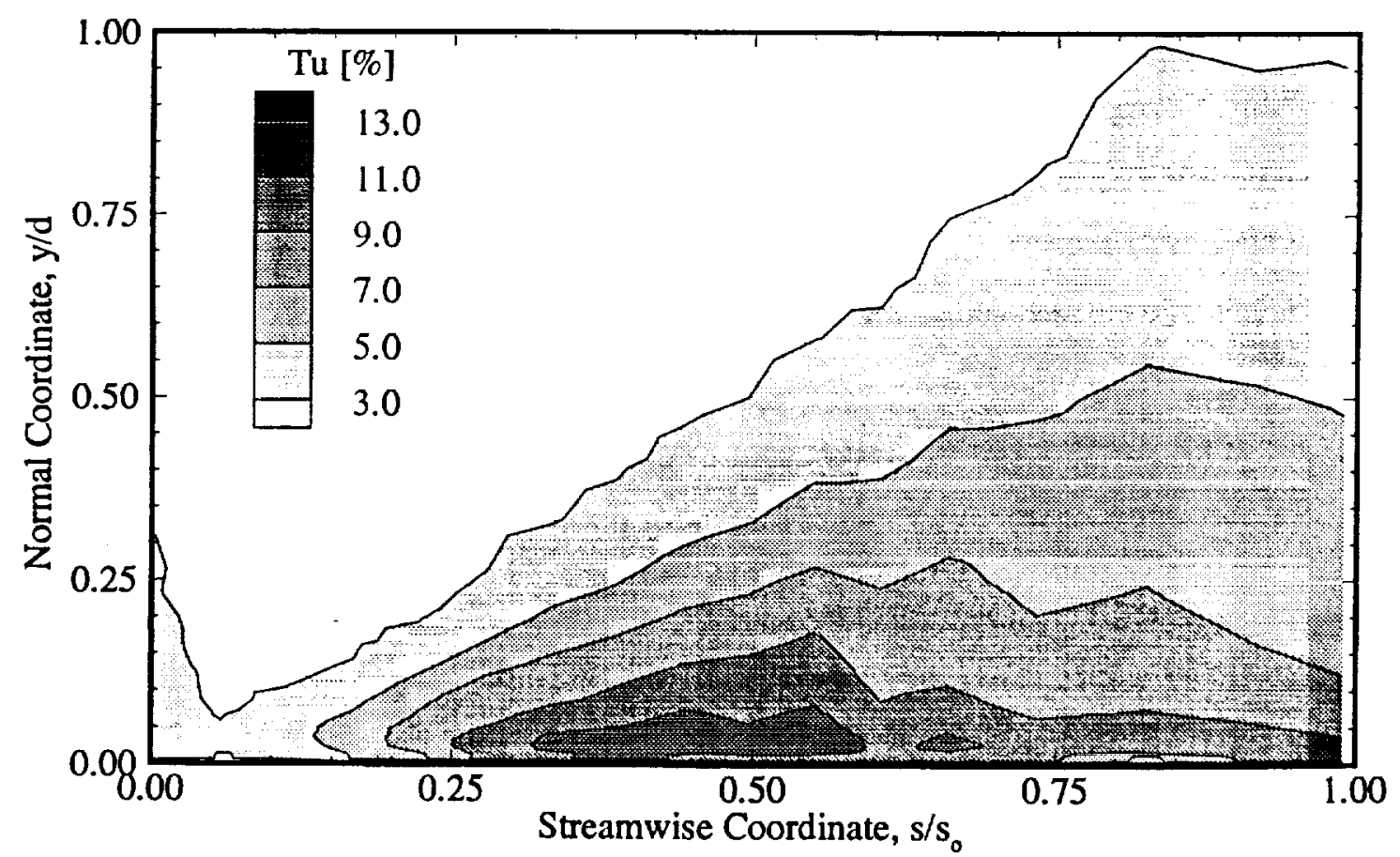

Figure 19. Time-averaged reference turbulence intensity contour for the periodic-unsteady case at zero pressure gradient (Case 3). 
layer.

The periodicity of the velocity is plainly visible after ensemble-averaging. Figure 21 shows the ensemble-averaged velocity distribution at the same position as that in Figure 20, using the calculation method discussed in Data Acquisition and Reduction. At the streamwise locations of $\mathrm{s} / \mathrm{s}_{\mathrm{o}}=0.11$ through 0.50 , the velocity is clearly periodic with respect to the wake passing frequency. The velocity at $s / s_{o}=0.61$ is still somewhat periodic, but is primarily composed of stochastic fluctuations. At $\mathrm{s} / \mathrm{s}_{\mathrm{o}}=0.73$ and 0.83 , ensemble-averaging reveals that there is not much periodicity at this streamwise location, which implies fully stochastic turbulence.

Figure 22 shows another set of instantaneous velocity traces, but at a distance from the plate of $y=2.0 \mathrm{~mm}$. As in Figure 20, the wakes are visibly apparent in the velocity signal, but they have different amplitudes, and widths of each wake. The earlier traces $\left(s / s_{o}=0.11\right.$ through 0.33$)$ are close to the edge of the boundary layer, if not in the freestream flow. Therefore, they represent the free-stream wake strip that passes over the boundary layer as the disturbance inside the boundary layer progresses from laminar or transitional to fully turbulent flow. This progression is exemplified at streamwise locations $\mathrm{s} / \mathrm{s}_{\mathrm{o}}=0.33$ through 0.73 . The random turbulent areas gradually increase their percentage of the velocity trace until a fully turbulent boundary layer is reached.

By expanding the ensemble-averaged data to a contour plot of the channel, a clear visualization of periodic-unsteady transition can be seen. Figure 23 shows the ensembleaveraged reference turbulence intensity of the channel at different times during the cycle. The value of $t / \tau$ corresponds to the point in the cycle at which the data acquisition system was triggered to collect data. Thus, at $t \tau=0.02$ the wake disturbance is in the boundary layer at $\mathrm{s} / \mathrm{s}_{\mathrm{o}}=0.25$ and the wake strip in the free-stream is centered at $\mathrm{s} / \mathrm{s}_{\mathrm{o}}=0.33$. The full penetration of the wake disturbance into the fully transitional/turbulent portion of the boundary layer is shown in Figure 23. Note that as the wake disturbance convects downstream, there is a laminar region travelling behind. At $t \tau=0.49$, the new wake strip is first visible in the channel. At this moment, the wake strip initiates a disturbance into the boundary layer. The wake strip above the boundary layer and the disturbance initially appear to travel at the same velocity, but, as shown in Figure 23, the two appear to be 
independent as suggested by Orth (1993) and reinforced by Walker (1993). Moving forward in time (i.e., $t / \tau=0.96,0.02,0.14$ ), the disturbance increases in turbulence intensity as it convects downstream, whereas the wake strip in the free-stream does not increase in turbulence intensity. The wake strip is travelling faster than the disturbance below, indicating its convection with the free-stream flow. It does not appear that the wake strip has any additional effect on the boundary-layer disturbance it caused at the entrance of the channel. In other words, it can be assumed that the wake strip and the boundary-layer disturbance are two independent entities after impingement upon the leading edge of the plate. Thus, the appearance of oscillating laminar and transitional regions appear at various streamwise positions. This demonstrates the illusion created by the time-averaged plot in Figure 19.

A unique picture of the periodic-unsteady transition process can be seen when the data is plotted in the temporal-spatial domain at a specific normal distance above the plate surface. Figures 24-31 show the temporal-spatial domain for Case 3. For a normal distance from the wall of $y=0.3 \mathrm{~mm}$, Figure 24 shows the ensemble-averaged turbulence intensity. The laminar regions are represented by the clear white portions of the plot. Five wake passes are visible, since the data was ensemble-averaged with respect to one rotation of the wake generator. At $s / s_{0}=0.23$, the turbulence level is greater than 3 percent throughout the cycle, but there is still intermittency between transitional and fully turbulent flow after this point. Before $s / s_{0}=0.23$, the velocity periodically changes from laminar to fully turbulent levels up to $T u=13$ percent. This region has the most drastic changes in boundary layer properties, although the downstream region goes through large changes also. In Figure 25 , the 3 percent or greater turbulence level moves upstream slightly to $\mathrm{s} / \mathrm{s}_{\mathrm{o}}=0.19$. This is an indication of the turbulence intensity gradient in the normal direction, and is also visible in the steady cases as well. The 3 percent or greater zone reaches its maximum movement upstream to $s / s_{o}=0.17$ in Figure 26 , at a wall distance of $y=0.7 \mathrm{~mm}$. This particular plot shows several periodic events occurring up to $s / s_{o}=0.70$, but this is not indicative of a fully turbulent boundary-layer after $s / s_{o}=0.70$, since Figure 27 reveals periodic transition events up through $\mathrm{s} / \mathrm{s}_{\mathrm{o}}=0.94$. The number of complex events happening at this level $(y=1.0 \mathrm{~mm})$ is overwhelming. 
The most important transition events are those that occur near the wall, since the shear stress and heat transfer coefficients at the wall are of primary concern. However, it is interesting to see how the periodic wakes affect the outer area of the boundary-layer. Figures 28-31 show how the transitional or turbulent regions decrease to wake strips in the free-stream as the normal distance from the plate surface is increased. In Figure 31 , at $y$ $=5.0 \mathrm{~mm}$, the periodicity is still apparent and reference turbulence intensity is oscillating between $T u=3$ and 7 percent.

This case has illustrated how periodic-unsteady wakes can and do affect the boundary-layer and the point of transition. It is clear that this case is a more complex flow situation, but ensemble-averaging of data gives much insight. 


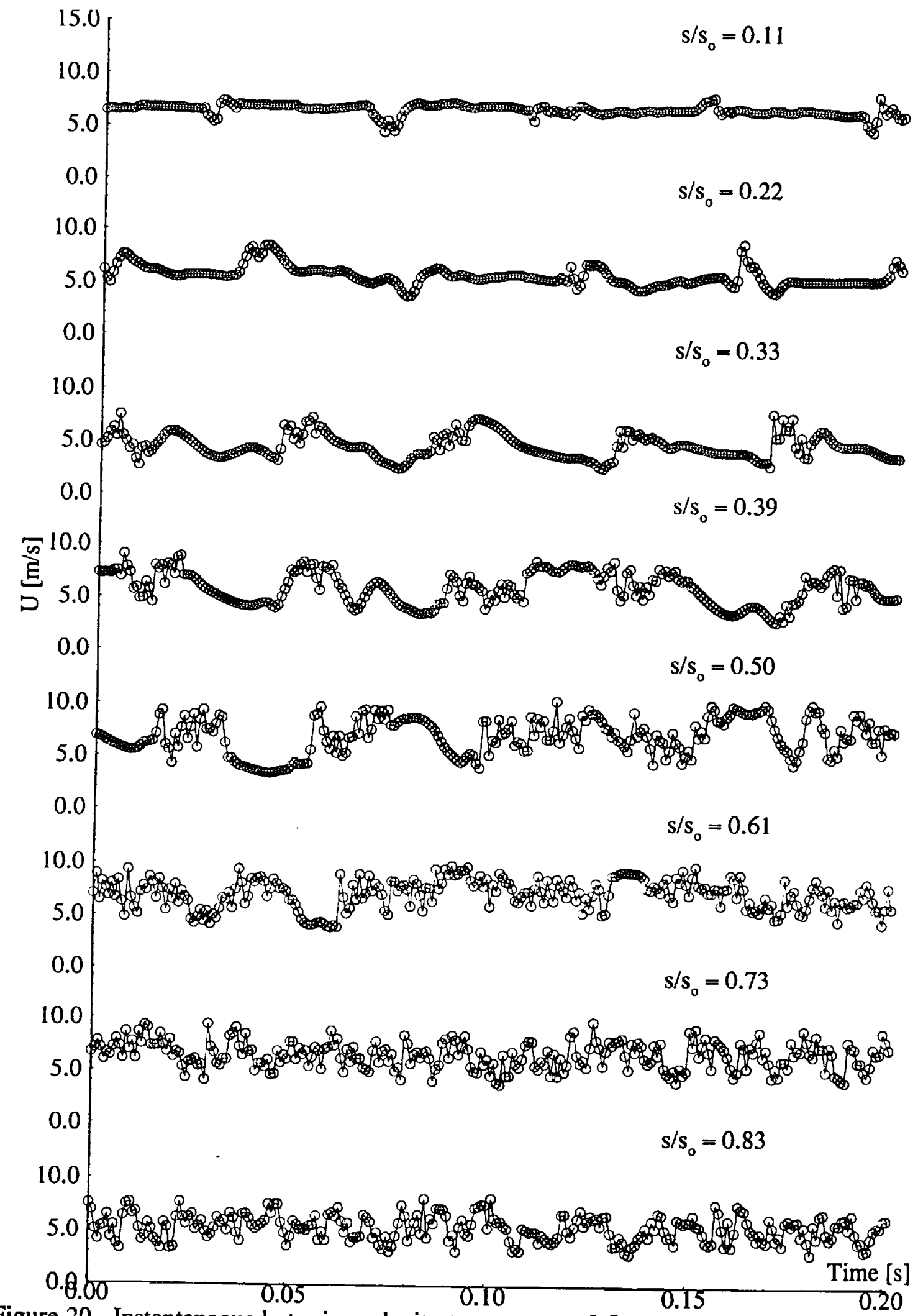

Figure 20. Instantaneous hot-wire velocity traces at $\mathrm{y}=0.5 \mathrm{~mm}$ at zero pressure gradient and periodic-unsteady flow (Case 3). 


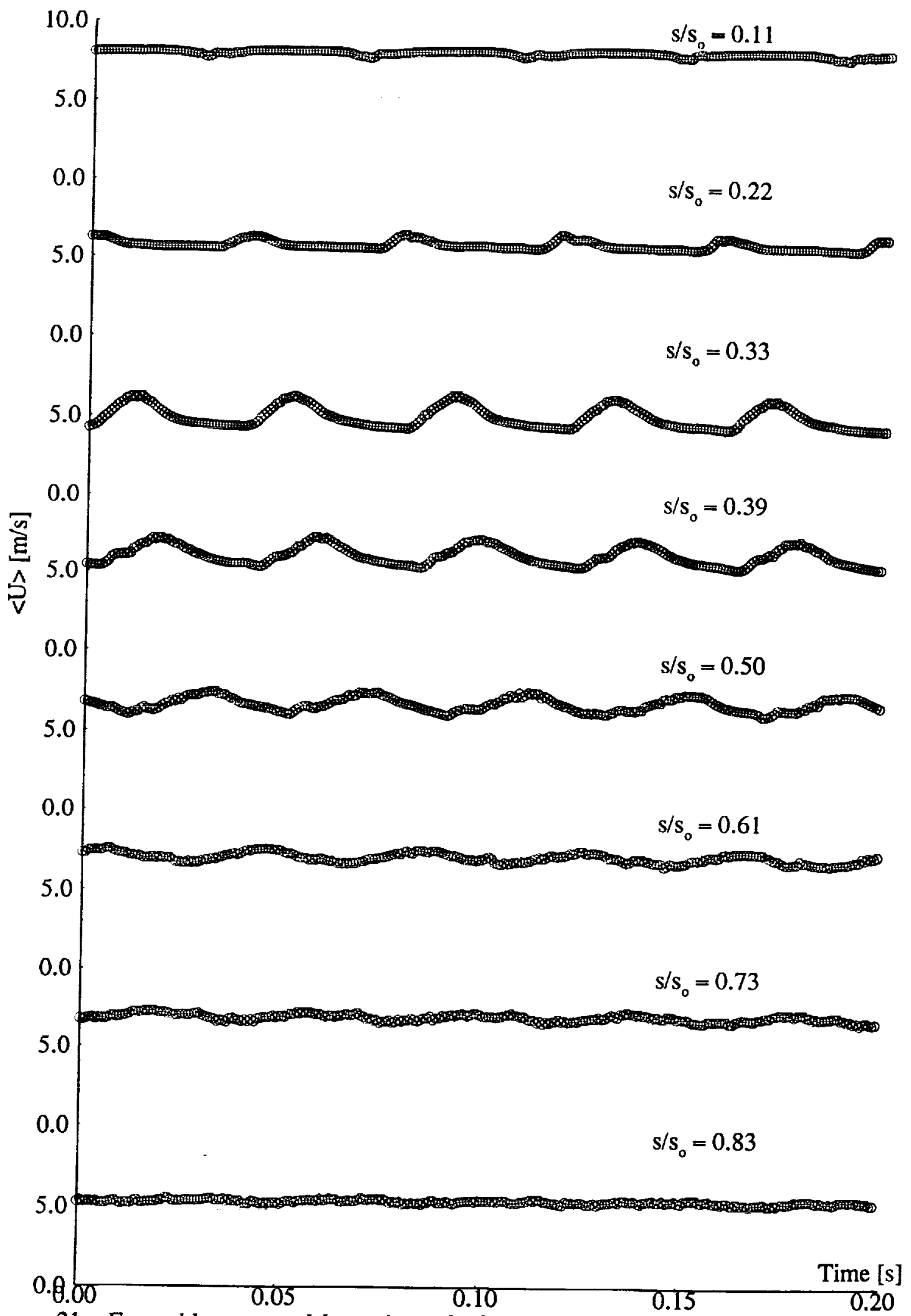

Figure 21. Ensemble-averaged hot-wire velocity traces at $\mathrm{y}=0.5 \mathrm{~mm}$ at zero pressure gradient and periodic-unsteady flow (Case 3). 


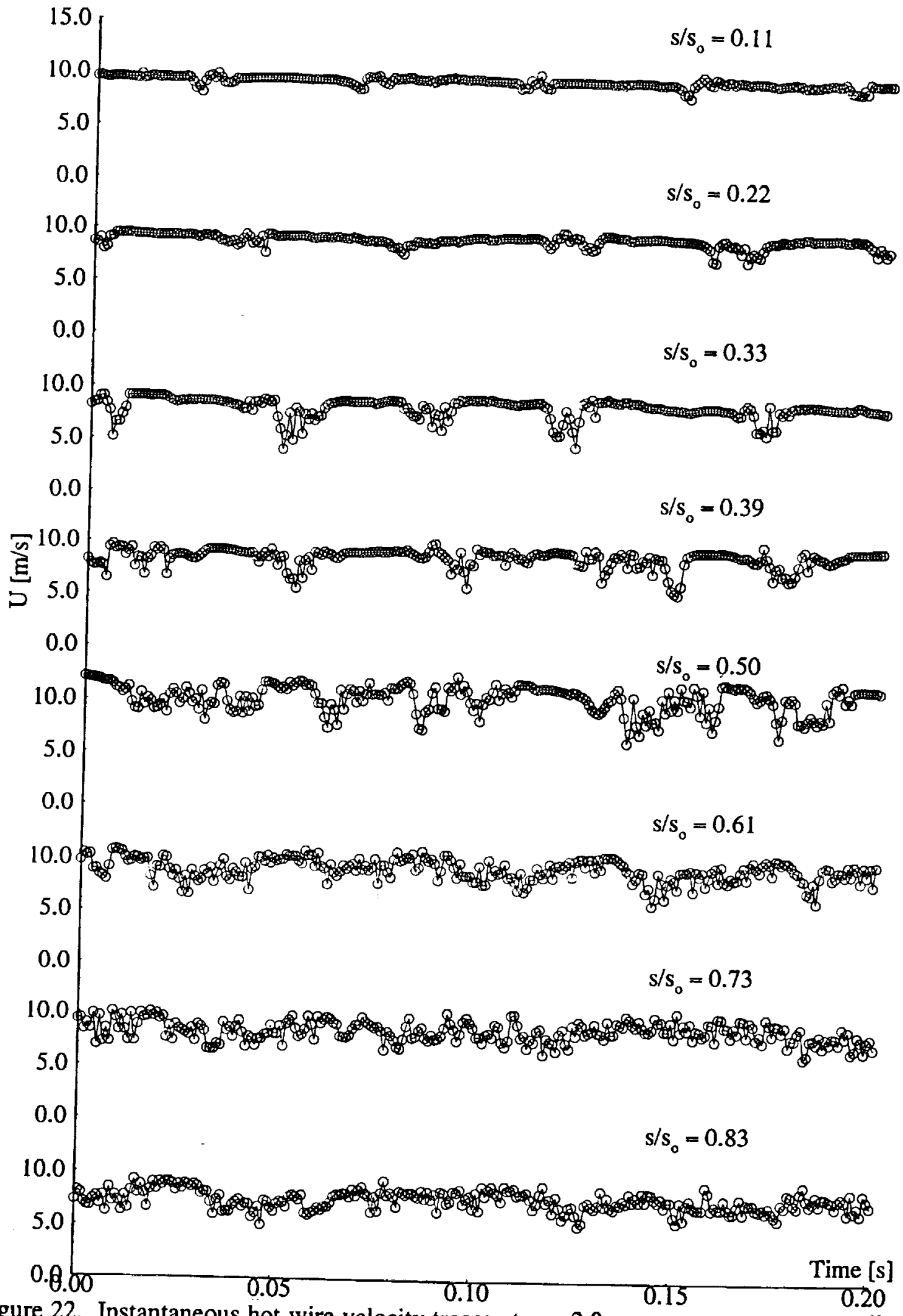

Figure 22. Instantaneous hot-wire velocity traces at $y=2.0 \mathrm{~mm}$ at zero pressure gradient and periodic-unsteady flow (Case 3). 


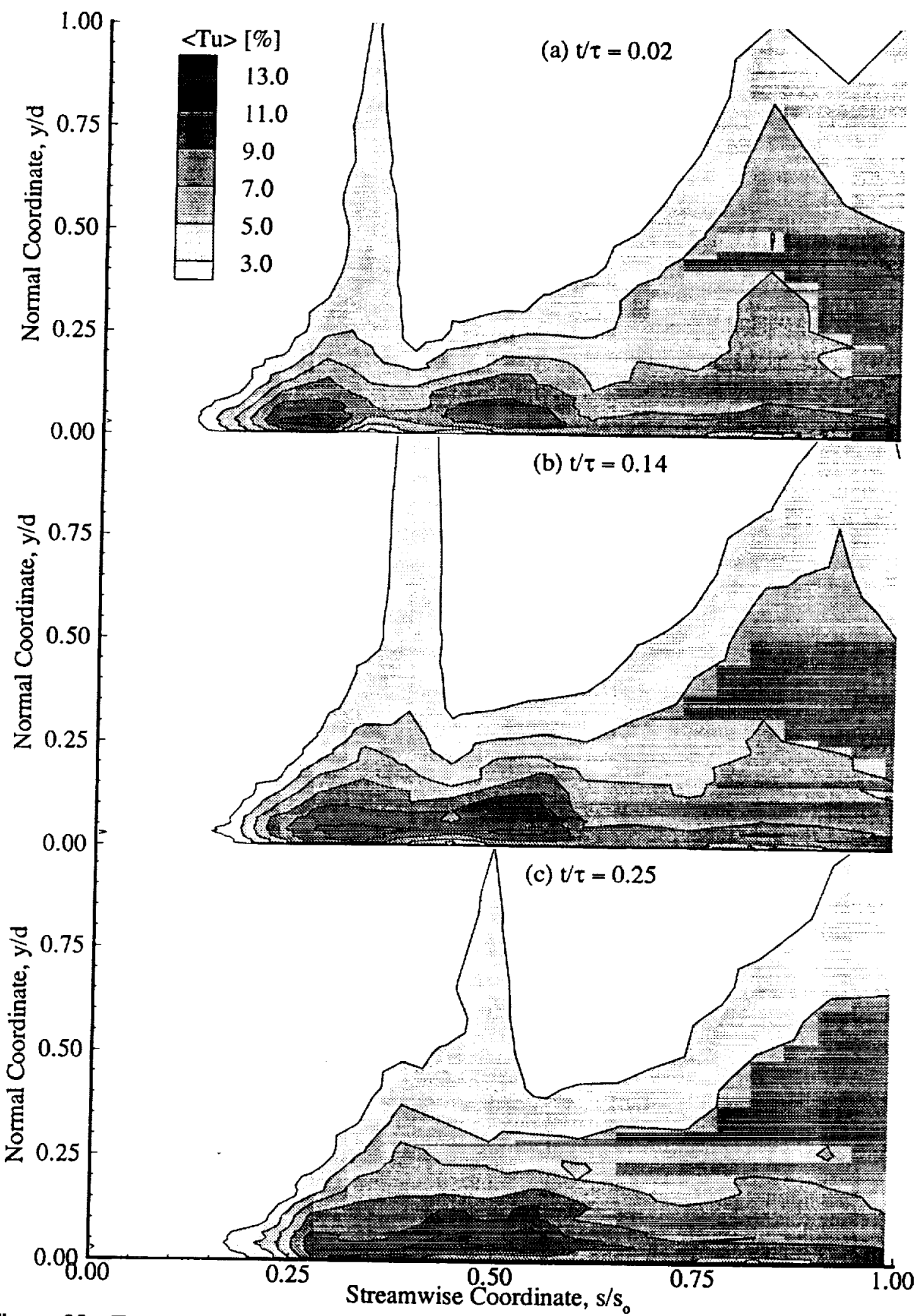

Figure 23. Ensemble-averaged reference turbulence intensity contours at various instants in the wake passing cycle (Case 3). 


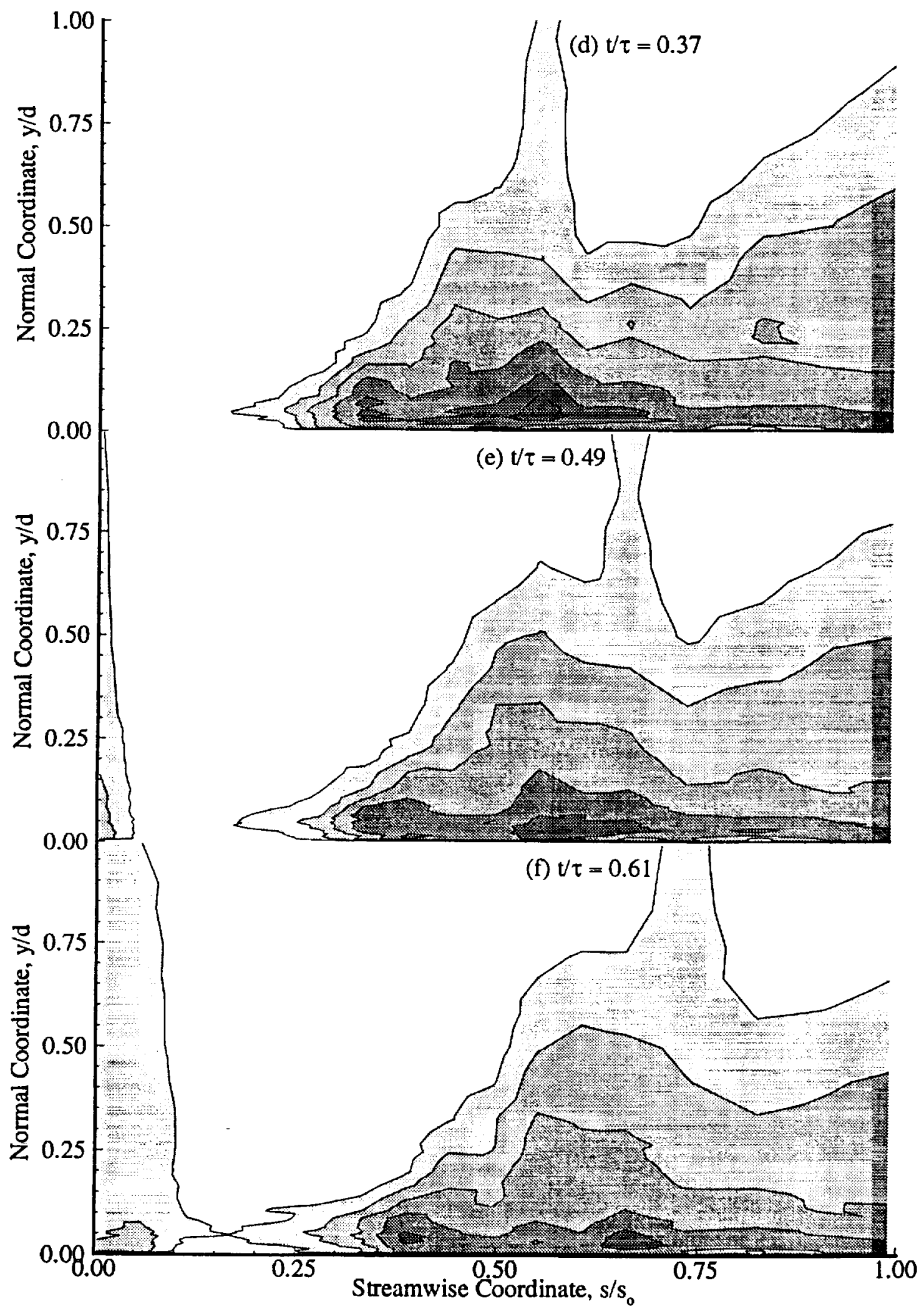

Figure 23. Continued. 


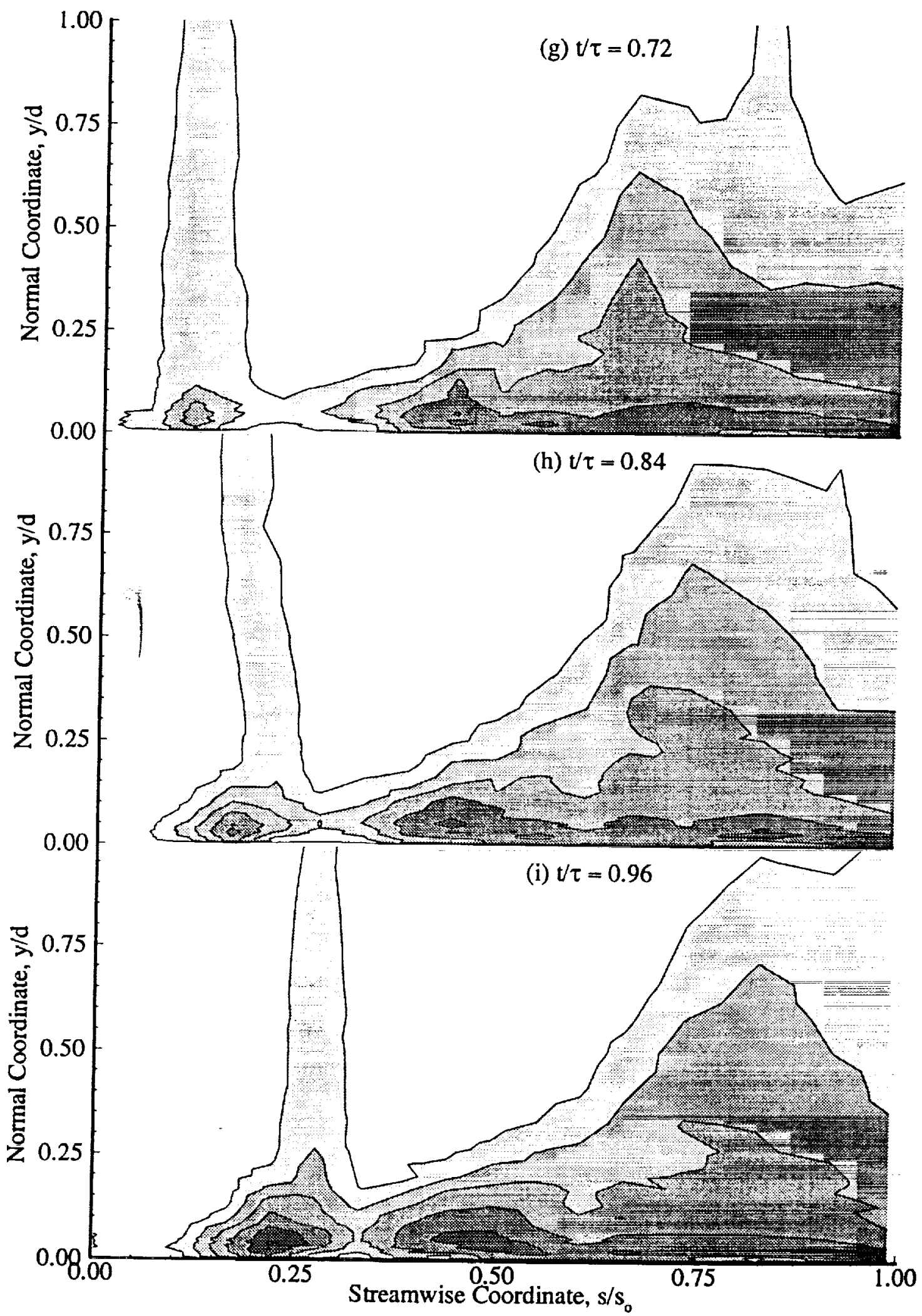

Figure 23. Continued. 


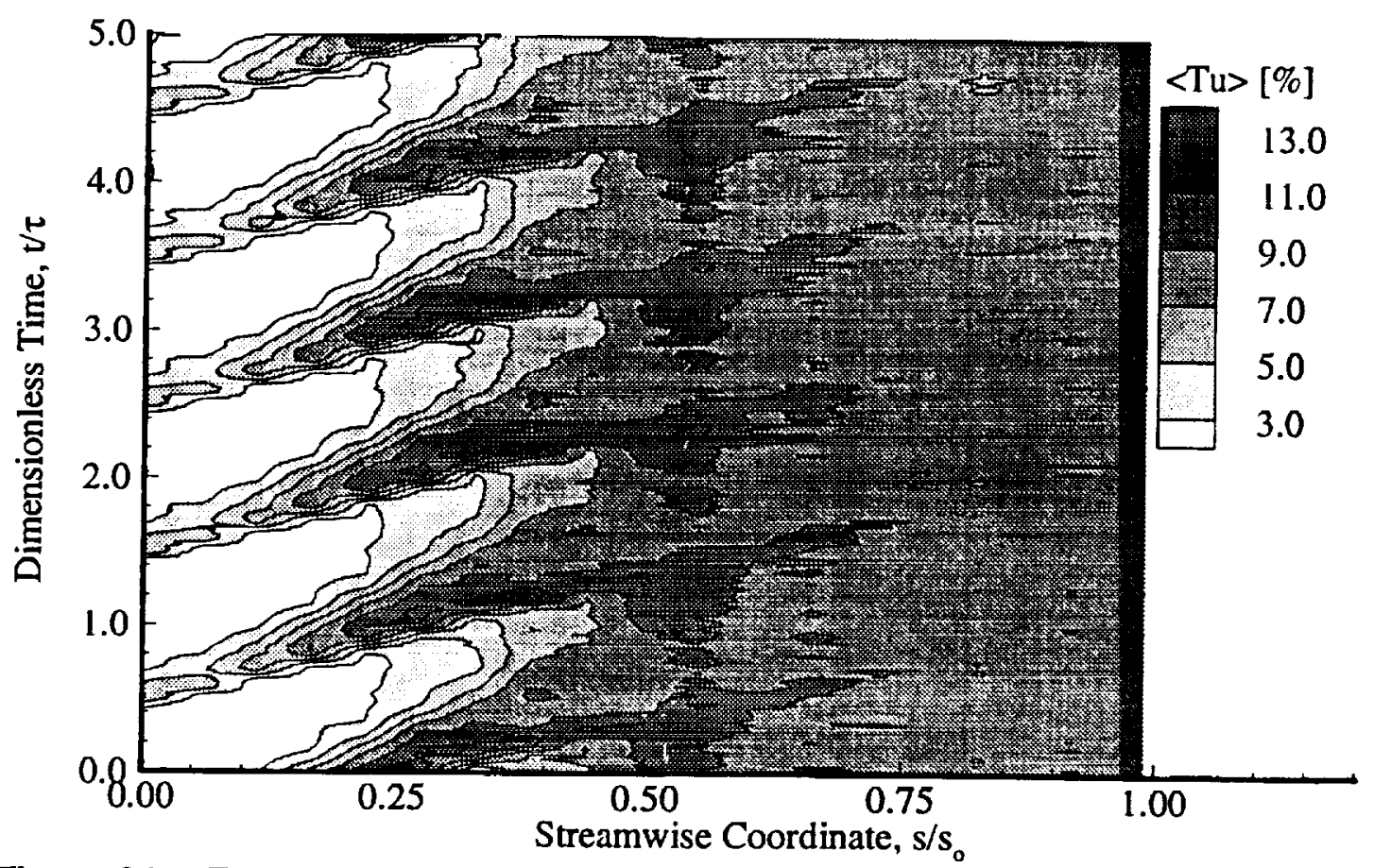

Figure 24. Ensemble-averaged reference turbulence intensity in the temporal-spatial domain at $\mathrm{y}=0.3 \mathrm{~mm}$ for zero pressure gradient (Case 3 ).

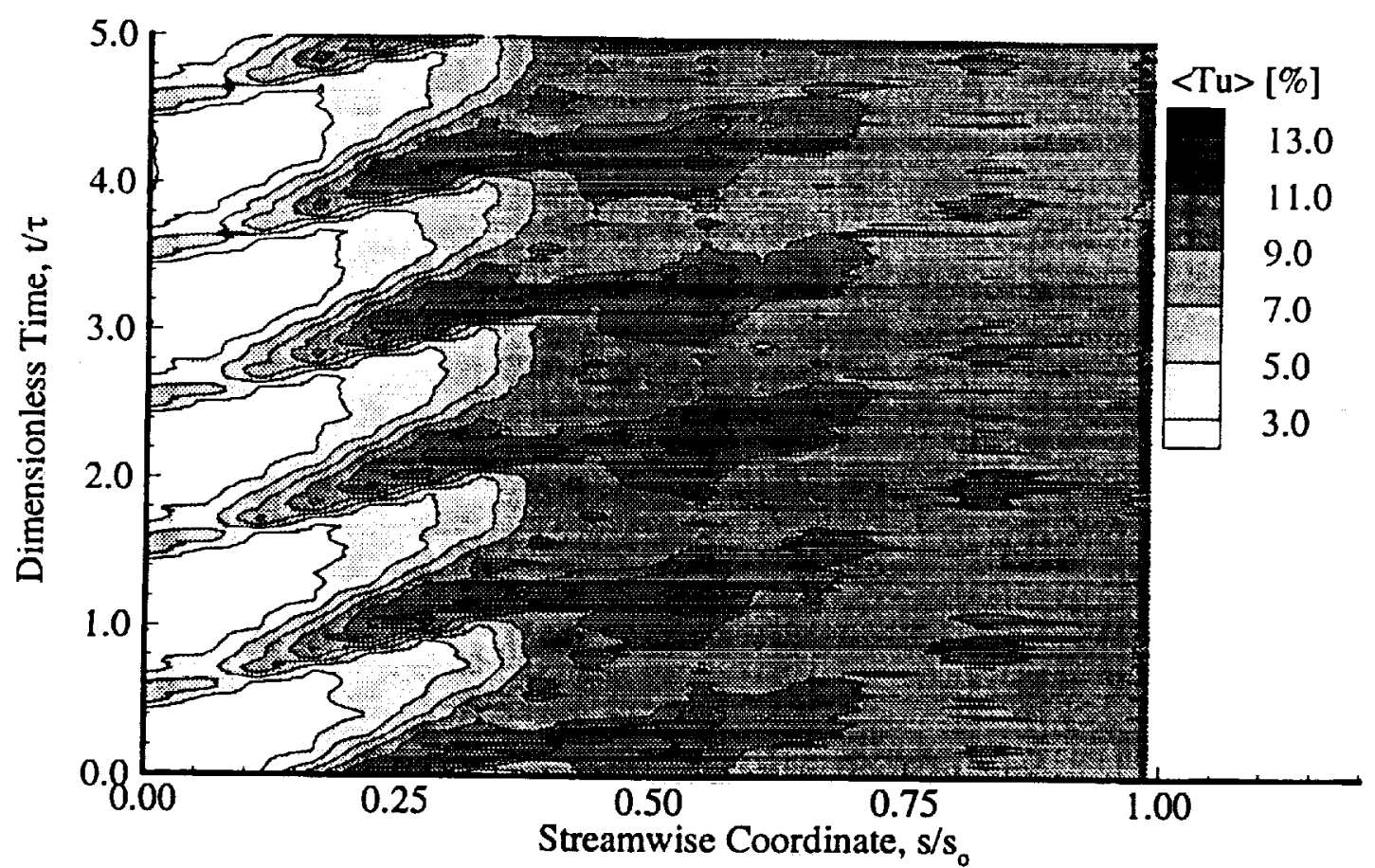

Figure 25. Ensemble-averaged reference turbulence intensity in the temporal-spatial domain at $\mathrm{y}=0.5 \mathrm{~mm}$ for zero pressure gradient (Case 3). 


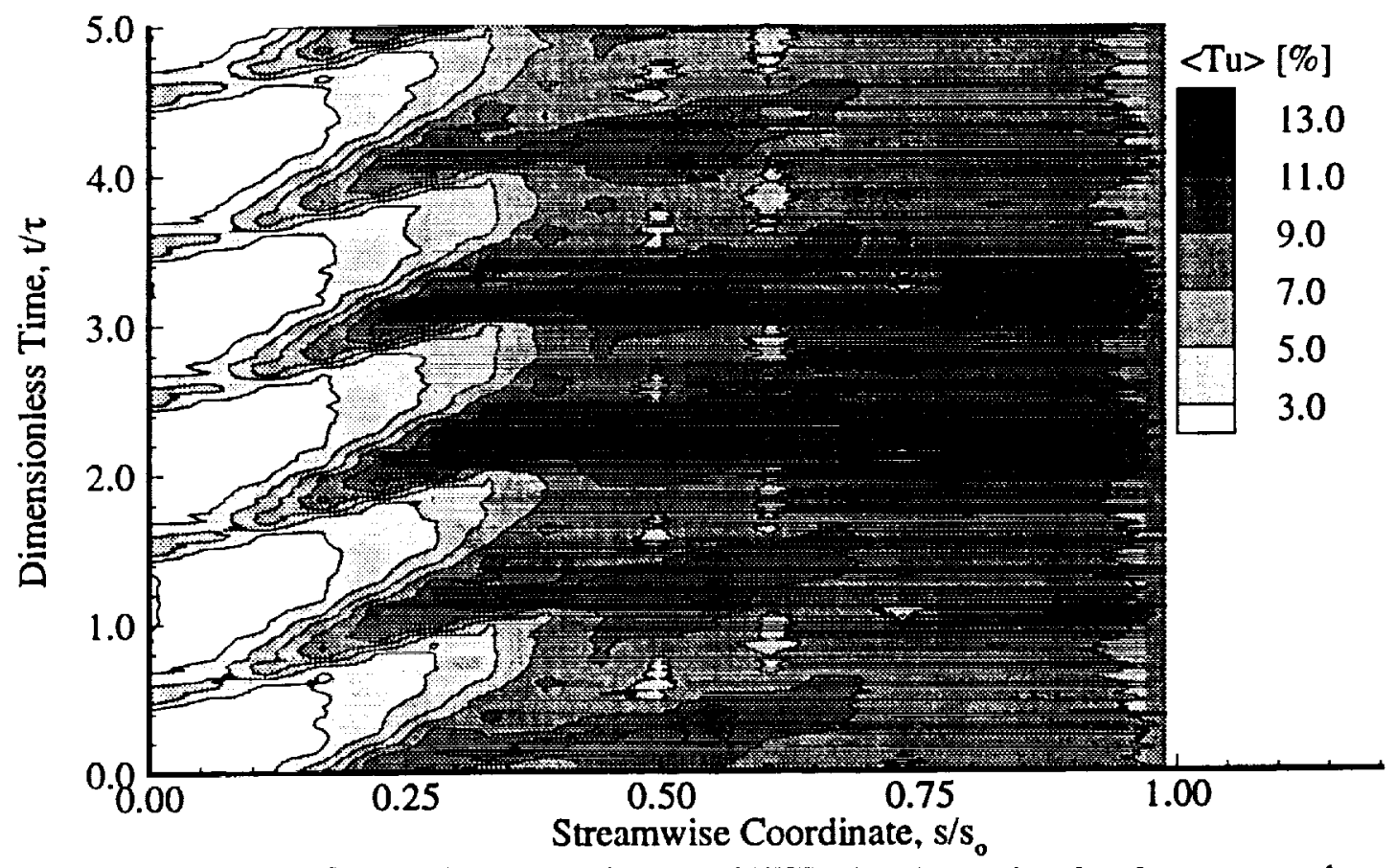

Figure 26. Ensemble-averaged reference turbulence intensity in the temporal-spatial domain at $\mathrm{y}=0.7 \mathrm{~mm}$ for zero pressure gradient (Case 3 ).

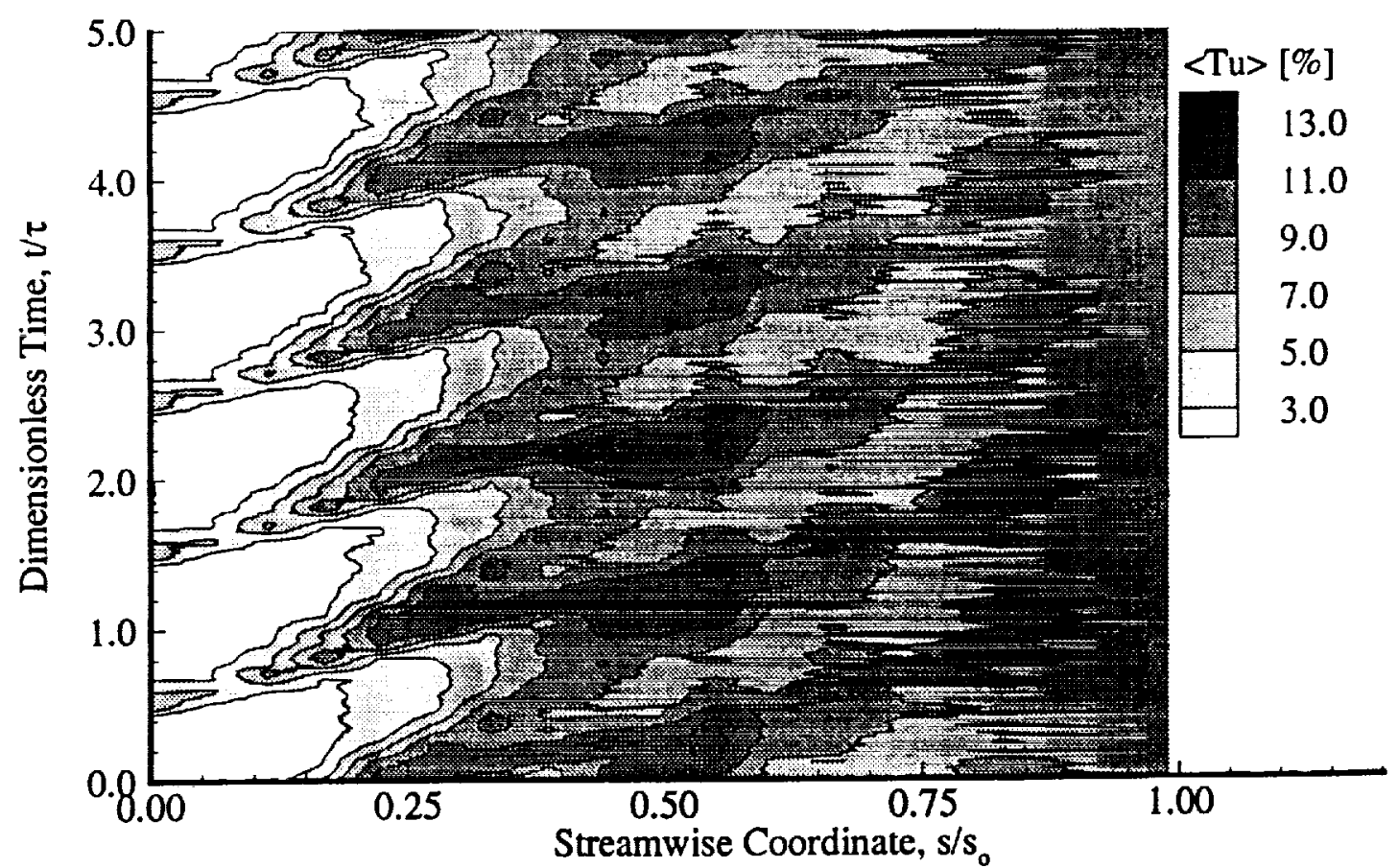

Figure 27. Ensemble-averaged reference turbulence intensity in the temporal-spatial domain at $\mathrm{y}=1.0 \mathrm{~mm}$ for zero pressure gradient (Case 3). 


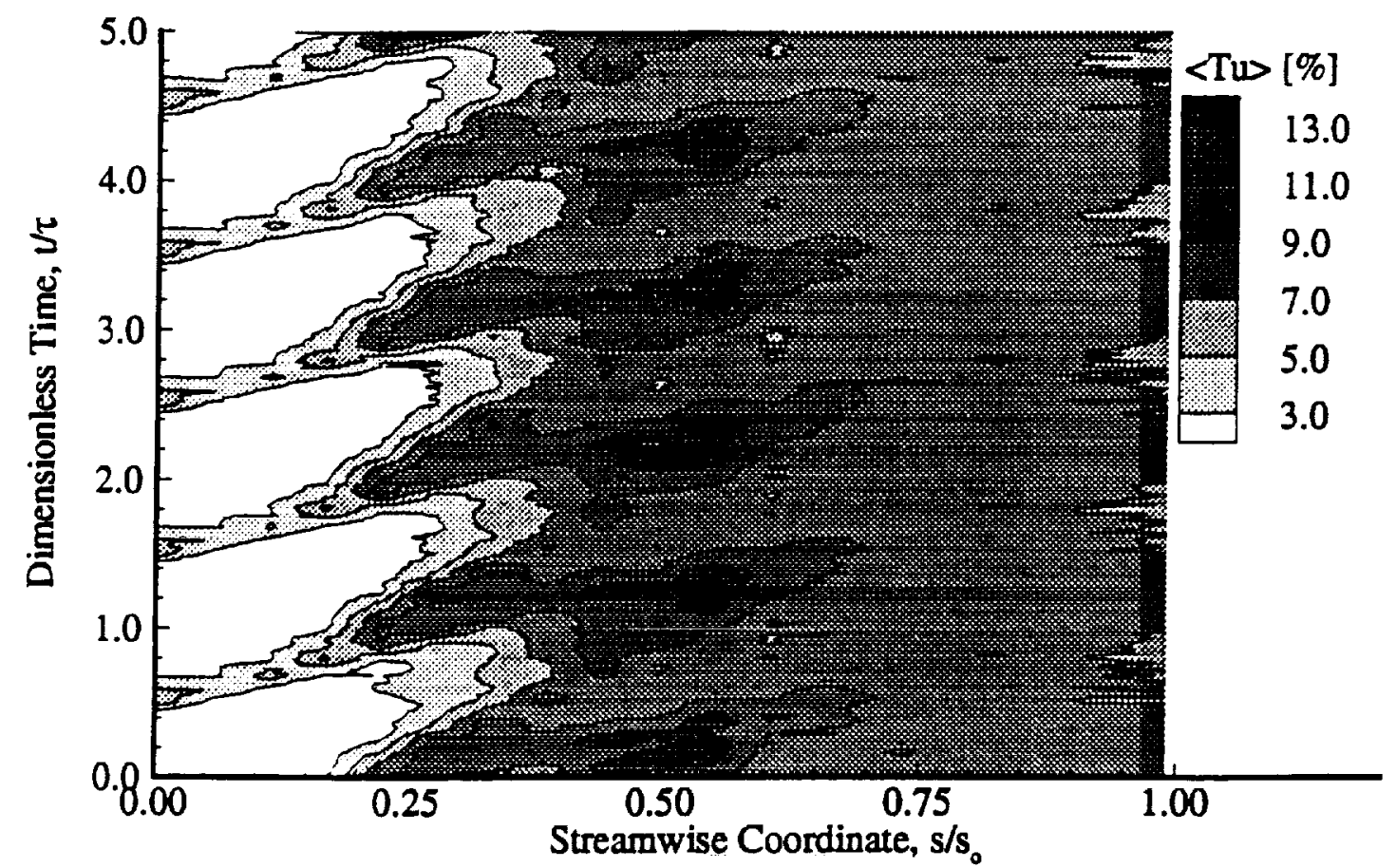

Figure 28. Ensemble-averaged reference turbulence intensity in the temporal-spatial domain at $\mathrm{y}=1.6 \mathrm{~mm}$ for zero pressure gradient (Case 3 ).

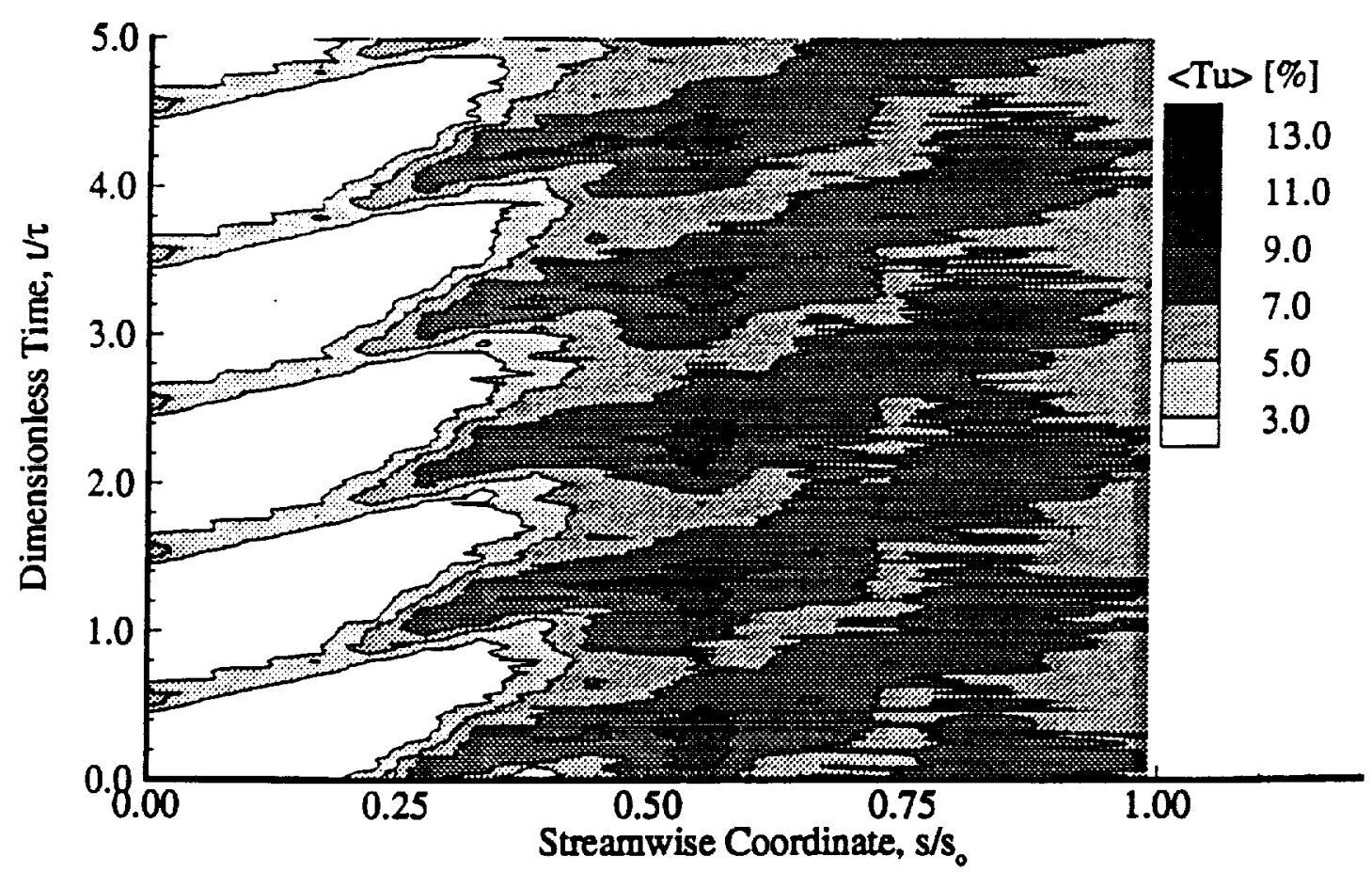

Figure 29. Ensemble-averaged reference turbulence intensity in the temporal-spatial domain at $\mathrm{y}=2.5 \mathrm{~mm}$ for zero pressure gradient (Case 3). 


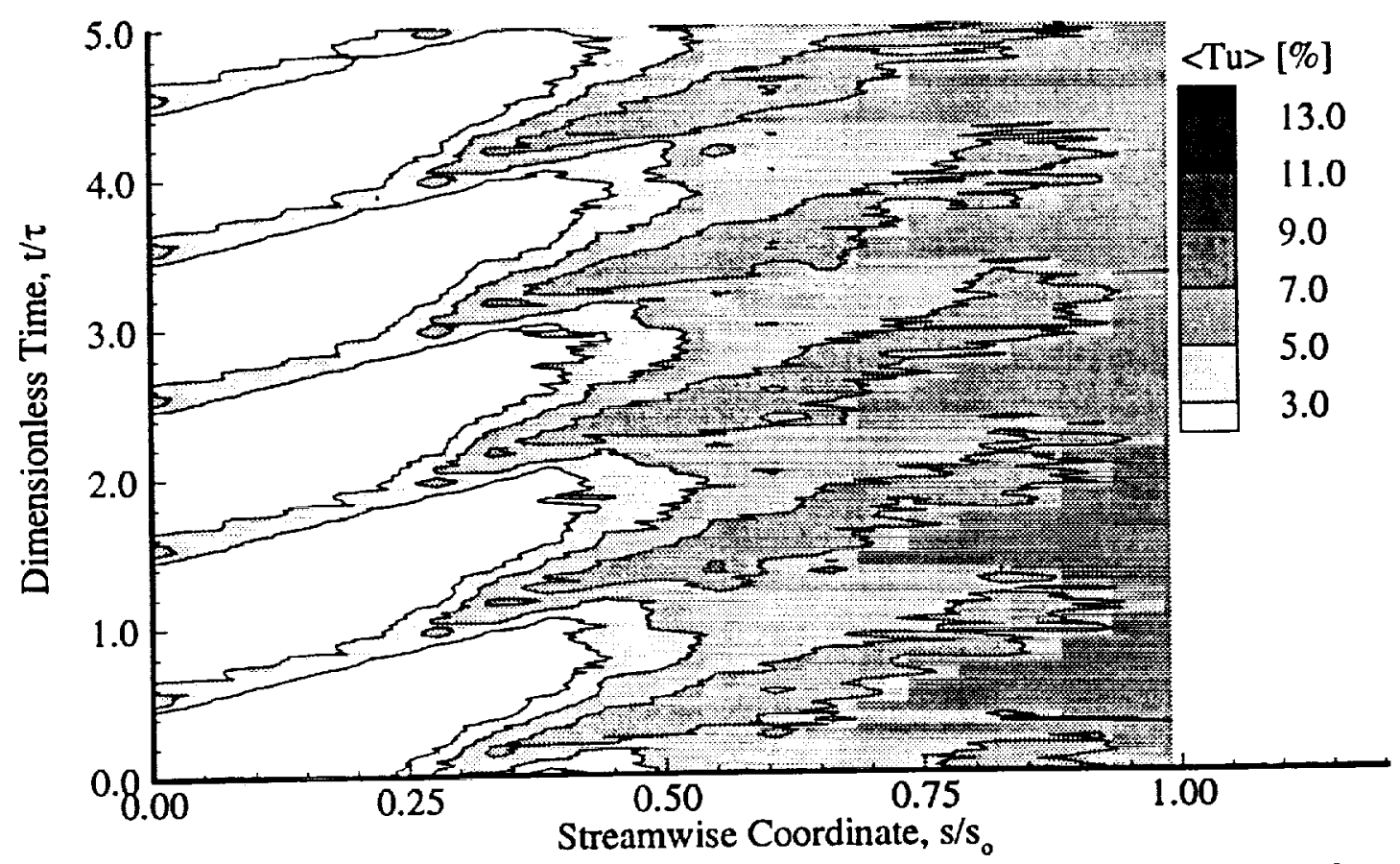

Figure 30. Ensemble-averaged reference turbulence intensity in the temporal-spatial domain at $\mathrm{y}=3.5 \mathrm{~mm}$ for zero pressure gradient (Case 3 ).

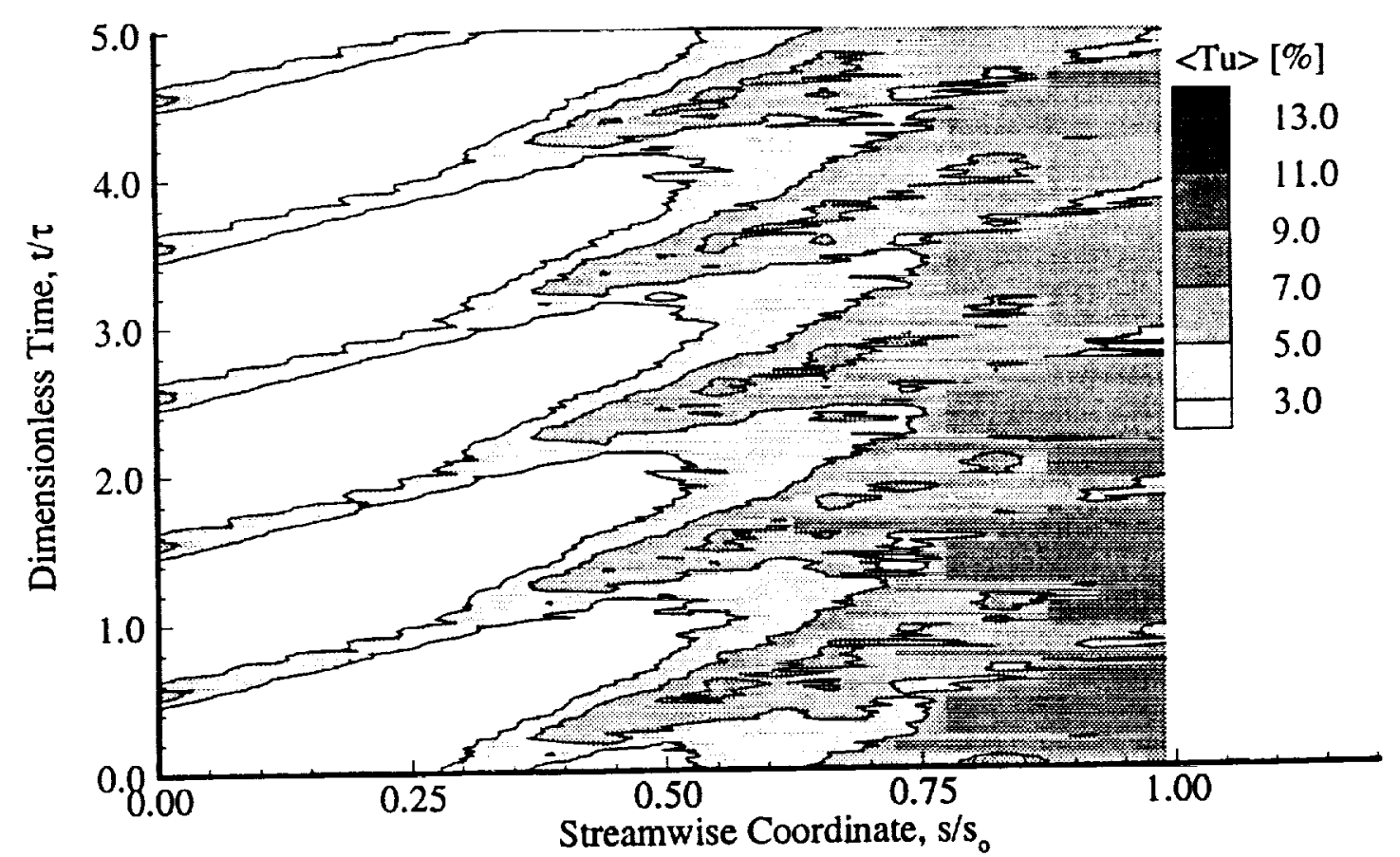

Figure 31. Ensemble-averaged reference turbulence intensity in the temporal-spatial domain at $\mathrm{y}=5.0 \mathrm{~mm}$ for zero pressure gradient (Case 3 ). 


\subsection{Case 4: Periodic-Unsteady Flow at Negative Pressure Gradient}

The complete time-averaged reference turbulence intensity contour for this case is given in Figure 32. As with Case 3, this plot gives the misleading indication that there is not a laminar region at any position on the plate surface. In light of the fact that periodic-unsteady events are known to occur, the ensemble-averaged quantities are much more valuable than time-averaged quantities. This plot shows a peak turbulence value occurring at $s / s_{\circ}=0.47$, compared to $s / s_{o}=0.66$ for Case 2 .

The presence of a negative pressure gradient under the periodic-unsteady flow condition shows many similarities and a few dissimilarities to Case 3 . The transition events are, again, presented in several formats. The hot-wire velocity traces at $y=0.5 \mathrm{~mm}$ are shown in Figure 33. Again, the wakes appear in the velocity trace spaced at the wake passing period of $40 \mathrm{~ms}$. In this case, the secondary and primary wakes are slightly out of phase, thus both are visible in the various plots of this section. The near and far wakes are not quite as distinct in the hot-wire trace, but after ensemble-averaging, the secondary wakes are slightly more visible (Figure $34 ; \mathrm{s} / \mathrm{s}_{\mathrm{o}}=0.29,0.37$, and 0.54 ). In Figure 33, the

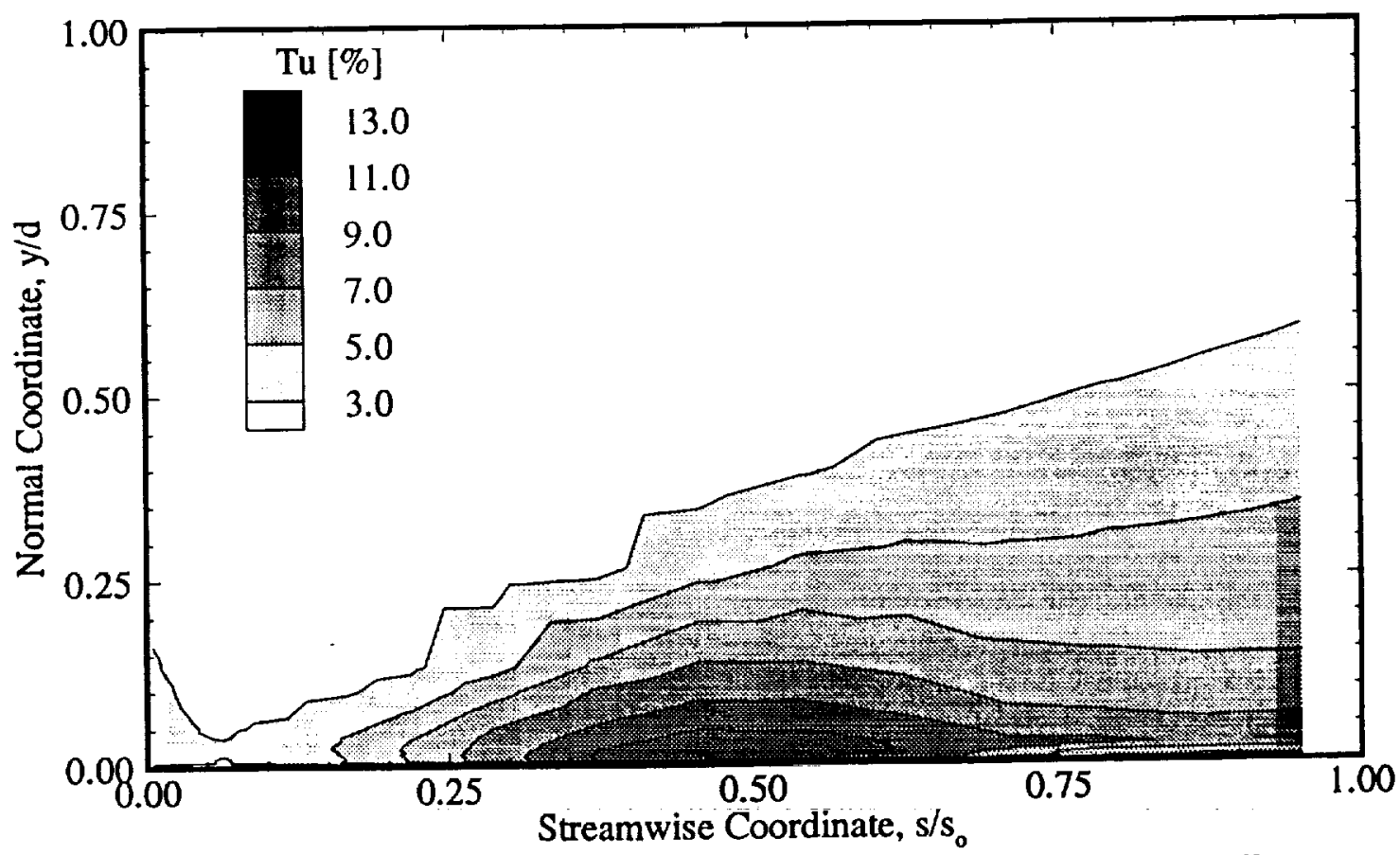

Figure 32. Time-averaged reference turbulence intensity contour for periodic-unsteady inlet flow at negative pressure gradient (Case 4). 
transition events appear to follow the same pattern as in Case 3, with the exception that particular events happen at different streamwise distances from the leading edge of the plate. From $\mathrm{s} / \mathrm{s}_{\mathrm{o}}=0.06$ to 0.62 , the velocity is clearly in a state of intermittency between wake passes and wave formations. Eventually the wave-forms amplify to cause turbulent spots that coalesce with the periodic-unsteady wakes to form a fully turbulent boundary layer. In Figure 32, at the streamwise distance of $s / s_{0}=0.71$, the velocity trace appears to be fully turbulent. But ensemble-averaging (Figure 34 ) reveals some periodic events still happening after this point. At $s / s_{o}=0.71$ and 0.87 , the effects of the periodicunsteady wakes are still causing time dependence of what appears to be a fully turbulent boundary layer.

Another instantaneous hot-wire velocity trace is given in Figure 35 for $\mathrm{y}=2.0 \mathrm{~mm}$. At this normal distance above the plate, transition appears to occur earlier with a turbulent spot appearing at $s / s_{o}=0.29$. The effect of the wakes is still visible, although it is not quite as pronounced as that of $y=0.5 \mathrm{~mm}$. This happens because the wake strip loses its strength at higher normal positions.

The ensemble-averaged instants of the reference turbulence intensity in the channel are presented in Figure 36. At $t / \tau=0.02$, a primary wake is centered in the channel at $s / s_{o}$ $=0.12$. A secondary wake is also visible at the leading edge of the plate, but is quickly attenuated and not too visible at other times in the period. Also note, that the primary wake-strip in the free-stream disappears at $t \tau=0.25$. As mentioned in Case 2 , the negative pressure gradient has an attenuating effect on velocity fluctuations. Thus, the primary wake eventually disappears in the free-stream and the secondary wake is only visible for a small instant. The disturbance generated in the boundary-layer by the wakestrip upon impingement on the leading edge does not disappear. It convects downstream while increasing in turbulence intensity very similar to that observed in Case 3 . Also note in the Figure 36 , the high turbulence intensity contour $(T u=13 \%)$ does not get as large as that of the corresponding steady case. This is probably due to a combination of the stabilizing effect characteristic to a negative pressure gradient in addition to the becalming effect the periodic-unsteady wakes have on the Tollmien-Schlichting instabilities as previously reported by Pfeil and Herbst (1983). 
The data for Case 4 are also presented in the temporal-spatial domain (Figures 37 44). At $y=0.3 \mathrm{~mm}$, Figure 37 shows that the near and far wakes are slightly out of phase. The amount of high turbulence contour $(T u=13 \%)$ surface area is much higher than that of Case 3, although the amount of laminar surface area appears to be about the same. This trend is also visible in Figures 38-44.

The boundary-layer thickness is smaller for this case, thus at $\mathrm{y}=4.0 \mathrm{~mm}$ and 6.0 $\mathrm{mm}$, Figures 43-44 show very low reference turbulence intensity levels, which indicates proximity to the free-stream flow. Also note, the free-stream wake-strips are very weak. Figure 44 shows that the wake strip gradually degrades between $\mathrm{s} / \mathrm{s}_{\mathrm{o}}=0.0$ and 0.50 .

Overall, Case 4 has increased turbulence levels in the boundary-layer, but also seems to have a prolonged transitional region. In addition, the free-stream wake strips are not capable of convecting to the trailing edge due to the attenuation of free-stream disturbances caused by the negative pressure gradient. 


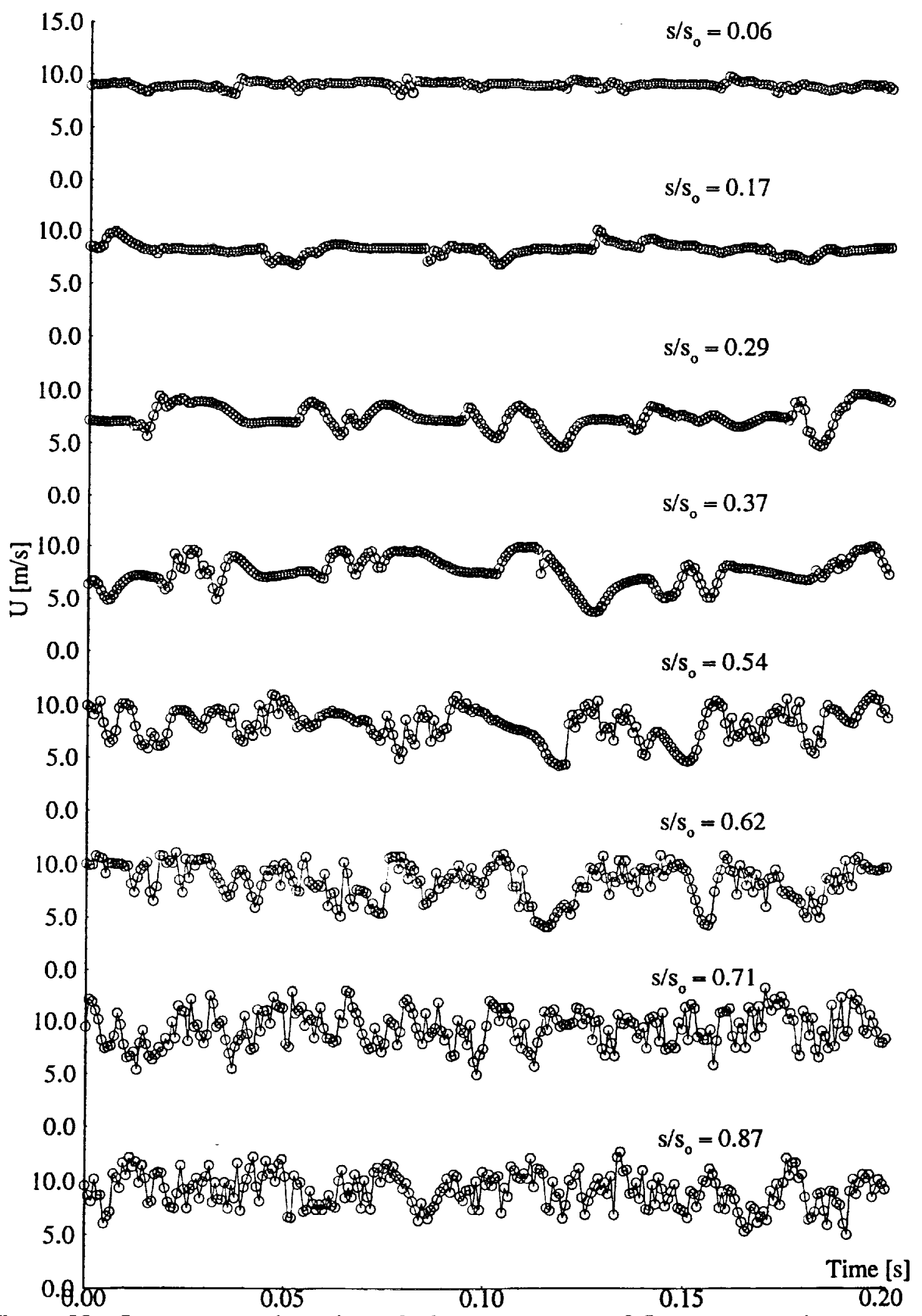

Figure 33. Instantaneous hot-wire velocity traces at $\mathrm{y}=0.5 \mathrm{~mm}$ at negative pressure gradient and periodic-unsteady flow (Case 4). 


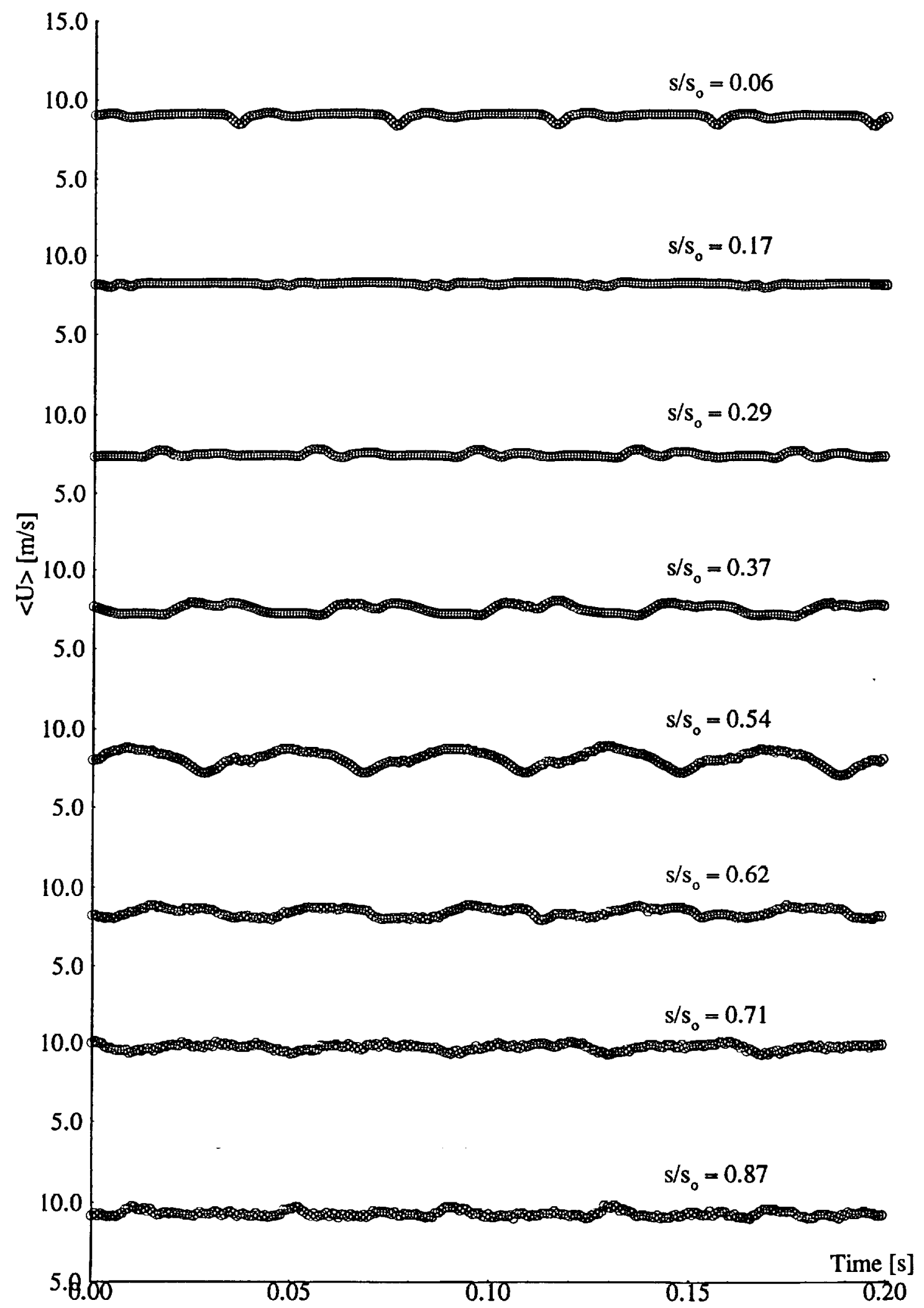

Figure 34. Ensemble-averaged hot-wire velocity traces at $\mathrm{y}=0.5 \mathrm{~mm}$ at negative pressure gradient and periodic-unsteady flow (Case 4). 


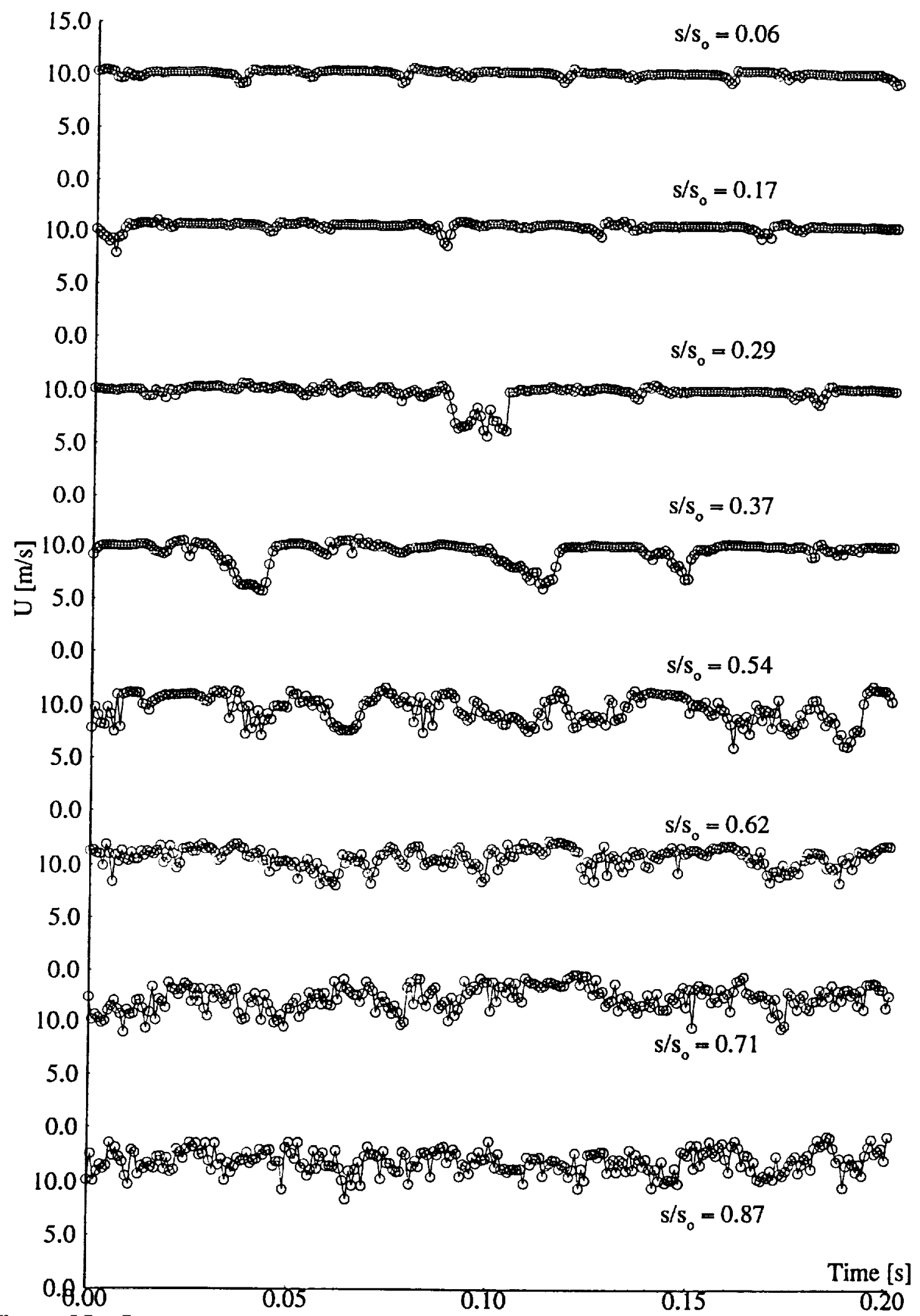

Figure 35. Instantaneous hot-wire velocity traces at $y=2.0 \mathrm{~mm}$ at negative pressure gradient and periodic-unsteady flow (Case 4). 


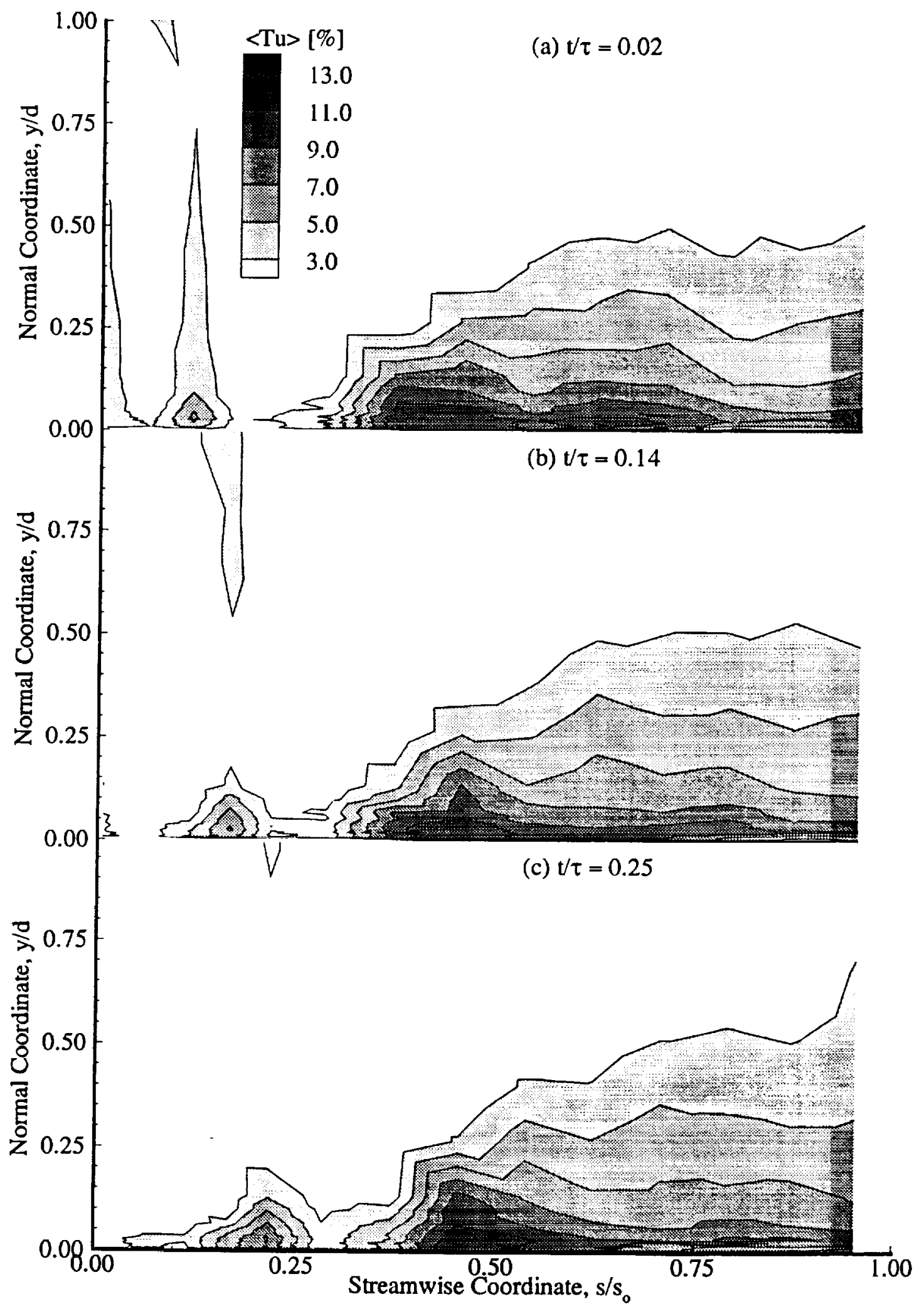

Figure 36 . Ensemble-averaged reference turbulence intensity contours at various instants in the wake passing cycle (Case 4). 


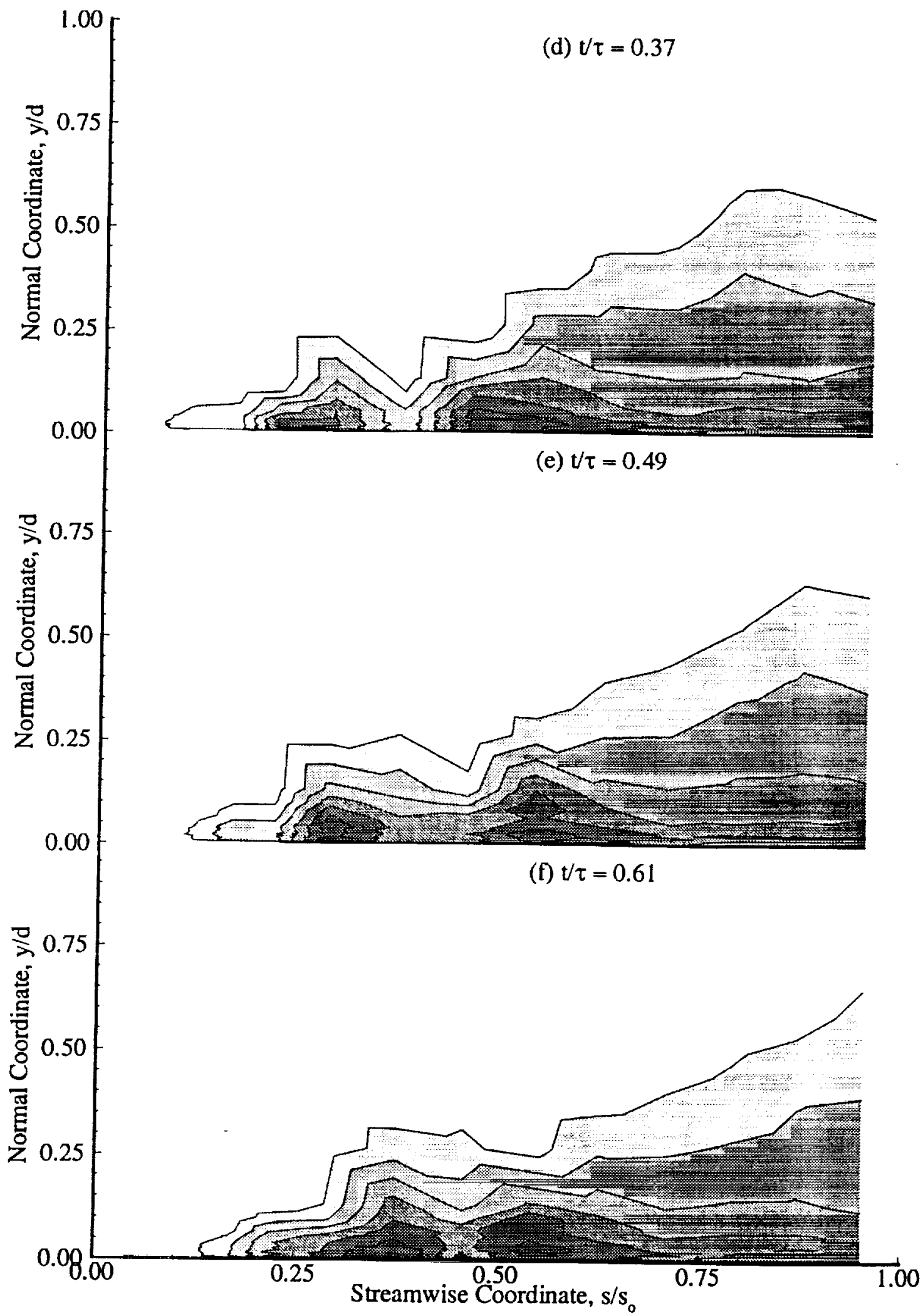

Figure 36. Continued. 


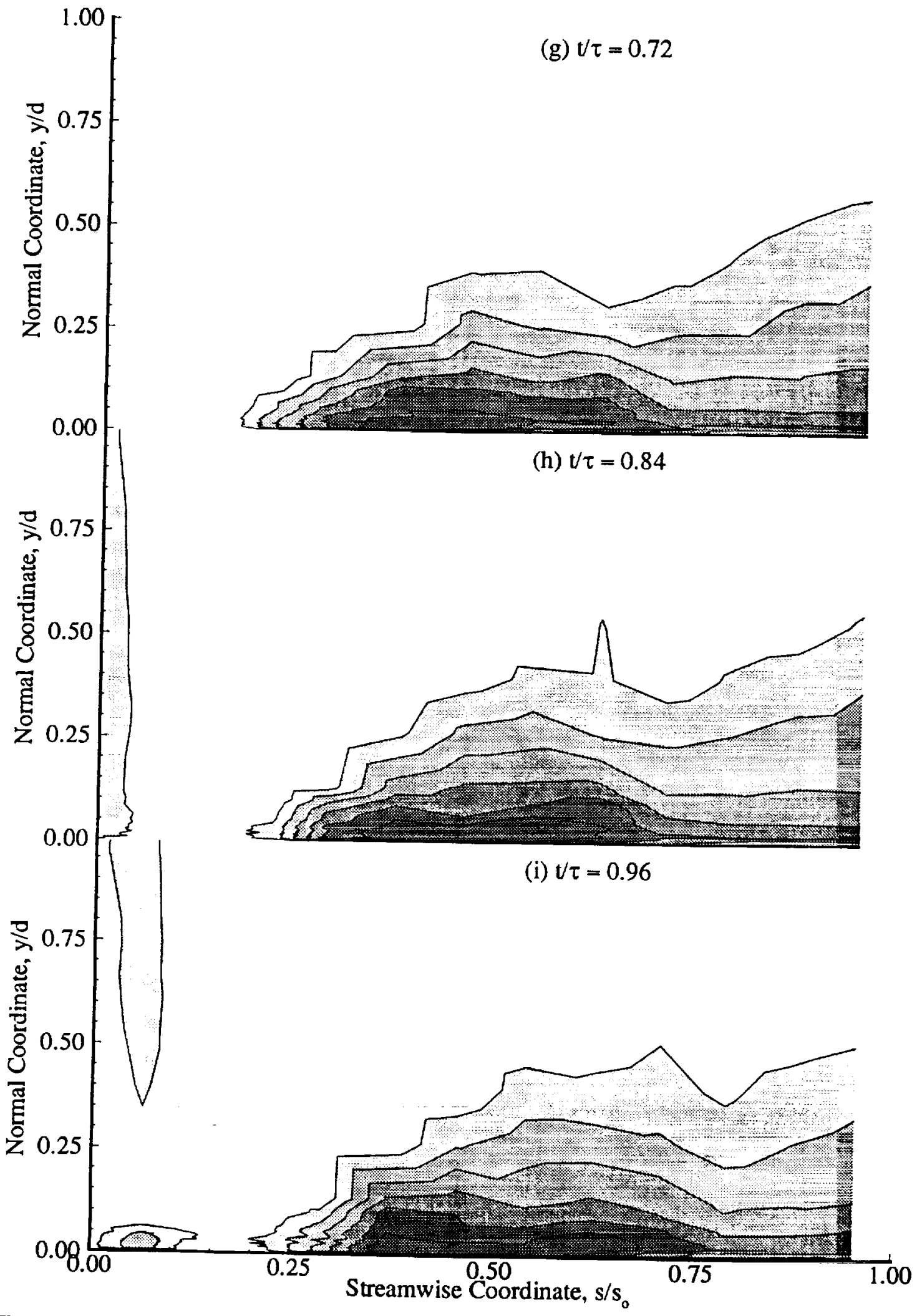

Figure 36. Continued. 


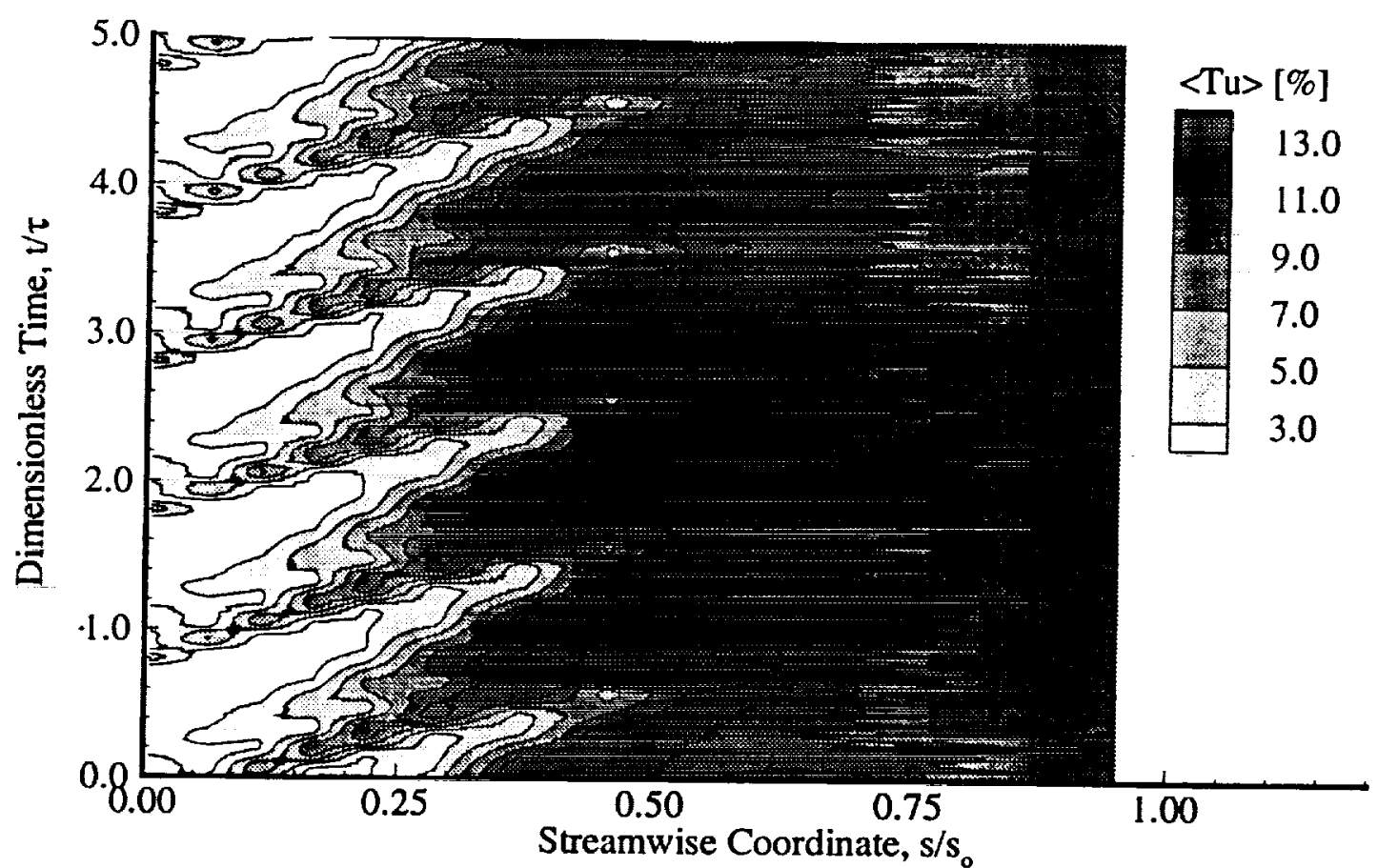

Figure 37. Ensemble-averaged reference turbulence intensity in the temporal-spatial domain at $\mathrm{y}=0.3 \mathrm{~mm}$ for negative pressure gradient (Case 4).

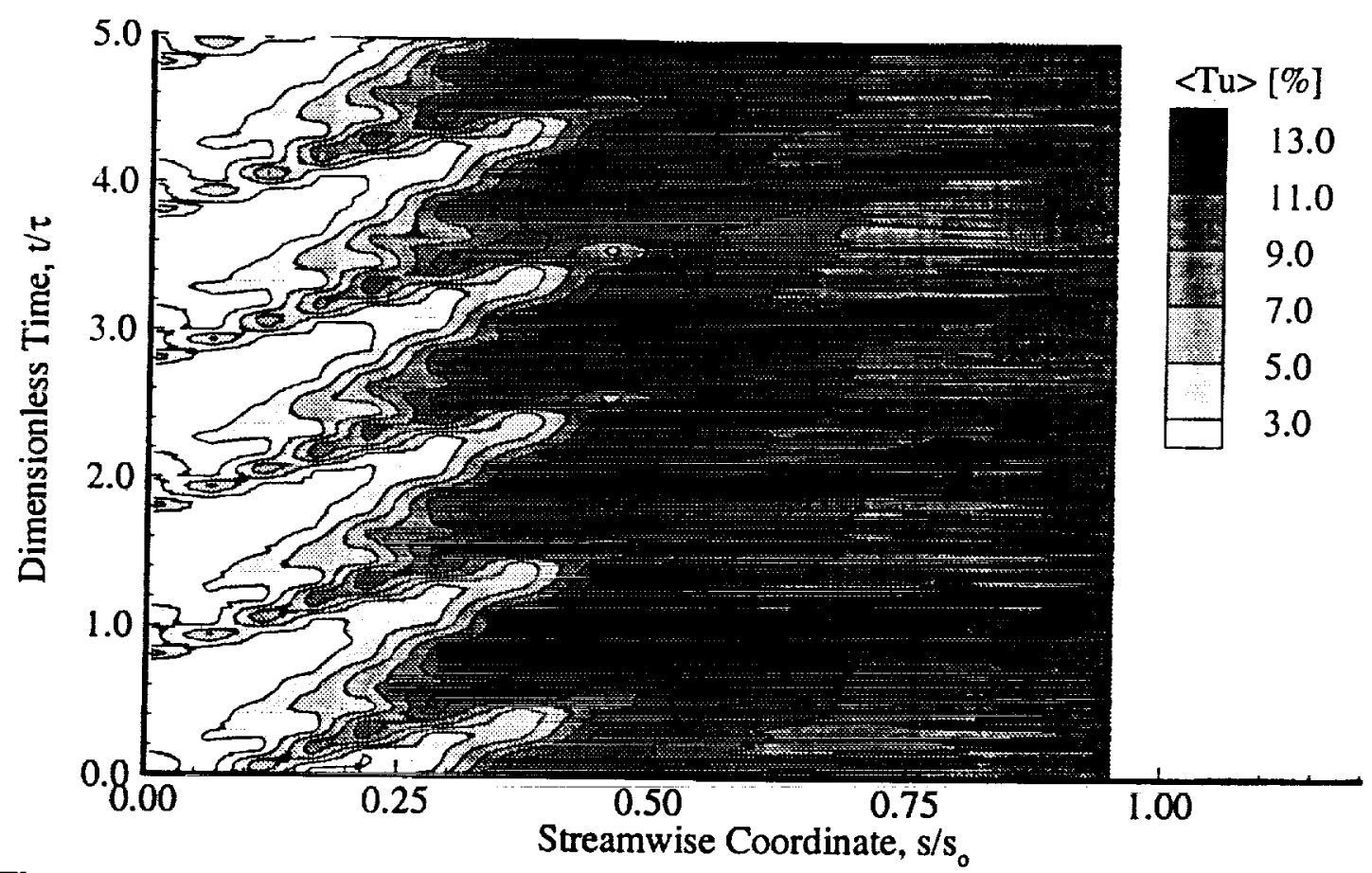

Figure 38. Ensemble-averaged reference turbulence intensity in the temporal-spatial domain at $y=0.5 \mathrm{~mm}$ for negative pressure gradient (Case 4 ). 


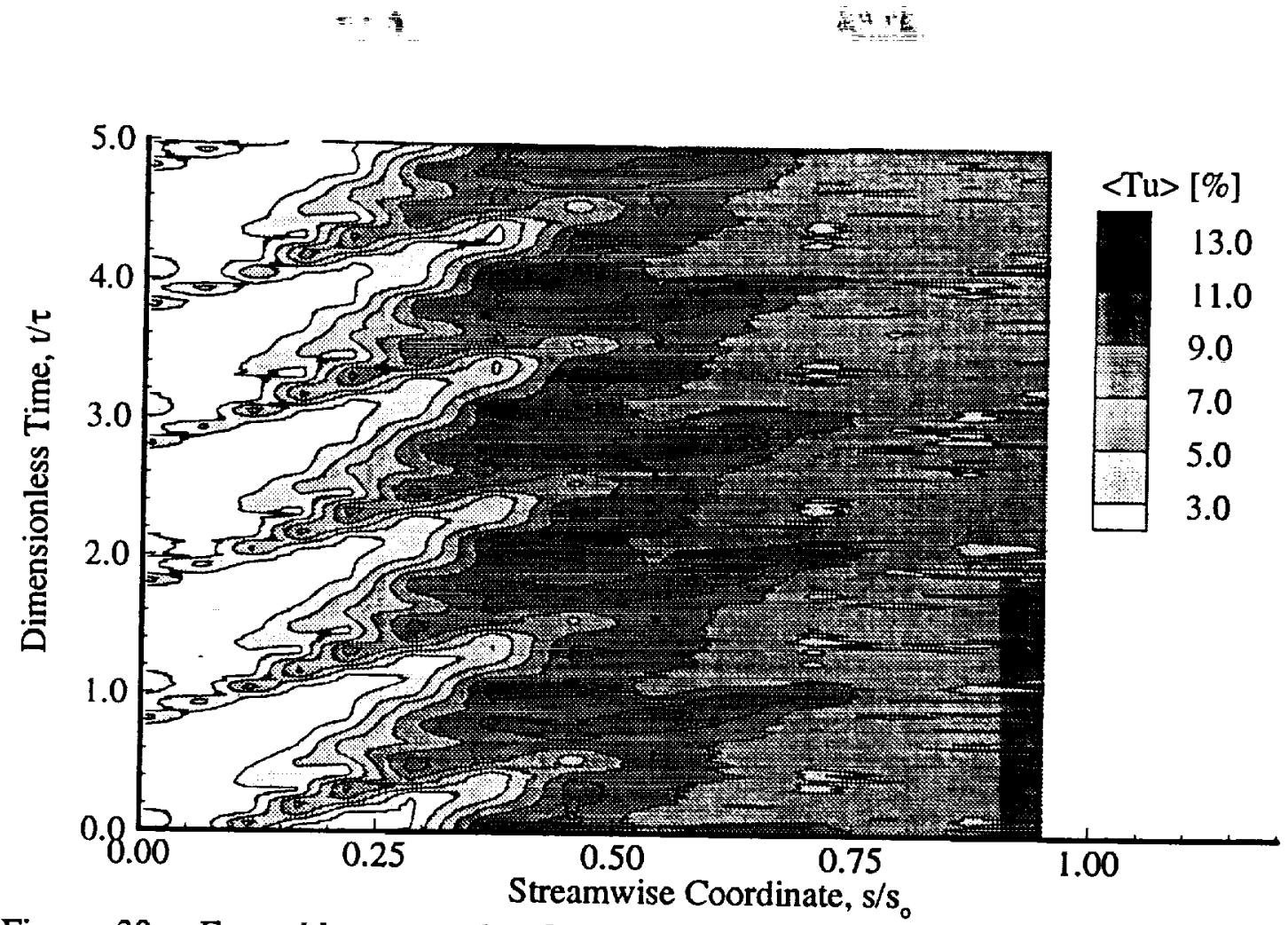

Figure 39. Ensemble-averaged reference turbulence intensity in the temporal-spatial domain at $\mathrm{y}=0.8 \mathrm{~mm}$ for negative pressure gradient (Case 4 ).

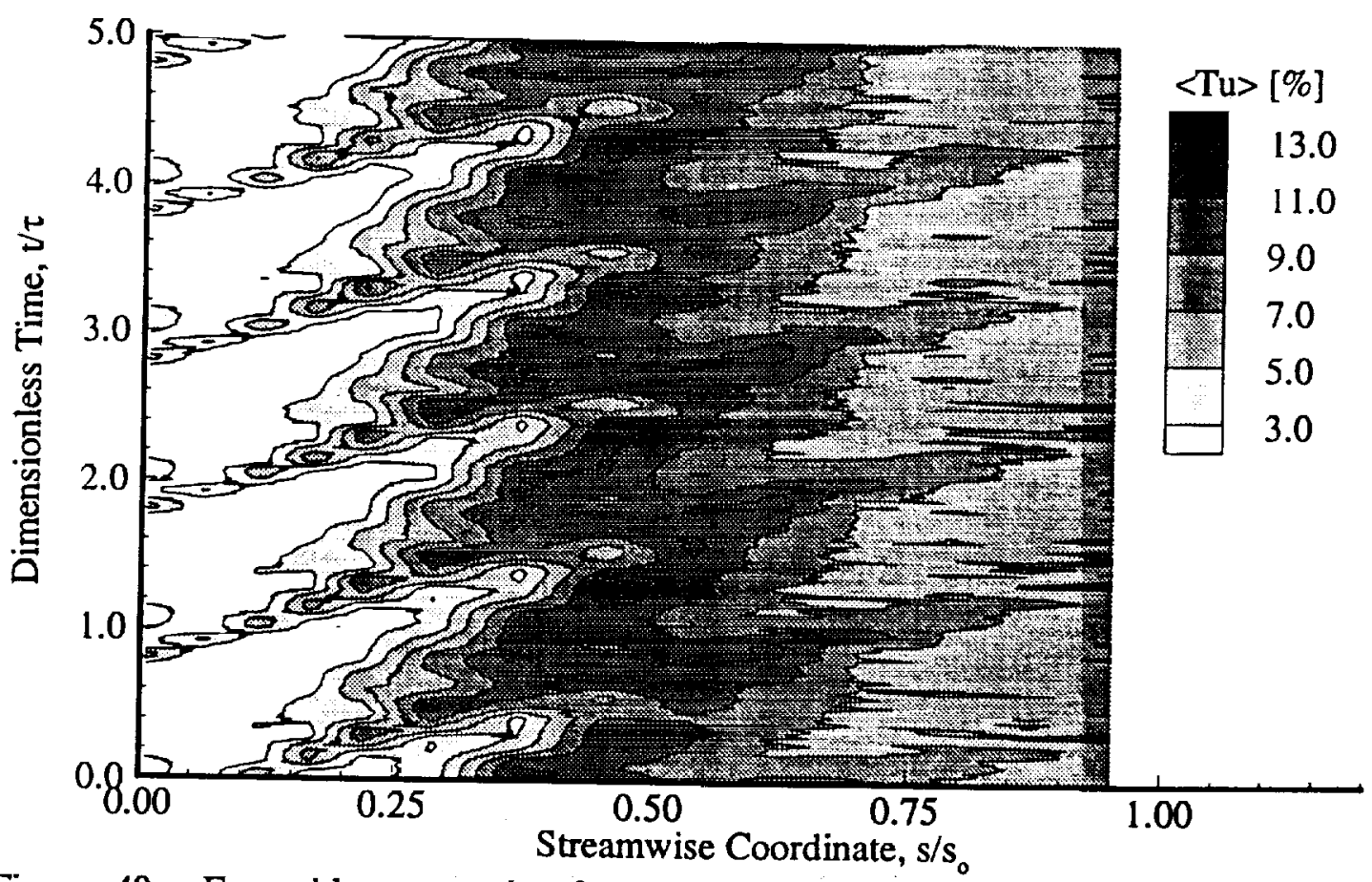

Figure 40. Ensemble-averaged reference turbulence intensity in the temporal-spatial domain at $\mathrm{y}=1.0 \mathrm{~mm}$ for negative pressure gradient (Case 4 ). 


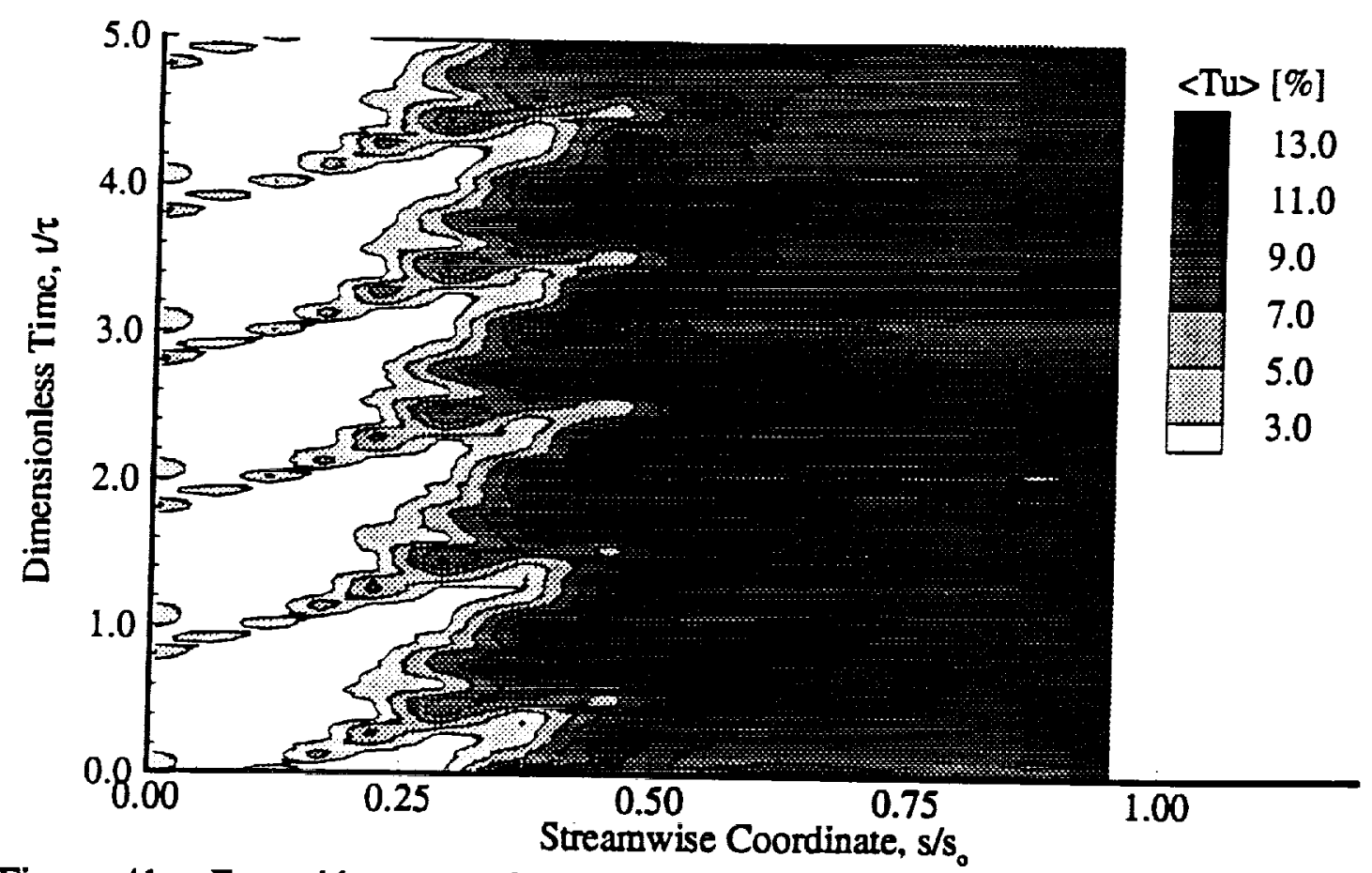

Figure 41. Ensemble-averaged reference turbulence intensity in the temporal-spatial domain at $\mathrm{y}=1.5 \mathrm{~mm}$ for negative pressure gradient (Case 4 ).

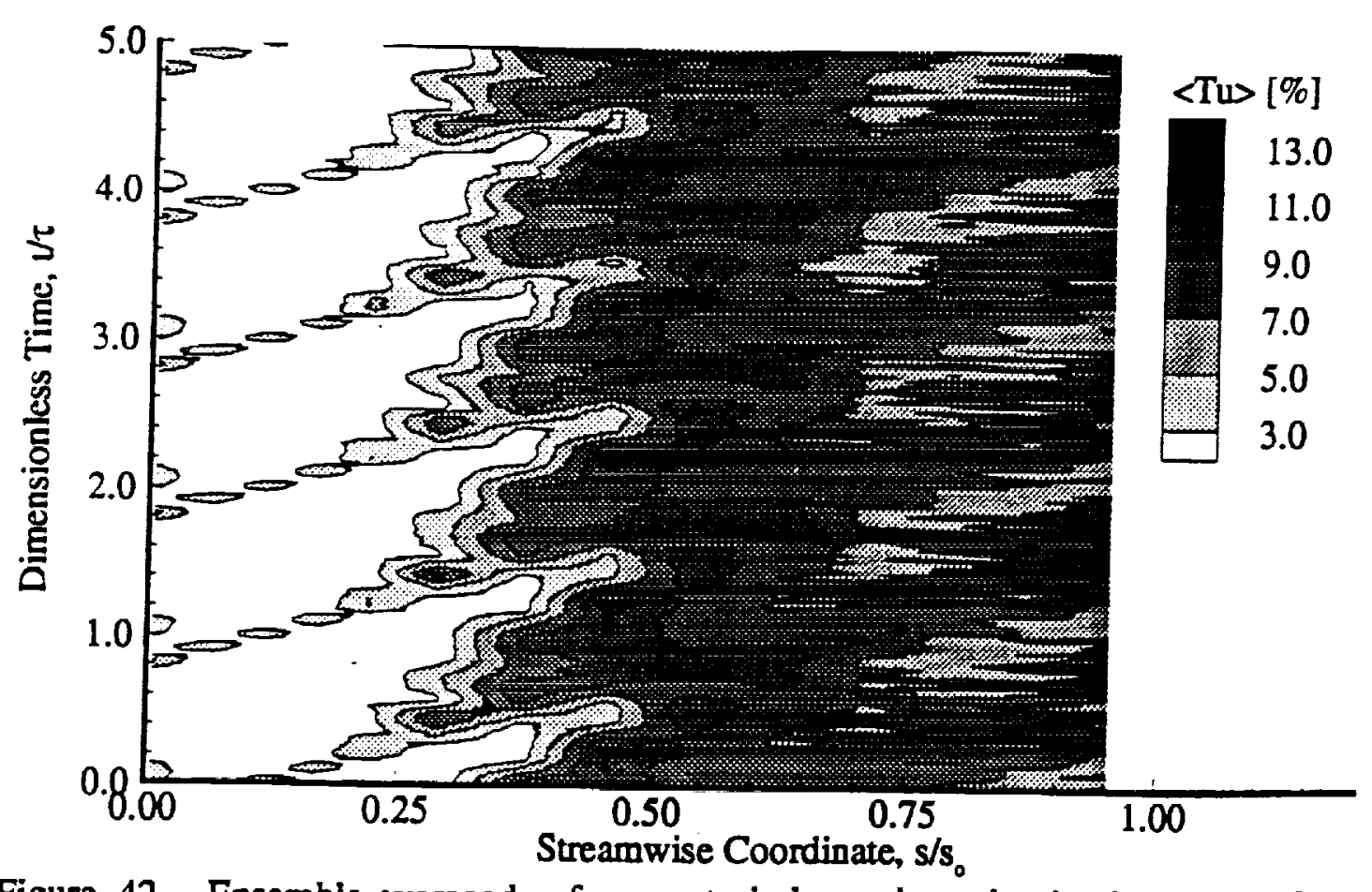

Figure 42. Ensemble-averaged reference turbulence intensity in the temporal-spatial domain at $\mathrm{y}=2.0 \mathrm{~mm}$ for negative pressure gradient (Case 4). 


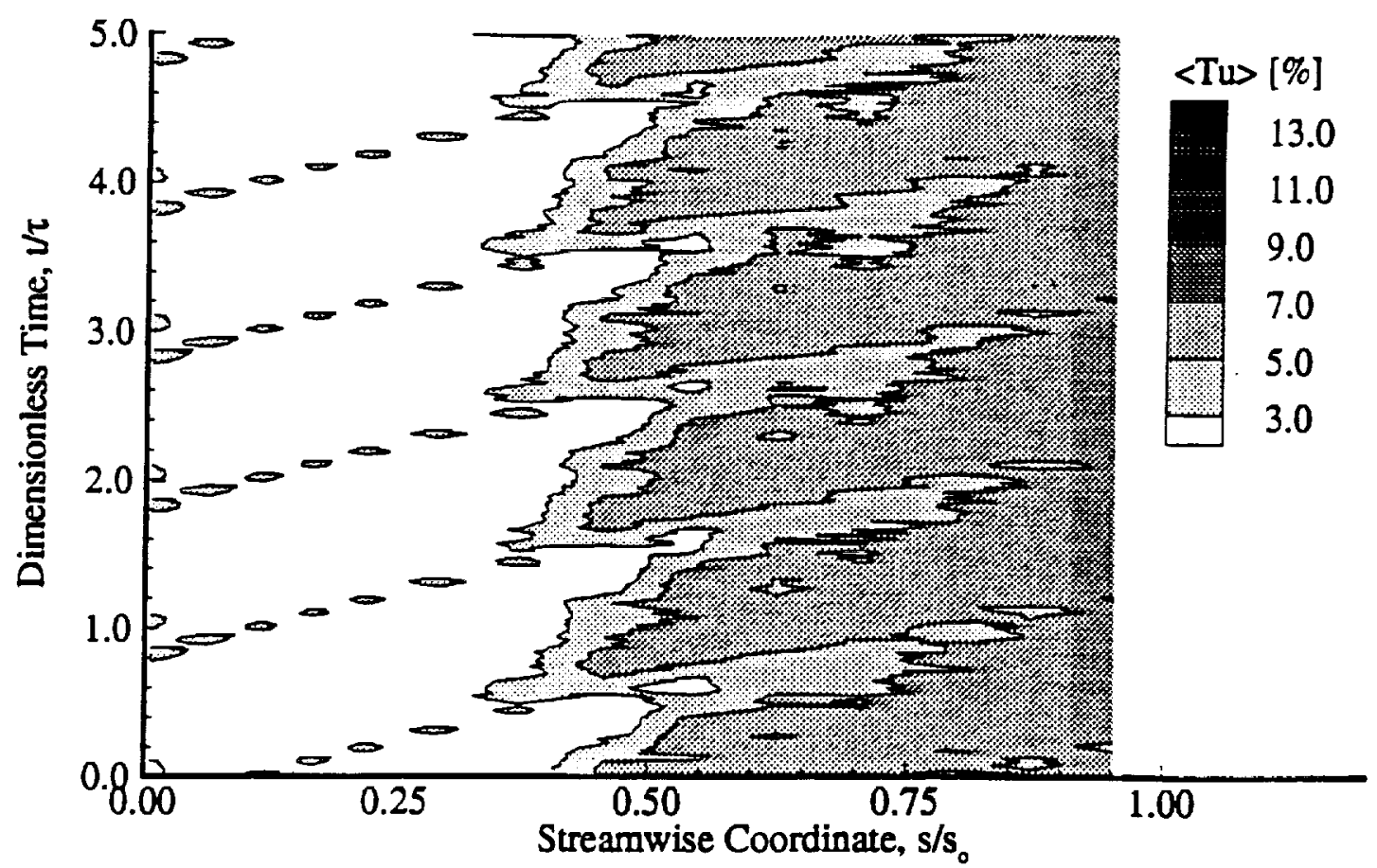

Figure 43. Ensemble-averaged reference turbulence intensity in the temporal-spatial domain at $\mathrm{y}=4.0 \mathrm{~mm}$ for negative pressure gradient (Case 4).

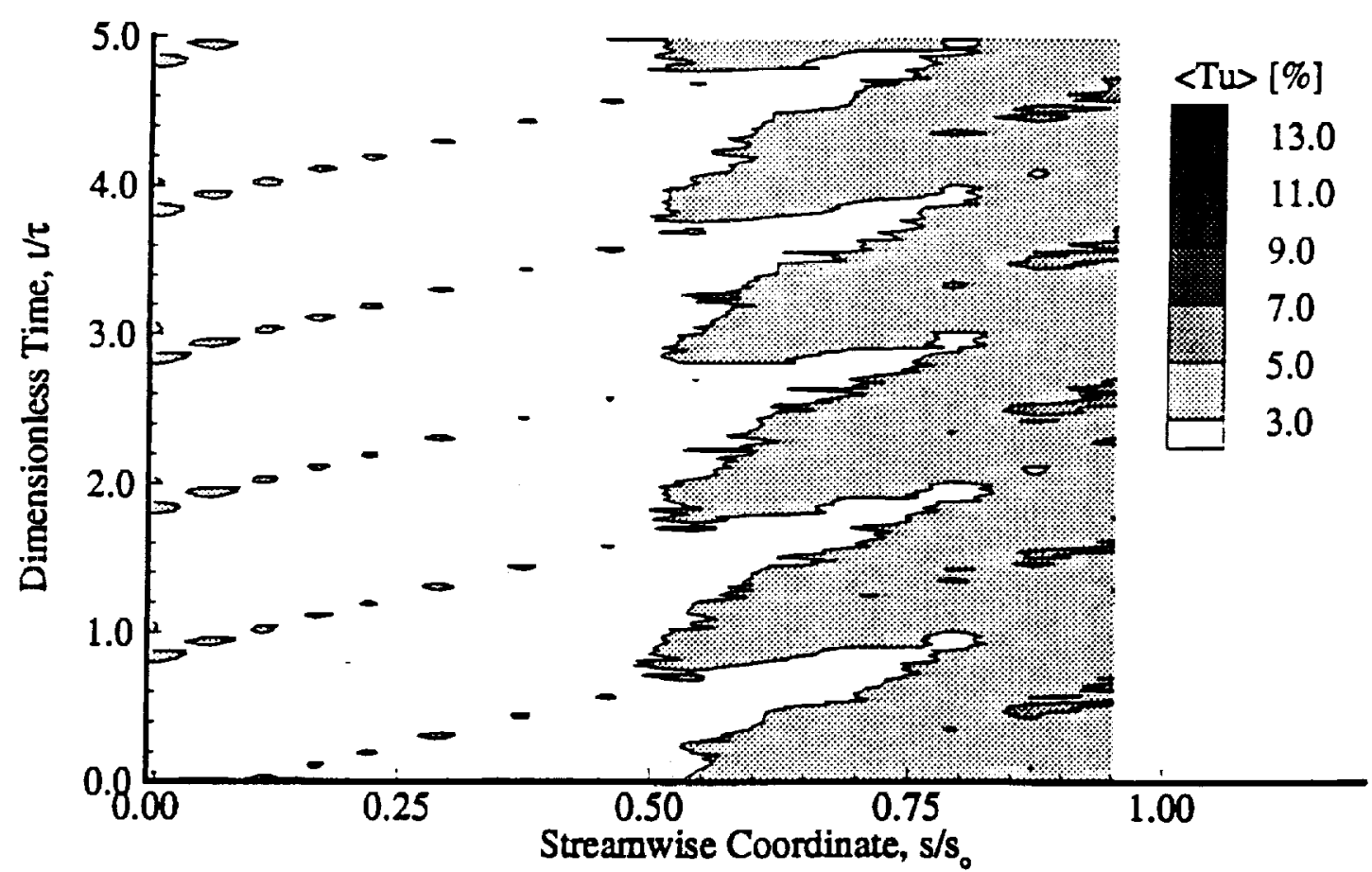

Figure 44. Ensemble-averaged reference turbulence intensity in the temporal-spatial domain at $\mathrm{y}=6.0 \mathrm{~mm}$ for negative pressure gradient (Case 4 ). 


\section{CASCADE TEST FACILITY DESIGN}

The effect of periodic-unsteady wakes on a concave surface with constant radius of curvature has been studied. The complexities caused by the periodic-unsteady wakes are many and quantification of this mode of transition will be the result of several research efforts. To further this pursuit, a periodic-unsteady two-dimensional turbomachinery cascade test facility was designed and manufactured (Figure 45).

The purpose was to design a test facility that was simple, mechanically reliable, versatile, and of modest cost. Several different design concepts were considered for the test section. The result is a structure that is both versatile and unique in the turbomachinery performance research field.

This wind tunnel employs a centrifugal fan of identical size to the other test facility of Figure 1. Furthermore, components include a diffuser, settling chamber (4 sections), and a nozzle positioned upstream of the test section. Details of the test section are given in Figures 46 through 48 . The periodic wakes are created by thin cylindrical rods attached between two parallel timing belts. The belts move the rods perpendicular to the exit flow

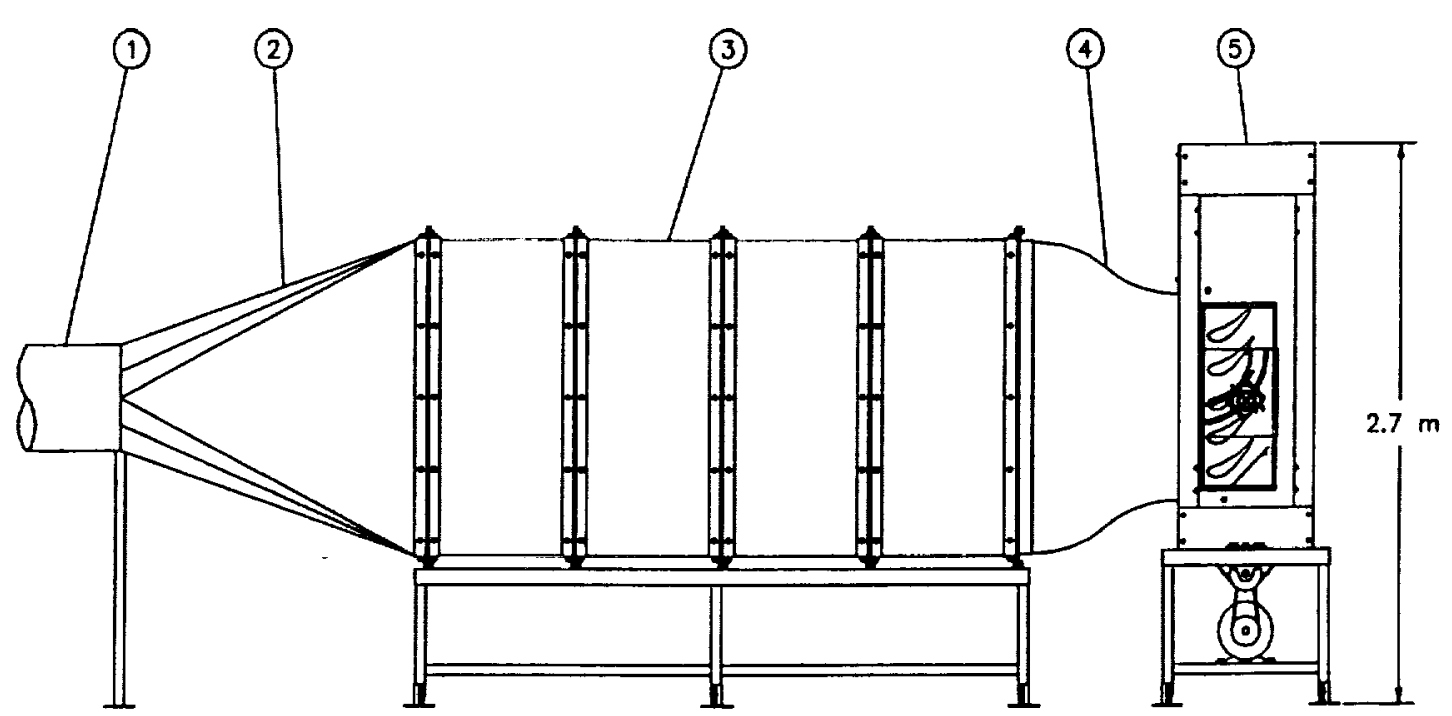

Figure 45. Wind tunnel for the investigation of periodic-unsteady wakes on a turbomachinery cascade. 1-inlet pipe, 2-diffuser, 3-settling chamber, 4-nozzle, 5-test section 

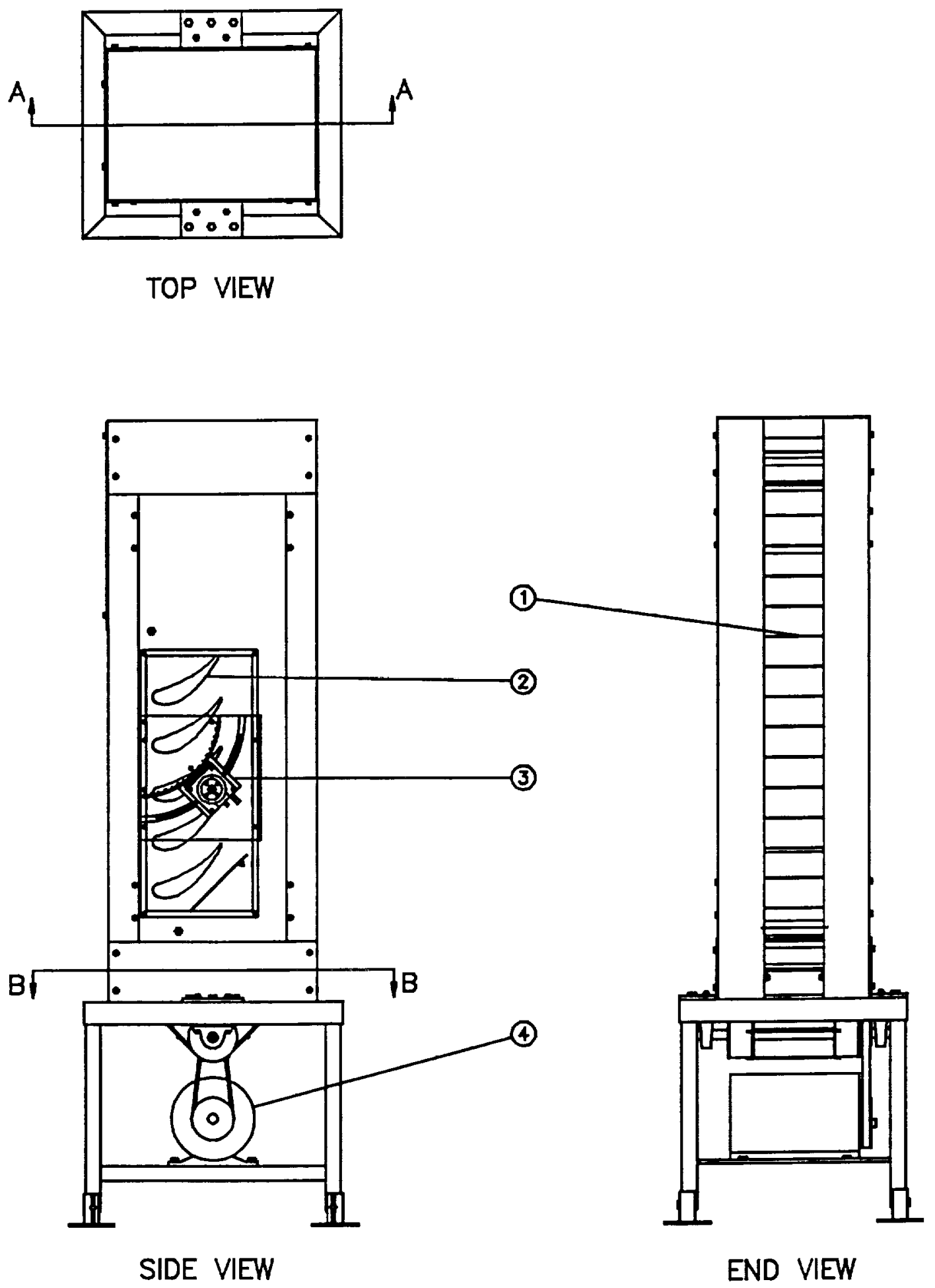

Figure 46. Wind tunnel test section. 1-thin cylindrical rod, 2-turbine blade, 3-boundarylayer traversing system, 4-frequency controlled electric motor. 


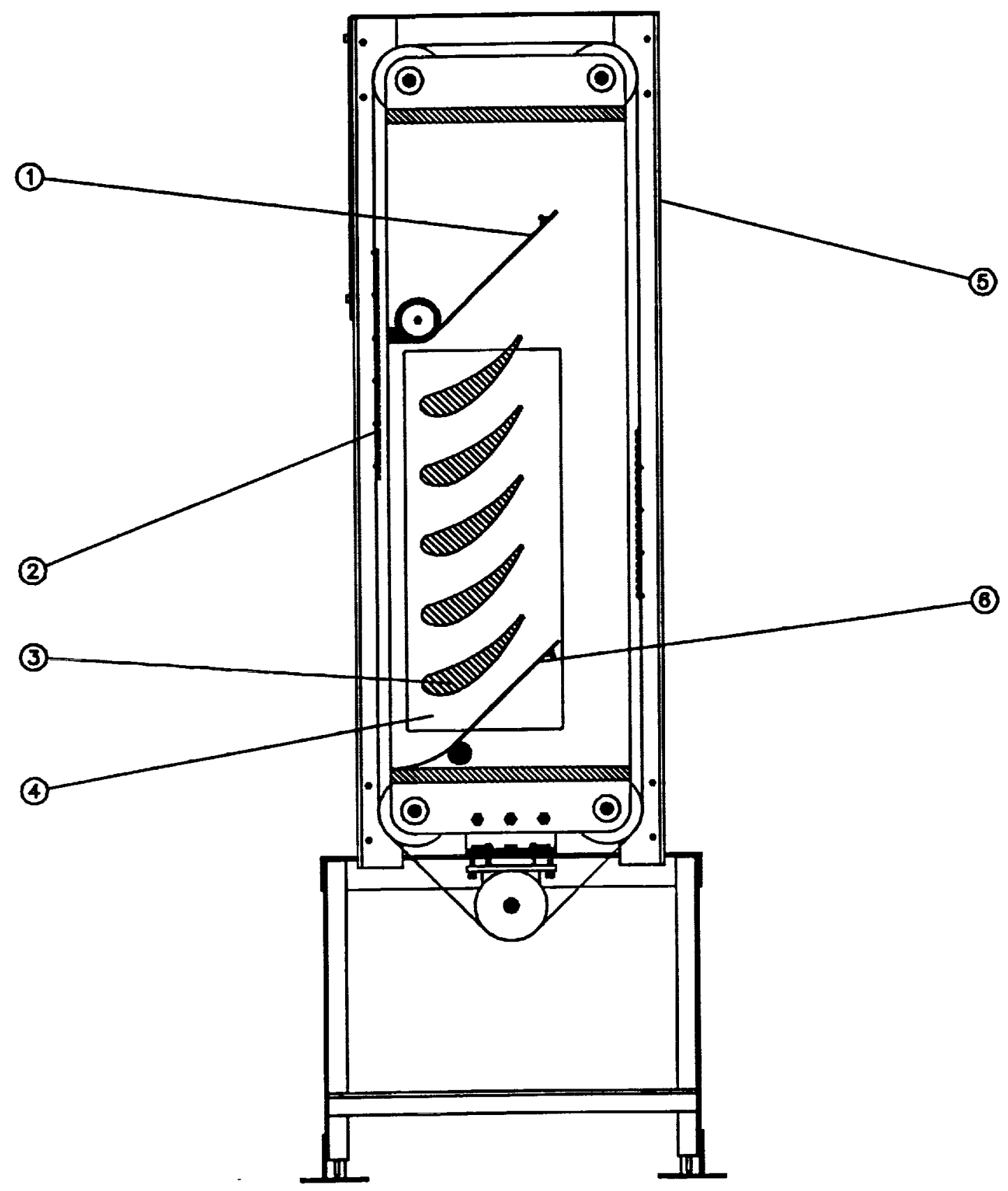

Figure 47. Section A-A of Figure 46. 1-upper adjustable border, 2-timing belt with attachments, 3-turbine blade, 4-transparent acrylic side wall, 5-timing belt guard, 6-lower adjustable border. 


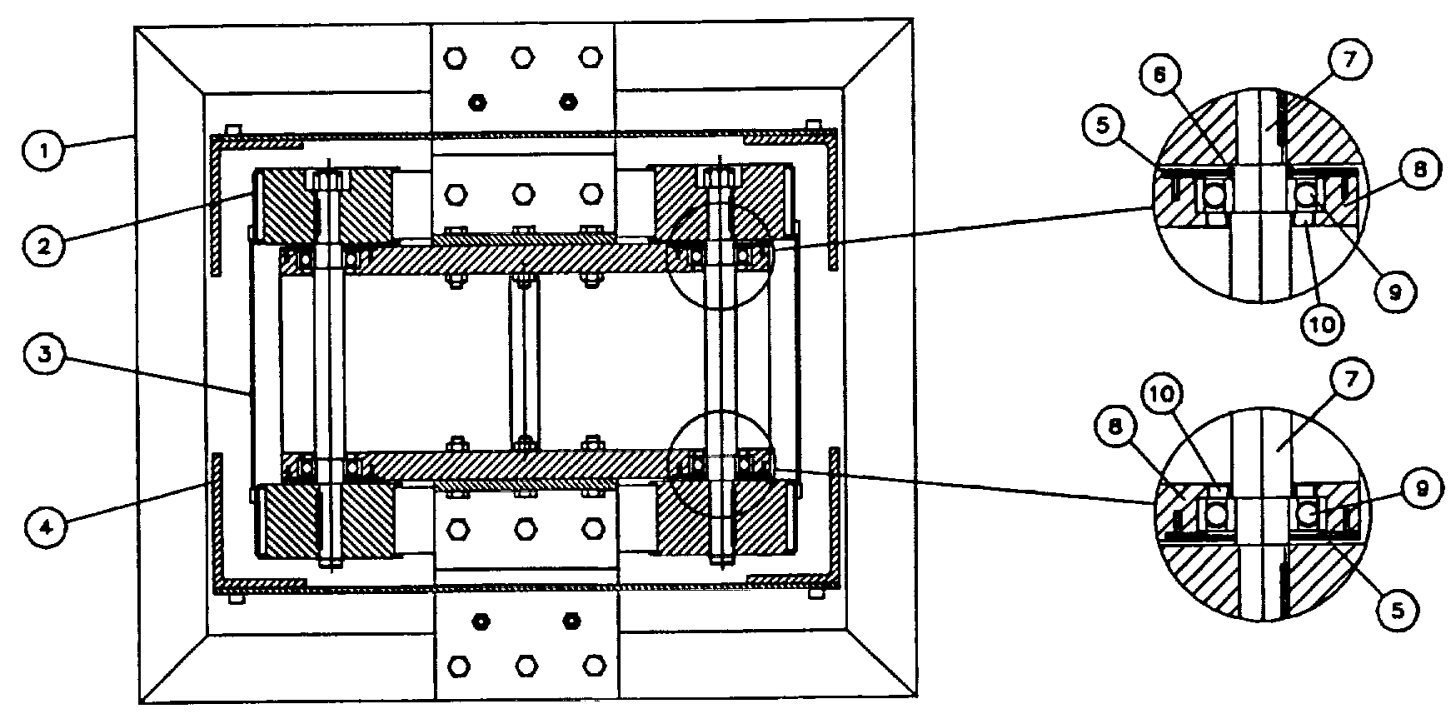

Figure 48. Section B-B of Figure 46. 1-table, 2-timing belt with attachments, 3-thin cylindrical rod, 4-timing belt guard, 5-end cap, 6-spacer, 7-pulley shaft, 8-test section wall, 9-deep groove ball bearing, 10-dust seal.

of the nozzle before entering the test section. Therefore, the blades (which are housed in the test section) are subjected to a periodic wake impingement, similar to that found in a turbomachine. The inlet area of the test section is $1000 \mathrm{~mm}$ by $200 \mathrm{~mm}$. The height of the test section allows the ability to house many different sizes of blades at different spacings. The first investigations will include two-dimensional versions of the NASA Space Shuttle Main Engine turbine blade. Five blades of $282 \mathrm{~mm}$ chord length spaced at $163 \mathrm{~mm}$ will be placed between the acrylic window side walls of the test section.

Detailed hot-wire and liquid crystal measurements will be made. To acquire the boundary-layer velocity profile, a manual traversing system was designed to reach every point between two blades with a hot-wire probe. A linear traversing system is used to measure the inlet and exit planes of the test section. One blade is equipped with static pressure taps around its circumference to measure the pressure distribution. Another blade is equipped with a liquid crystal surface to measure the heat transfer coefficient of the blade.

This is a versatile test facility with many different research options. The capability to measure many different blade types and sizes make this test facility unique. The 
complete periodic-unsteady velocity and heat transfer data can be attained for a given blade arrangement. Therefore, this is a strong research tool that will aid in investigating the flow physics of periodic-unsteady transition as well as experimental verification of turbomachinery cascade flow parameters. 


\section{CONCLUSION}

Boundary-layer measurements on the concave surface of a curved plate with and without the presence of periodic-unsteady wakes were collected at zero and negative pressure gradients. The data were presented as instantaneous, time-averaged, and ensemble-averaged quantities. In addition, a new turbomachinery cascade test facility with periodic-unsteady inlet flow was designed and manufactured to aid in continuation of this research program. From this work, the following conclusions can be drawn:

1. The steady flow transition process (Cases 1 and 2) on a concave surface follows the classical view of Tollmien-Schlichting wave amplification with the exception of the possible presence of longitudinal Görtler vortices. From the instantaneous velocity traces, it appears that the only effect the Görtler vortices (if they exist here) might have are minor modifications to the Tollmien-Schlichting waves. A three-dimensional flow visualization study would be the only way to determine if Görtler vortices exist here.

2. The presence of a negative streamwise pressure gradient delays transition on a concave surface with and without presence of periodic-unsteady wakes.

3. The wake strip in periodic-unsteady flow initiates a disturbance in the boundarylayer at the leading edge of the plate. The disturbance in the boundary-layer and the wake strip in the free-stream appear to convect downstream independently of one another.

4. Periodic-unsteady flow causes intermittent regions of laminar and mildly transitional flow occurring far beyond the streamwise positions they are confined to without wakes present.

5. The presence of a negative pressure gradient attenuates the free-stream wake strip until it no longer exists, but the disturbance initiated by the wake strip in the boundary-layer progresses downstream increasing in turbulence intensity along the way.

6. The turbomachinery cascade test facility with periodic-unsteady inlet flow is unique and versatile. It allows the ability to measure many different turbine and 
compressor blade cascade configurations.

7. The boundary-layer traversing system on the new test facility has the ability to traverse the complete blade channel with a hot-wire probe. This will be useful for determination of boundary-layer transition on blade surfaces under periodicunsteady inlet flow. 


\section{REFERENCES}

Abu-Ghannam, B. J., Shaw, R., 1980, "Natural Transition of Boundary Layers-The Effects of Turbulence, Pressure Gradient, and Flow History," Journal of Mechanical Engineering Science, Vol. 22, pp. 213-228.

Dhawan, S., Narasimha, R., 1958, "Some Properties of Boundary Layer Flow During the Transition from Laminar to Turbulent Motion," Journal of Fluid Mechanics, Vol. 3, pp. 418-436.

Dong, Y., and Cumpsty, N. A., 1990a, "Compressor Blade Boundary Layers: Part 1-Test Facility and Measurements With No Incident Wakes," ASME Journal of Turbomachinery, Vol. 112, pp. 222-230.

Dong, Y., and Cumpsty, N. A., 1990b, "Compressor Blade Boundary Layers: Part 2-Measurements With Incident Wakes," ASME Journal of Turbomachinery, Vol. 112, pp. 231-240.

Görtler, H., 1940, "Über eine dreidimensionale Instabiltät laminar Grenzschichten an konkaven Wänden," Nachr. Wiss. Ges. Göttingen, Math. Phys. Klasse, Neue Folge 2, No. 1 .

John, J., 1993, "A Study of the Development of Steady and Periodic-Unsteady Turbulent Wakes through Curved Channels at Positive, Zero, and Negative Streamwise Pressure Gradients," Ph.D. Dissertation, Texas A\&M University.

John, J., Schobeiri, T., 1993, "A Simple and Accurate Method for Calibrating XProbes," ASME Journal of Fluid Engineering, Vol. 115, pp. 148-152.

Kim, J., Simon, T. W., and Russ, S. G., 1992, "Free-Stream Turbulence and Concave Curvature Effects on Heated, Transitional Boundary Layers," ASME Journal of Heat Transfer, Vol. 114, pp. 338-347.

Liepmann, H. W., 1943, "Investigations on Laminar Boundary-Layer Stability and Transition on Curved Boundaries," NACA-WR-W-107.

Liepmann, H. W., 1945, "Investigation of Boundary-Layer Transition on Concave Walls," NACA-WR-W-87. 
Liu, X., Rodi, W., 1991, "Experiments on Transitional Boundary Layers with Wake-Induced Unsteadiness," Journal of Fluid Mechanics, Vol. 231, pp. 229-256.

Liu, X., Rodi, W., 1992, "Measurement of Unsteady Flow and Heat Transfer in a Linear Turbine Cascade," ASME Paper No. 92-GT-323.

Mayle, R. E., 1991, "The Role of Laminar-Turbulent Transition in Gas Turbine Engines," ASME Journal of Turbomachinery, Vol. 113, pp. 509-537.

Orth, U., 1993, "Unsteady Boundary-Layer Transition in Flow Periodically Disturbed by Wakes," ASME Journal of Turbomachinery, Vol. 115, pp. 707-713.

Pardivala, D., 1991, "Establishment of a Research Facility for Investigating the Effects of Unsteady Inlet Flow, Pressure Gradient, and Curvature on Boundary-Layer Development, Wake Development, and Heat Transfer," M.S. Thesis, Texas A\&M University.

Pfeil, H., Herbst R., 1979 "Transition Procedure of Instationary Boundary Layers," ASME Paper No. 79-GT-128.

Pfeil, H., Herbst, R., Schröder, T., 1983, "Investigation of the Laminar Turbulent Transition of Boundary Layers Disturbed by Wakes," ASME Journal of Engineering for Power, Vol. 105, pp. 130-137.

Raj, R., Lakshminarayana, B. 1973, "Characteristics of the Wake behind a Cascade of Airfoils," Journal of Fluid Mechanics, Vol. 81, part 4, pp. 707-730.

Riley, S., Johnson, M. W., and Gibbings, J. C., 1989, "Boundary-Layer Transition of Strongly Concave Surfaces," ASME Paper 89-GT-321.

Sabzvari, J. and Crane, R. I., 1985, "Effect of Görtler Vortices on Transitional Boundary-Layers," Int. Symp. on 3-D Flow Phenomena in Fluid Machinery, ASME W.A.M., Miami, Florida.

Schlichting, H., 1979, Boundary-Layer Theory, 7th Edition, McGraw Hill, New York.

Schobeiri, T., 1976, "Näherungslösung der Navier-Stokes'schen Differentialgleichung für eine zweidimensionale stationäre Laminarströmung konstanter Viskosität in konvexen und konkaven Diffusoren und Düsen," Zeitschrift fïr angewandte Mathematik und Physik, Vol. 27, Fasc. 1. 
Public reporting burden for this collection of hiformation is estimated to average I hour per response, including the time lor reviewing Instructions, searching exlsting dala sources, gathering and maintainling the data needed, and completing and revlewing the collection of Iniormation. Send comments regarding this burden estimate or any other aspect of this collection of intormation, Including suggestlons for reducing this burden, to Washington Headquarters Services, Directorate lor Inlormation Operations and Reports. 1215 Jefferson Davis Highway, Sulte 1204, Arlington, VA 22202-4302, and to the Oftice of Managerrent and Budget. Papenwork Reduction Project (0704-0168). Washinglon. DC 20503.

\begin{tabular}{l|l|l} 
1. AGENCY USE ONLY (Leave blank) & 2. REPORT DATE & 3. REPORT TYPE AND DATES COVEAED
\end{tabular}

\begin{tabular}{|l|l|l}
\hline & January 1996 & Final Contractor Report \\
\hline
\end{tabular}

4. TITE AND SUBTITLE

5. FUNDING NUMBERS

Effects of Periodic Unsteady Wake Flow and Pressure Gradient on Boundary

Layer Transition Along the Concave Surface of a Curved Plate, Part III

6. AUTHOP(S)

WU-505-90-52

G-NAG3-1256

M.T. Schobeiri and R.E. Radke

7. PERFORMING ORGANIZATION NAME(S) AND ADDRESS(ES)

Texas A\&M University

Department of Mechanical Engineering

College Station, Texas 77843

8. PERFormING ORGANIZATION

REPORT NUMBER

E-10099

9. SPONSORING/MONITORING AGENCY NAME(S) AND ADDRESS(ES)

National Aeronautics and Space Administration

Lewis Research Center

Cleveland, Ohio 44135-3191

10. SPONSORINGMONITORING AGENCY REPORT NUMBER

NASA CR-198450

\section{SUPPLEMENTARY NOTES}

Project Manager, Barbara L. Lucci, Internal Fluid Mechanics Division, NASA Lewis Research Center, organization code 2630, (216) 433-5902.

12a. DISTRIBUTIONAVAILABILITY STATEMENT

12b. DISTRIBUTION CODE

Unclassified - Unlimited

Subject Category 34

This publication is available from the NASA Center for Aerospace Information, (301) 621-0390.

13. ABSTRACT (Maximum 200 words)

Boundary layer transition and development on a turbomachinery blade is subjected to highly periodic unsteady turbulent flow, pressure gradient in longitudinal as well as lateral direction, and surface curvature. To study the effects of periodic unsteady wakes on the concave surface of a turbine blade, a curved plate was utilized. On the concave surface of this plate, detailed experimental investigations were carried out under zero and negative pressure gradient. The measurements were performed on an unsteady flow research facility using a rotating cascade of rods positioned upstream of the curved plate. Boundary layer measurements using a hot-wire probe were analyzed by the ensemble-averaging technique. The results presented in the temporal-spatial domain display the transition and further development of the boundary layer, specifically the ensemble-averaged velocity and turbulence intensity. As the results show, the turbulent patches generated by the wakes have different leading and trailing edge velocities and merge with the boundary layer resulting in a strong deformation and generation of a high turbulence intensity core. After the turbulent patch has totally penetrated into the boundary layer, pronounced becalmed regions were formed behind the turbulent patch and were extended far beyond the point they would occur in the corresponding undisturbed steady boundary layer.

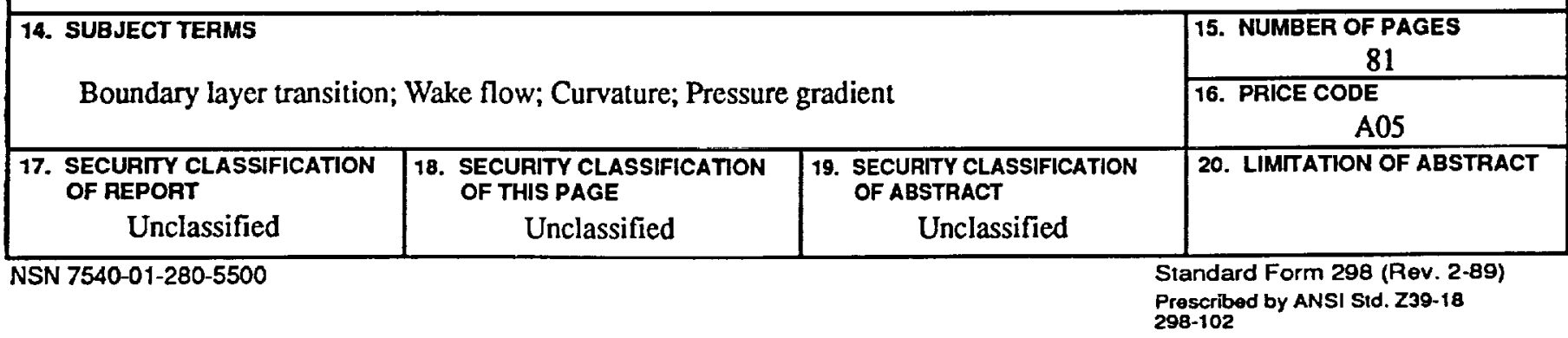


Schobeiri, T., 1980, "Geschwindigkeits- und Temperaturverteilung in Hamelscher Spiralströmung," Zeitschrift für angewandte Mathematik und Mechanik, Vol. 60, pp. 195200.

Schobeiri, T., 1990, "The Influence of Curvature and Pressure Gradient on the Flow Temperature and Velocity Distribution," International Journal of Mechanical Sciences, Vol. 32, pp. 851-861.

Schobeiri, T., and Pardivala, D., 1992, "Development of a Subsonic Flow Research facility for Simulating the Turbomachinery Flow and Investigating its Effects on Boundary layer Transition, wake Development and Heat Transfer", Fourth International Symposium on Transport Phenomena and Dynamics of Rotating Machinery, pp. 98-114.

Schobeiri, T., John, J., Pappu, K., 1993, "Development of Two-Dimensional Wakes within Curved Channels, Theoretical Framework and Experimental Investigation," submitted to ASME for publication.

Tani, I. and Aihara, Y., 1969, "Görtler Vortices and Boundary-Layer Transition," ZAMP, Vol. 20, Fasc. 5.

Walker, G. J., 1993, "The Role of Laminar-Turbulent Transition in Gas Turbine Engines: A Discussion," ASME Journal of Turbomachinery, Vol. 115, pp. 207-217. White, F. M., 1991, Viscous Fluid Flow, 2nd Edition, McGraw Hill, New York. 